\author{
Universidade de São Paulo \\ Instituto de Química de São Carlos
}

\title{
Reatividade de iso- $\alpha$-ácidos e seus derivados hidrogenados frente ao radical 1-hidroxietila: implicações na perda de qualidade sensorial da cerveja
}

Natália Ellen Castilho de Almeida

Dissertação apresentada ao Instituto de Química de São Carlos, da Universidade de São Paulo, como um dos requisitos para o obtenção do título de Mestre em Ciências. Área de Concentração: Química Analítical

Orientador: Prof. Dr. Daniel Rodrigues Cardoso

São Carlos

2011 
Este exemplar foi revisado e alterado em relação à versão original, sob a exclusiva responsabilidade do autor.

São Carlos, 11/03/2011

Natália Ellen Castilho de Almeida 
Aos meus pais, Antônio e Élia, e ao meu irmão Kayo, pelo apoio, incentivo constante e amor. A minha avó Maria pelos ensinamentos e carinho.

Ao meu namorado Gustavo Metzker pelo carinho, apoio, conselhos e ajuda. 
"A diferença entre o possível e o impossível está na vontade humana"

(Louis Pasteur) 


\section{Agradecimentos}

Agradeço primeiramente a Deus por me acompanhar sempre. "O meu Deus é o Deus do impossível”.

Ao Prof. Dr. Daniel R. Cardoso pela orientação e ensinamentos. Ao Prof. Dr. Douglas W. Franco pela infra-estrutura utilizada.

Aos amigos Clayston e Tatiane (Fefe) por compartilharem momentos bons e difíceis.

A Rafaela e Leandro pelo companheirismo desde 2004 (Turma de Bacharelado do IQSC-USP).

Aos colegas do Laboratório da Química da Aguardente e Laboratório de Química Analítica e Inorgânica, IQSC-USP, pela convivência. Em especial, agradeço ao Wendel Aquino, Fernanda Seixas, Juliana Grippa e André (Barbie) pela ajuda e amizade.

Ao Sr. Julio Landmann (Hopsteiner) pela gentileza de doar o extrato de lúpulo isomerizado.

Ao Prof. Dr. Antônio Gilberto Ferreira e Eduardo Sanches pela disponibilidade na realização dos experimentos de ressonância magnética nuclear (DQ - UFSCar).

Ao Instituto de Química de São Carlos (IQSC), Universidade de São Paulo (USP) pela oportunidade.

Ao Prof. Dr. Antonio C. Burtoloso e a Viviana pela ajuda nas sínteses (IQSC USP).

A FAPESP pelo auxílio financeiro. 


\section{SUMÁRIO}

Lista de Esquemas

Lista de Figuras

Lista de Tabelas

Abreviaturas

Resumo

Abstract

1. INTRODUÇÃO

2. OBJETIVOS 33

3. MATERIAL E MÉTODO 34

3.1. Reagentes 34

3.2. Isolamento das trans-isohumulonas 35

3.3. Isolamento das cis-isohumulonas 36

3.4. Preparo das dihidro-isohumulonas 37

3.5. Preparo das tetrahidro-isohumulonas 38

3.6. Caracterização química dos compostos 39

3.6.1. Estudo eletroquímico das isohumulonas 40

3.7. Reatividade dos compostos de interesse frente ao radical 41 1-hidroxietila

3.7.1. Estudos com o radical 1-hidroxietila: formação e 41 estabilidade do aduto radical [4-POBN/CH$\left.\left(\mathrm{CH}_{3}\right) \mathrm{OH}\right]^{*}$

3.7.2. Determinação das constantes de velocidade aparentes decorrentes das reações dos compostos de interesse frente ao radical 1-hidroxietila

3.8. Cálculo quântico, ab initio $D F T$, na determinação das 45 propriedades eletrônicas das isohumulonas

3.9. Caracterização química dos produtos da reação entre o 46 radical 1-hidroxietila e os iso- $\alpha$-ácidos

4. RESULTADOS E DISCUSSÃO 47

4.1. Isolamento das isohumulonas $\quad 47$

4.2. Preparo dos derivados reduzidos/hidrogenados das 48 isohumulonas 
4.2.1. Preparo das dihidro-isohumulonas 48

4.2.2. Preparo das tetrahidro-isohumulonas $\quad 49$

4.3. Caracterização química das isohumulonas isoladas e seus 50 derivados reduzidos/hidrogenados

4.3.1. Caracterização química das trans-isohumulonas 50 isoladas

4.3.2. Caracterização química das cis-isohumulonas isoladas $\quad 57$

4.3.3. Caracterização química das dihidro-isohumulonas 61

4.3.4. Caracterização química das tetrahidro-isohumulonas 65

4.3.5. Estudo eletroquímico das isohumulonas 70

4.4. Reatividade dos iso- $\alpha$-ácidos e seus derivados e alguns 73 fenóis frente o radical 1-hidroxietila

4.4.1. Estudos com o radical 1-hidroxietila: formação do aduto 73 radical [4-POBN/CH$\left.\left(\mathrm{CH}_{3}\right) \mathrm{OH}\right]^{\circ}$

4.4.2. Estudos com o radical 1-hidroxietila: estabilidade do 79 aduto radical [4-POBN/CH$\left.\left(\mathrm{CH}_{3}\right) \mathrm{OH}\right]^{\cdot}$

4.4.3. Estudos com o radical 1-hidroxietila: determinação das constantes de velocidades aparentes da reação entre 0 radical 1-hidroxietila e os compostos de interesse

4.4.3.1. Reatividade dos iso- $\alpha$-ácidos e seus derivados frente o radical 1-hidroxietila

4.4.3.2. Reatividade de alguns fenóis frente ao radical 1hidroxietila

4.5. Identificação dos produtos de reação

4.6. Mecanismo da reação 99

5. CONCLUSÕES 102

REFERÊNCIAS BIBLIOGRÁFICAS 105

APÊNDICES 


\section{Lista de Esquemas}

Esquema 1. Reação de isomerização térmica das humulonas à cis(2-ac) e trans-isohumulonas (1-ac) durante o cozimento do mosto fermentado e adicionado de lúpulo. A relação trans-/cis-ishumulonas em condições normais de fabricação da cerveja é de 32:68. (a) iso-nhumulona, (b) isocohumulona, (c) isoadhumulona

Esquema 2. Reação de degradação fotoquímica dos iso- $\alpha$-ácidos em cerveja

Esquema 3. Formação e reações subseqüentes dos radicais 30 1-hidroxietila, em destaque, e 2-hidroxietila em cerveja, de acordo com o proposto dor Andersen e Skibsted

Esquema 4. Reação de Fenton

Esquema 5. Reação de formação do spin radical [4-POBN/CH$\left.\left(\mathrm{CH}_{3}\right) \mathrm{OH}\right]^{\circ}$

Esquema 6. Ilustração da reação de competição entre a armadilha 44 química 4-POBN e a isohumulonas pelo radical 1-hidroxietila

Esquema 7. Reação de formação das espécies aduto oxidado e 82 4-POBN ligado a duas moléculas de radical 1-hidroxietila

Esquema 8. Esquema de reação propondo o efeito de polifenóis 96 contendo o grupo catecol na oxidação do etanol no vinho e na cerveja. Adaptado de Elias e Andersen

Esquema 9. Mecanismo proposto para a reação entre as isohumulonas e o radical 1-hidroxietila 


\section{Lista de Figuras}

Figura 1. Consumo médio anual de cerveja per capita por país e gráfico 18 da distribuição de bebidas alcoólicas no mercado brasileiro

Figura 2. Fluxograma do processo industrial cervejeiro

Figura 3. Estrutura química dos $\beta$-ácidos (1a-c) e $\alpha$-ácidos (2a-c). (1a) nlupulona, (1b) colupulona, (1c) adlupulona, (2a) n-humulona, (2b) cohumulona, (2c) adhumulona

Figura 4. Estrutura química das isohumulonas em sua forma molecular (a) e aniônica (b)

Figura 5. Estrutura química da dihidro-isohumulonas (1a-c) e tetrahidroisohumulonas (2a-c), derivados reduzidos e hidrogenados dos iso- $\alpha$ ácidos, respectivamente. (1a) dihidro-iso-n-humulona, (1b) dihidroisocohumulona, (1c) dihidro-isoadhumulona, (2a) tetrahidro-iso-nhumulona, (2b) tetrahidro-isocohumulona, (2c) tetrahidro-isoadhumulona

Figura 6. Estrutura química de alguns fenóis presentes na cerveja. (a) 32 quercetina, (b) morina, (c) kaempferol, (d) ácido p-cumárico, (e) ácido clorogênico, (f) ácido cafeico

Figura 7. Ilustração esquemática da separação dos diastereoisômeros por complexação com a $\beta$-ciclodextrina

Figura 8. Evolução dos precursores - isohumulonas - e produtos da reação - dihidro-isohumulonas - no sistema de cromatografia planar utilizando sílica gel como fase estacionária e hexano/éter etílico (1:4 v/v) acidificado com ácido acético como fase móvel. (R) reação; (M) mistura; (P) precursores

Figura 9. Evolução dos precursores - isohumulonas - e produtos da reação - tetrahidro-isohumulonas - no sistema de cromatografia planar utilizando sílica gel como fase estacionária e hexano/éter etílico (1:1 v/v) acidificado com ácido acético como fase móvel.(R) reação; (M) mistura; (P) precursores

Figura 10. Espectro eletrônico de absorção das trans-isohumulonas isoladas em solução contendo $10 \mathrm{~mL}$ de etanol e $1 \mathrm{~mL}$ de solução aquosa de $\mathrm{HCl}\left(2,0 \mathrm{~mol} \mathrm{~L}^{-1}\right)$. Concentração de trans-isohumulonas de 3,2 $10^{-5} \mathrm{~mol} \mathrm{~L}^{-1}$ 
Figura 11. (a) Cromatograma de íons total da amostra comercial contendo as isohumulonas, formas cis- e trans- (em vermelho) e das trans-isohumulonas isoladas (em azul). (b) Espectro de massas (ESI(-)MS) da espécie trans-coisohumulona referente ao pico $2, t_{r}=11,4$ min. (c) Espectro de massas (ESI(-)MS) da espécie trans-iso-n-humulona referente ao pico $4, \mathrm{t}_{\mathrm{r}}=16,5 \mathrm{~min}$

Figura 12. Espectro de $1 \mathrm{H} \mathrm{RMN} \mathrm{(200} \mathrm{MHz)} \mathrm{das} \mathrm{trans-isohumulonas}$ isoladas, em $\mathrm{CDCl}_{3}$. Os sinais marcados com $\left(^{*}\right)$ indicam impurezas presentes na amostra

Figura 13. Cromatograma característico das trans-isohumulonas em meio alcoólico $\left(5,010^{-3} \mathrm{~mol} \mathrm{~L}^{-1}\right)$ submetido a separação em uma coluna LUNA C-18 e eluição isocrática $56 \%$ do solvente B. Vazão da fase móvel $2,5 \mathrm{~mL} \mathrm{~min} .^{-1}$ Volume de injeção $500 \mu \mathrm{L}$. Comprimento de onda de monitoramento $\lambda=270 \mathrm{~nm}$

Figura 14. Espectro de massas (ESI(-)MS) resultante de injeção direta da fração 1 contendo trans-isohumulona

Figura 15. Espectro de massas (ESI(-)MS) resultante de injeção direta da fração 2 contendo trans-isohumulonas

Figura 16. Espectro eletrônico de absorção das cis-isohumulonas isoladas em solução contendo $10 \mathrm{~mL}$ de etanol e $1 \mathrm{~mL}$ de solução aquosa de $\mathrm{HCl}\left(2,0 \mathrm{~mol} \mathrm{~L}^{-1}\right)$. Concentração de $4,610^{-5} \mathrm{~mol} \mathrm{~L}^{-1}$

Figura 17. (a) Cromatograma de íons total da amostra comercial contendo as isohumulonas, formas cis- e trans-, (em vermelho) e das cisisohumulonas isoladas (em azul). (b) Espectro de massas (ESI(-)MS) da espécie cis-isocohumulona referente ao pico 1, $\mathrm{t}_{\mathrm{r}}=10,5 \mathrm{~min}$. (c) Espectro de massas (ESI(-)MS) das espécies cis-isoadhumulona e cis-iso-nhumulona referente ao pico $3, \mathrm{t}_{\mathrm{r}}=14,7$ min. Os sinais marcados com $\left({ }^{*}\right)$ indicam impurezas presentes na amostra

Figura 18. Espectro de $1 \mathrm{H}$ RMN (200 MHz) das cis-isohumulonas isoladas, em $\mathrm{CDCl}_{3}$. Os sinais marcados com $\left(^{*}\right)$ indicam impurezas presentes na amostra

Figura 19. Cromatograma característico das cis-isohumulonas em meio alcoólico $\left(1,010^{-3} \mathrm{~mol} \mathrm{~L}^{-1}\right)$ submetido a separação em uma coluna LUNA C-18 e eluição isocrática $56 \%$ do solvente B. Vazão da fase móvel 2,5 $\mathrm{mL}$ min. $^{-1}$ Volume de injeção $500 \mu \mathrm{L}$. Comprimento de onda de monitoramento $\lambda=270 \mathrm{~nm}$

Figura 20. Espectro de massas (ESI(-)MS) resultante de injeção direta da fração 1 contendo cis-isohumulonas

Figura 21. Espectro de massas (ESI(-)MS) resultante de injeção direta da fração 2 contendo cis-isohumulonas 
Figura 22. Espectro eletrônico de absorção das dihidro-isohumulonas, formas cis- e trans-, em solução contendo $10 \mathrm{~mL}$ de etanol e $1 \mathrm{~mL}$ de solução aquosa de $\mathrm{HCl}\left(2,0 \mathrm{~mol} \mathrm{~L}^{-1}\right)$. Concentração de $2,310^{-5} \mathrm{~mol} \mathrm{~L}^{-1}$

Figura 23. (a) Cromatograma de íons total das dihidro-isohumulonas. (b) Espectro de massas (ESI(-)MS) da espécie trans- e cis-dihidroisocohumulona referente aos picos 1 e 2, $t_{r}=6,3$ e 7,6 min. (c) Espectro de massas (ESI(-)MS) da espécie trans- e cis-dihidro-iso-n-humulona referente aos picos 3 e 4, $t_{r}=8,2$ e 10,0 min. (d) Espectro de massas (ESI(-)MS) da espécie cis- e trans-dihidro-isoadhumulona referente aos picos 5 e $6, t_{r}=11,7$ e 15,1 $\min$

Figura 24. Espectro de $1 \mathrm{H} \mathrm{RMN} \mathrm{(200} \mathrm{MHz)} \mathrm{das} \mathrm{dihidro-isohumulonas,}$ formas cis- e trans-, em $\mathrm{CDCl}_{3}$. Os sinais marcados com $\left(^{*}\right)$ indicam impurezas presentes na amostra

Figura 25. Espectro eletrônico de absorção das tetrahidro-isohumulonas, formas cis- e trans-, em meio etanol. Concentração de $2,310^{-5} \mathrm{~mol} \mathrm{~L}^{-1}$

Figura 26. (a) Cromatograma de íons total das tetrahidro-isohumulonas, formas cis- e trans-. (b) Espectro de massas (ESI(-)MS) da espécie cis- e trans-tetrahidro-isocohumulona referente aos picos 1 e 2, $t_{r}=19,2$ e 21,5 min., respectivamente. (c) Espectro de massas (ESI(-)MS) das espécies cis- e trans-tetrahidro-iso-n-humulona referente ao pico $3, t_{r}=26,0 \mathrm{~min}$. (d) Espectro de massas (ESI(-)MS) das espécies cis- e trans-tetrahidroisoadhumulona referente ao pico $4, \mathrm{t}_{\mathrm{r}}=29,6 \mathrm{~min}$

Figura 27. Espectro de $1 \mathrm{H} \mathrm{RMN} \mathrm{(200} \mathrm{MHz)} \mathrm{das} \mathrm{tetrahidro-isohumulonas,}$ formas cis- e trans-, em $\mathrm{CDCl}_{3}$. Os sinais marcados com $\left(^{*}\right)$ indicam impurezas presentes na amostra

Figura 28. Voltamograma cíclico das trans-isohumulonas em sua forma aniônica, em acetonitrila contendo $0,2 \mathrm{~mol} \mathrm{~L}^{-1}$ de perclorato de tetrabutilamônio como eletrólito suporte. Eletrodos: diamante dopado com boro (trabalho), platina (contra-eletrodo), ferroceno (referência interna). A velocidade de varredura foi $50 \mathrm{mV} \mathrm{s}^{-1}$

Figura 29. Voltamograma cíclico das trans-isohumulonas em sua forma molecular, em acetonitrila contendo $0,2 \mathrm{~mol} \mathrm{~L}^{-1}$ de perclorato de tetrabutilamônio como eletrólito suporte. Eletrodos: diamante dopado com boro (trabalho), platina (contra-eletrodo), ferroceno (referência interna). As velocidades de varredura foram: $a=10 \mathrm{mV} \mathrm{s}^{-1}, b=50 \mathrm{mV} \mathrm{s}^{-1}$, $\mathrm{c}=100 \mathrm{mv} \mathrm{s}^{-1}, \mathrm{~d}=200 \mathrm{mV} \mathrm{s}^{-1}$ 
Figura 30. (a) Cromatograma de íons total dos produtos decorrentes da reação de formação do aduto radical [4-POBN/CH$\left.\left(\mathrm{CH}_{3}\right) \mathrm{OH}\right]^{\circ}$ sob atmosfera de $\mathrm{O}_{2} . \mathrm{T}=25^{\circ} \mathrm{C} ; \mathrm{t}=5$ minutos. (b) Espectro de massas $(\mathrm{ESI}(+) \mathrm{MS})$ do eluato em $\mathrm{t}_{r}=6$ min referente à espécie 4-POBN

Figura 31. (a) Cromatograma de íons total dos produtos decorrentes da reação de formação do aduto radical [4-POBN/CH$\left(\mathrm{CH}_{3}\right) \mathrm{OH}$ ] sob atmosfera de $\mathrm{Ar}$. $\mathrm{T}=25^{\circ} \mathrm{C} ; \mathrm{t}=5$ minutos. (b) Espectro de massas $(E S I(+) M S)$ com atribuição dos íons do eluato em $t_{r}=7,9$ min. (c) Espectro de massas (ESI(+)MS) com atribuição dos íons do eluato em $\mathrm{t}_{r}$ = 8,6 min. (d) Espectro de massas (ESI(+)MS) com atribuição dos íons do eluato em $t_{r}=9,2$ min. (e) Espectro de massas (ESI(+)MS) com atribuição dos íons do eluato em $t_{r}=12,8 \mathrm{~min}$

Figura 32. Estruturas químicas das quatro espécies formadas da reação entre 4-POBN e o radical 1-hidroxietila: (a) aduto oxidado; (b) aduto radical; (c) e (d) 4-POBN ligado a duas moléculas do radical 1-hidroxietil; (e) aduto reduzido

Figura 33. Espectro de ressonância paramagnética de elétrons (RPE) registrado em banda-X $(9,521 \mathrm{GHz})$ do aduto radical [4POBN/CH $\left.\left(\mathrm{CH}_{3}\right) \mathrm{OH}\right]^{\circ}$ obtido em solução aquosa água/etanol $(\cong 5 \%)$ a temperatura de $25^{\circ} \mathrm{C}$

Figura 34. Decaimento do aduto radical $\left[4-\mathrm{POBN} / \mathrm{CH}\left(\mathrm{CH}_{3}\right) \mathrm{OH}\right]^{\circ}$ na presença e ausência de catalase $\left(47,4 \mathrm{mg} \mathrm{mL}^{-1}\right) . \mathrm{T}=25^{\circ} \mathrm{C}$

Figura 35. Área dos picos cromatográficos referentes às espécies aduto oxidado, aduto radical [4-POBN/CH $\left(\mathrm{CH}_{3}\right) \mathrm{OH}$ ] e 4-POBN contendo duas moléculas do radical 1-hidroxietila em função do tempo de reação e na presença de catalase

Figura 36. Gráfico $(\mathrm{F} / \mathrm{F}-1)^{*} \mathrm{k}_{2}{ }^{*}[4-\mathrm{POBN}]$ vs. concentração de transisohumulonas. Medidas obtidas por espectrometria de massas (ESI-(+)MS/MS e espectroscopia de ressonância paramagnética de elétrons (EPR). $\mathrm{T}=25^{\circ} \mathrm{C} ; 1$ minuto de reação

Figura 37. Configuração espacial das cis-isohumulonas (a) e transisohumulonas (b), com os respectivos momentos de dipolo elétrico

Figura 38. Ilustração dos orbitais moleculares ocupados de maior energia (HOMO) calculados para os diastereoisômeros cis- (a) e transisohumulonas (b)

Figura 39. Representação das ligações $\mathrm{C}-\mathrm{H}$ envolvidas na abstração do átomo de hidrogênio na reação. (a) trans-isohumulonas; (b) cisisohumulonas 
Figura 40. Espectro de íon isolado $240,1 \mathrm{~m} / \mathrm{z}$ decorrente da reação do 94 radical 1-hidroxietila e 4-POBN (pico 1), na presença de ácido clorogênico (pico 2) ou ácido cafeico (pico 3). As injeções foram realizadas em batelada

Figura 41. Espectros de ressonância paramagnética de elétrons (RPE) registrados em banda-X $(9,521 \mathrm{GHz})$ do aduto radical [4$\mathrm{POBN} / \mathrm{CH}\left(\mathrm{CH}_{3}\right) \mathrm{OH}$ ]'decorrente da reação controle (em preto), reação processada na presença ácido clorogênico (em vermelho) e reação processada na presença do ácido cafeico (em azul). Os espectros foram obtidos a temperatura de $25^{\circ} \mathrm{C}$

Figura 42. (a) Cromatogramas de íons total da solução alcoólica contendo as trans-isohumulonas (em vermelho) e dos produtos decorrentes da reação das trans-isohumulonas e o radical 1-hidroxietila (em azul),sob atmosfera de $\mathrm{Ar}, \mathrm{T}=25^{\circ} \mathrm{C}, \mathrm{t}=1$ minuto de reação. (b) Espectro de massas (ESI(-)MS) com atribuição do íon do eluato em $\mathrm{t}_{\mathrm{r}}=$ 17,7 min. (c) Espectro de massas (ESI(-)MS) com atribuição do íon do eluato $\mathrm{em}_{\mathrm{r}}=21,5 \mathrm{~min}$ 


\section{Lista de Tabelas}

Tabela 1. Percentuais de isohumulonas no extrato de lúpulo pré- 53 isomerizado

Tabela 2. Dados cinéticos com respeito ao decaimento do aduto radical [4-POBN/CH $\left.\left(\mathrm{CH}_{3}\right) \mathrm{OH}\right]^{\circ}$ no meio reacional e a temperatura de $25{ }^{\circ} \mathrm{C}$

Tabela 3. Constantes de velocidade aparentes da reação entre o radical

1-hidroxietila e os iso- $\alpha$-ácidos e seus derivados, em sua forma aniônica, determinadas por EPR e ESI-(+)-MS/MS, em 1 minuto de amostragem

Tabela 4. Constantes de velocidade aparentes da reação entre o radical 1-hidroxietila e as iso-n-humulonas, em sua forma molecular, determinadas ESI-(+)-MS/MS, em 1 minuto de amostragem

Tabela 5. Propriedades eletrônicas dos diastereisômeros cis- e trans-isoa-ácidos, em sua forma molecular, calculadas usando o método M06/6$31+G(d)$ 


\section{Abreviaturas}

\begin{tabular}{|c|c|c|}
\hline 4-POBN & - & a-4-piridil-1-óxido-N-tert-butilnitrona \\
\hline$\beta-C D$ & - & $\beta$-ciclodextrina \\
\hline$B D E$ & - & Bond Dissociation Energy \\
\hline $\mathrm{CDCl}_{3}$ & - & Clorofórmio deuterado \\
\hline$C I D$ & - & Colision Induced Dissociation \\
\hline ESI-MS $^{n}$ & - & Espectrômetro de Massas \\
\hline$D F T$ & - & Density Functional Theory \\
\hline IEF-PCM & - & $\begin{array}{l}\text { Integral Equation Formalism as Polarizable } \\
\text { Continuum Model }\end{array}$ \\
\hline HER & - & 1-hydroxyethyl radical \\
\hline${ }^{1} \mathrm{H}$ RMN & - & Ressonância Magnética Nuclear de Hidrogênio \\
\hline HOMO & - & Highest Occuped Molecular Orbital \\
\hline IAA & - & Iso-a-ácidos \\
\hline $\mathrm{LC}^{-M S^{n}}$ & - & Liquid Chromatography/Mass Spectrometry \\
\hline MBT & - & 3-metil-but-2-eno-1-tiol \\
\hline NHE & - & Normal hydrogen electrode \\
\hline $\mathrm{Rf}$ & - & Riboflavina 5'-monofosfato de sódio \\
\hline RPE & - & Ressonância Paramagnética de elétrons \\
\hline
\end{tabular}




\section{RESUMO}

Os iso-a-ácidos são os principais constituintes responsáveis pelo sabor amargo da cerveja, sendo estes facilmente degradados durante 0 seu processo de envelhecimento ou exposição a radiação luminosa, em particular o diastereoisômero trans-. O radical 1-hidroxietila é o radical majoritário formado na cerveja durante o processo de envelhecimento. O presente trabalho descreve a reatividade dos iso- $\alpha-$ ácidos frente ao radical 1-hidroxetila através do uso da técnica de spin-trapping com detecção por espectroscopia de ressonância paramagnética de elétrons (RPE) e espectrometria de massas (ESI-(+)-MS/MS). Observou-se que ambos os diastereoisômeros cis- e trans-iso- $\alpha$-ácidos são degradados na presença do radical 1-hidroxietila com constantes de velocidade aparentes de $1,810^{8}$ e 9,2 $10^{9} \mathrm{~L} \mathrm{~mol}^{-1} \mathrm{~s}^{-}$ ${ }^{1}$, respectivamente. A reatividade dos dihidro-iso- $\alpha$-ácidos com o radical estudado foi similar à reatividade da mistura diastereoisomérica dos iso- $\alpha$-ácidos, apresentando constante de velocidade aparente de $1,510^{9} \mathrm{~L} \mathrm{~mol}^{-1} \mathrm{~s}^{-1}$. Os análogos tetrahidro-isoa-ácidos não apresentaram reatividade para com o radical 1-hidroxietila, sugerindo os hidrogênios alílicos como sítio reacional. Adicionalmente, os cálculos ab initio por DFT demonstraram que os valores de BDE para os hidrogênios alílicos das cadeias laterais prenila e isohexenoila são equivalentes e, desta maneira, sugerindo a maior reatividade do diastereoisômero trans- a ser creditada a um fator entrópico, já que ambos os grupos estão no mesmo plano espacial. Os produtos de oxidação foram determinados por LC-ESI-MS ${ }^{n}$ e verificou-se a formação dos hidroxi-allo-iso- $\alpha$ ácidos, recentemente descritos na literatura. O conjunto de resultados obtidos possibilitou a proposta de mecanismo para processo de oxidação e perda dos ácidos amargos da cerveja, observado no envelhecimento da bebida. 


\begin{abstract}
The iso- $\alpha$-acids are the main responsible constituents for the bitter taste of beer, they are easily degraded during the aging and light exposed process, specially the transdiastereoisomer. The 1-hydroxyethyl radical is the major radical produced during the beer aging process. The present work describes the reactivity of iso- $\alpha$-acids towards the 1-hydroxyethyl radical as probed by the spin-trapping technique and detected by electron paramagnetic resonance (EPR) and mass spectrometry (ESI-(+)-MS/MS). It was observed that both diastereoisomers cis- and trans-iso- $\alpha$-acids are degraded in the presence of 1-hydroxyethyl radical with apparent rate constant of $1.810^{8}$ e 9.2 $10^{9} \mathrm{~L} \mathrm{~mol}^{-1} \mathrm{~s}^{-1}$, respectively. The reactivity of dihydro-iso- $\alpha$-acids towards the studied radical was similar to the reactivity of the iso- $\alpha$-acids diastereoisomeric mixture, showing apparent rate Constant of $1.510^{9} \mathrm{~L} \mathrm{~mol}^{-1} \mathrm{~s}^{-1}$. The tetrahydro-iso- $\alpha$-acids analogues did not observed reactivity towards the 1-hydroxyethyl radical suggesting the allilic hydrogens as the reaction sites. In addition, the ab initio DFT calculations demonstrated that the BDE values for the allilic hydrogens of the prenyl and isohexenoyl side chains are equivalents and according to that suggesting the higher reactivity of the trans- diastereoisomer to be accounted to an entropic factor since both goups are in the same plane of the space. The oxidation products were determined by LC-ESI-MS ${ }^{n}$ and its was verified the formation of hydroxyl-allo-iso- $\alpha-$ acids. The data colected allows a mechanism to be proposed for the oxidation process and loss of bitter acids of beer during the beverage aging.
\end{abstract}




\section{INTRODUÇÃO}

A cerveja é considerada a bebida alcoólica mais consumida mundialmente, com um consumo mundial médio per capita ao redor de 21,9 litros/ano e uma produção anual em torno de $1,2210^{6}$ hectolitros $^{1}$. O consumo per capita no Brasil apresenta uma média de 47,6 litros $/ a^{2} o^{2}$, representando $66 \%$ do mercado de bebidas alcoólicas no país, Figura 1.
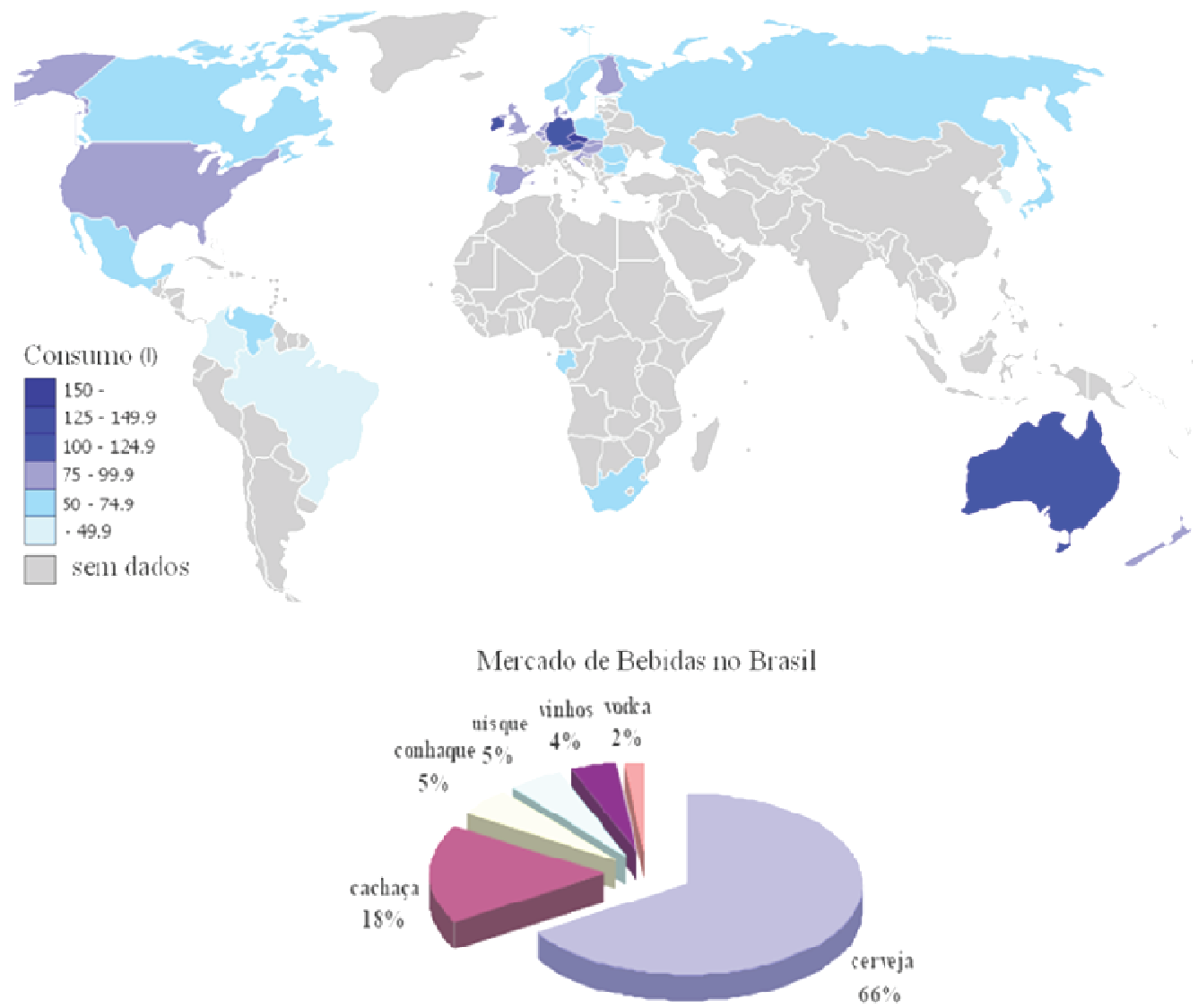

Figura 1. Consumo médio anual de cerveja per capita por país e gráfico da distribuição de bebidas alcoólicas no mercado brasileiro ${ }^{1}$. 
Por regulamentação, a cerveja é produzida a partir de água de boa qualidade, malte de cevada, fermento e lúpulo (Humulus lupulus), podendo ainda ser utilizadas outras fontes de carboidratos como co-adjuntos tais como arroz, milho e trigo ${ }^{3}$. A cerveja é, por definição, uma bebida carbonatada de baixo teor alcoólico que tem atraído consumidores há mais de 100 anos por apresentar atributos sensoriais peculiares, tais como frescor, aroma e amargor característico ${ }^{4}$.

O processo industrial para a produção de cerveja encontra-se ilustrado na Figura 2. O início do processo ocorre pela moagem do malte de cevada juntamente com a água, resultando em uma suspensão que é submetida a aquecimento a temperatura de aproximadamente $60{ }^{\circ} \mathrm{C}$ para que as enzimas, amilase e protease, degradem o amido e proteínas do malte, formando uma mistura de glicose e aminoácidos também denominada mosto doce.

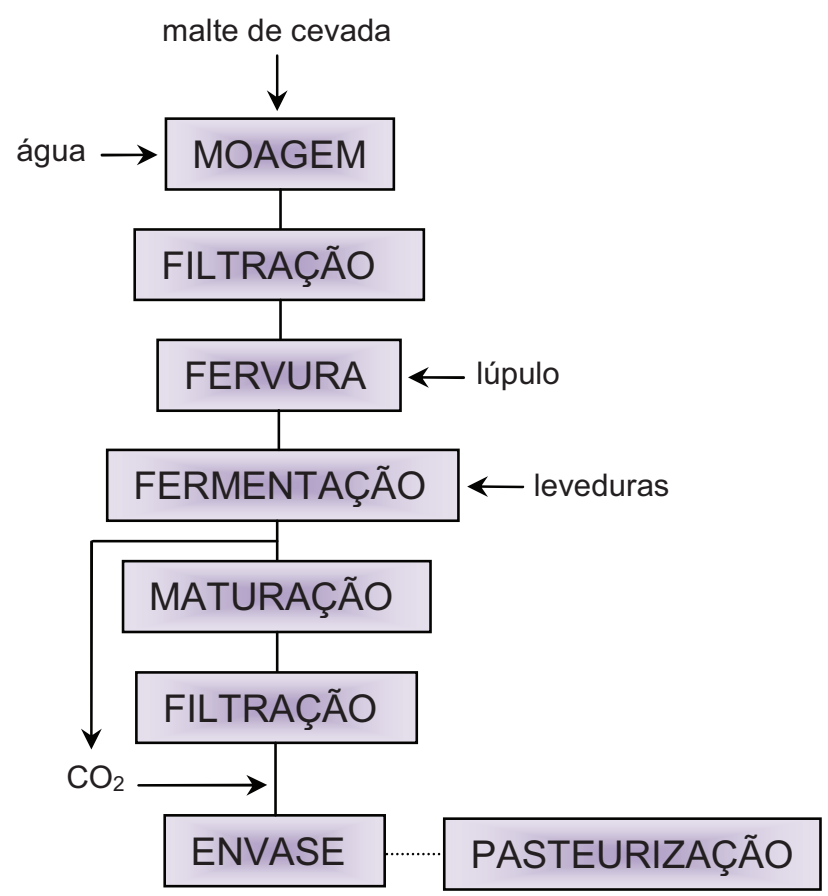

Figura 2. Fluxograma do processo industrial cervejeiro. 
Logo após a etapa de filtração, há adição do lúpulo\# e em seguida aplica-se um gradiente de temperatura, podendo chegar até $95{ }^{\circ} \mathrm{C}$, durante aproximadamente uma hora; tem-se então o processo de fervura/cozimento dos mosto doce. Em seguida, os materiais suspensos provenientes do lúpulo são retidos e a mistura é então resfriada para a adição das leveduras; dar-se-á a fermentação. Esta etapa é dividida em dois estágios: aeróbico e anaeróbico. No estágio aeróbico ocorre o crescimento das leveduras na presença de oxigênio, ao passo que no estágio anaeróbico, as leveduras transformam a glicose em etanol e dióxido de carbono, sendo este último recuperado e armazenado para o reaproveitamento ao final do processo. Existem dois tipos de leveduras que são utilizadas no processo cervejeiro, Saccharomyces carlsbergensis e Saccharomyces cerevisiae, as quais conferem o tipo de fermentação empregado. Utilizando leveduras do tipo Saccharomyces carlsbergensis tem-se uma cerveja de baixa fermentação, as quais decantam durante a produção de etanol, ao passo que uma cerveja tida como de alta fermentação são empregadas leveduras do tipo Saccharomyces cerevisiae, as quais ficam suspensas no final do processo e suportam altas concentrações de etanol.

Ao final da fermentação, as leveduras são removidas, obtendo uma cerveja denominada "green beer", esta última ainda não adequada ao consumo imediato por apresentar compostos de sabor e aroma indesejáveis. Consequentemente, é requerido um período denominado de maturação, no qual a cerveja é mantida em torno de $0{ }^{\circ} \mathrm{C}$ por um tempo relativamente grande (semanas) para que tais compostos sejam vagarosamente degradados/transformados até atingirem níveis de concentração abaixo de seus valores críticos (limiares de sensação). Ainda, é comumente empregada, ao final do processo cervejeiro, uma correção do amargor

\footnotetext{
\# O lúpulo pode ser adicionado ao processo cervejeiro através da adição direta de flores secas (in natura), pellets ou extratos ${ }^{3}$.
} 
da cerveja acabada adicionando-se extrato de lúpulo pré-isomerizado. Por fim, a cerveja segue para o envase, após filtração e adição de dióxido de carbono, podendo ainda passar ou não pelo processo de pasteurização ${ }^{5,6}$.

De acordo com a Lei da Pureza da Cerveja ("Reinheitsgebot"), promulgada pelo Duque Guilherme IV da Baviera em 1516, foi instituído na Alemanha o uso apenas do malte de cevada, água, lúpulo e fermento como ingredientes para a fabricação da cerveja ${ }^{7}$. Desta forma, o uso do lúpulo no processo de fabricação da cerveja foi reforçado. Este ingrediente foi introduzido na cervejaria durante a Idade Média pelos monges europeus que refinaram as técnicas de produção. Inicialmente, o lúpulo era adicionado como um preservativo de ação bactericida de origem natural para que a cerveja pudesse ser estocada por longos períodos; porém, passou a ser um agente de aroma essencial e singular da cerveja.

O lúpulo é uma planta trepadeira perene, pertencente à família Cannabinaceae, espécie Humulus lupulus, cuja composição química é complexa, compreendendo uma gama muito grande de metabólitos secundários localizados especialmente nas glândulas localizadas atrás das brácteas do cone de lúpulo. Estas glândulas são cobertas com um pó resinoso amarelo chamado de lupulina. Entre as diversas classes de compostos químicos presentes na lupulina encontramse os óleos essenciais $(0,5-5 \% \mathrm{v} / \mathrm{m})$, polifenóis $(3-6 \% \mathrm{~m} / \mathrm{m})$ e os $\alpha$-ácidos e $\beta$ ácidos $(4-30 \% \mathrm{~m} / \mathrm{m})^{5,8}$, também denominados humulonas e lupulonas respectivamente, os quais possuem grande impacto na qualidade da cerveja. As estruturas químicas dos $\alpha$-ácidos e $\beta$-ácidos estão apresentadas na Figura 3. 


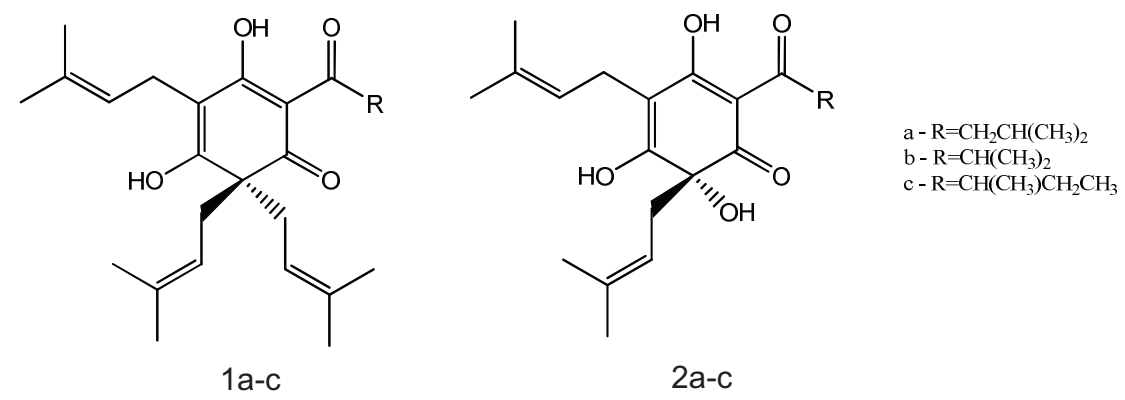

Figura 3. Estrutura química dos $\beta$-ácidos (1a-c) e $\alpha$-ácidos (2a-c). (1a) n-lupulona, (1b) colupulona, (1c) adlupulona, (2a) n-humulona, (2b) cohumulona, (2c) adhumulona.

Desta forma, o lúpulo e seus componentes são considerados essenciais na produção de cerveja e responsáveis pela distinção desta de qualquer outra bebida alcoólica carbonatada. Ainda, dentre os componentes utilizados no processo industrial da cerveja, o lúpulo representa o de menor custo $^{6}$ e, neste contexto, é interessante enfatizar que apenas as plantas femininas formam o cone de lúpulo e, portanto, somente estas são comercializadas.

Apesar de não possuírem impacto direto nas propriedades sensoriais da cerveja, os $\alpha$-ácidos são os precursores dos iso- $\alpha$-ácidos, comumente chamadas por isohumulonas, responsáveis pelo amargor característico e qualidade da espuma da cerveja $^{9,10}$. Conforme já mencionado, as humulonas são introduzidas ao processo cervejeiro pela adição do lúpulo ao mosto e, após a fervura deste, há conversão das humulonas, pouco solúveis em meio aquoso $\left(60 \mathrm{mg} \mathrm{L}^{-1}\right.$ a $\left.100{ }^{\circ} \mathrm{C}\right)$, às espécies mais hidrofílicas denominadas isohumulonas, conforme ilustrado no Esquema 1. 


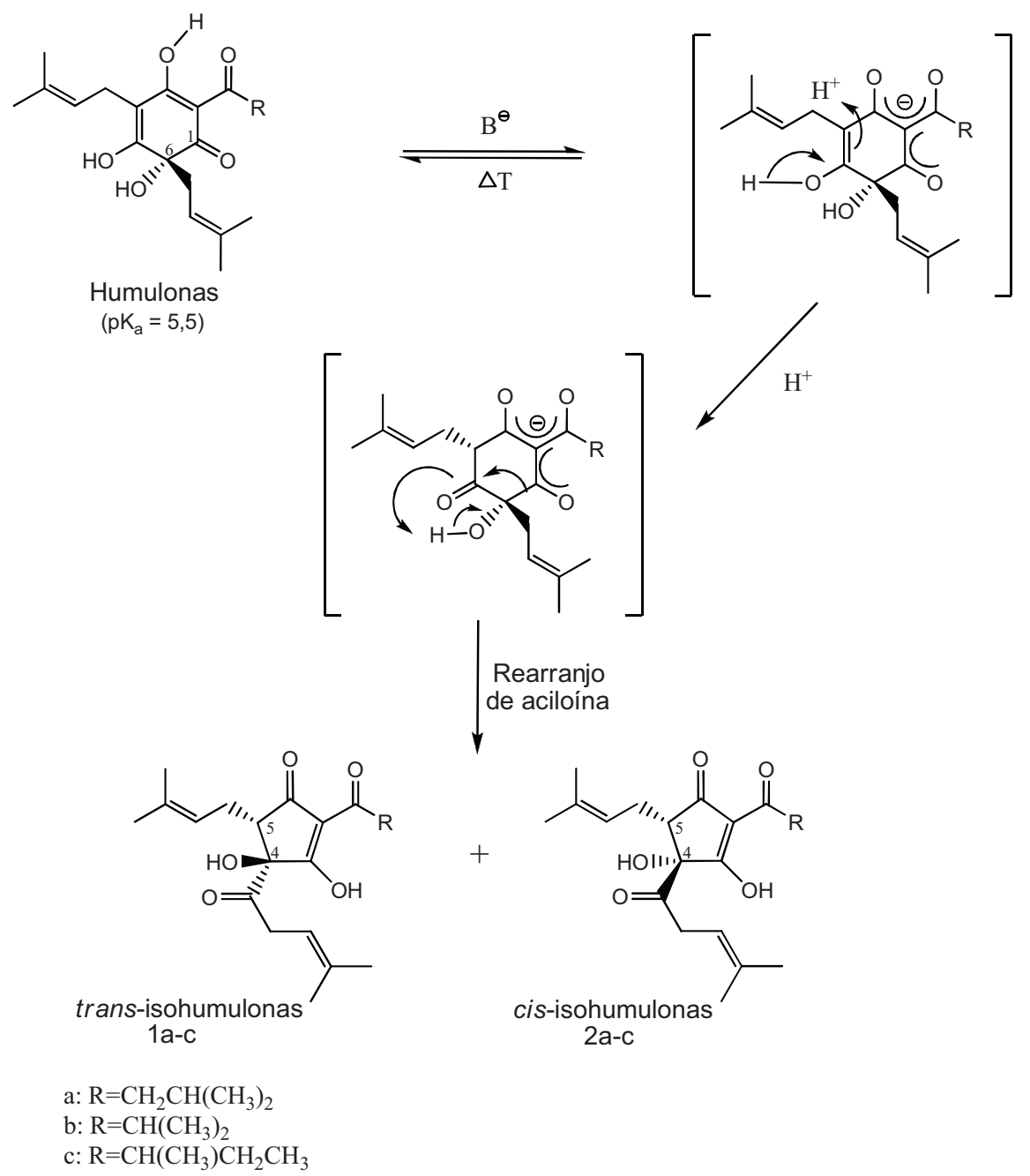

Esquema 1. Reação de isomerização térmica das humulonas à cis- (2-ac) e trans-isohumulonas (1-ac) durante o cozimento do mosto fermentado e adicionado de lúpulo. A relação trans-/cisishumulonas em condições normais de fabricação da cerveja é de 32:68. (a) iso-n-humulona, (b) isocohumulona, (c) isoadhumulona ${ }^{9}$.

Estes compostos contendo um anel de 5 membros consistem em pares de diastereoisômeros, trans-isohumulonas (1a-c, Esquema 1) e cis-isohumulonas (2ac, Esquema 1), cada qual com 3 análogos: iso-n-humulona (a), isocohumulona (b) e isoadhumulona (c), Esquema 1. A configuração absoluta cis-/trans- é determinada pela orientação do grupo hidroxila em C4 e a cadeia lateral prenila em C5, sendo a denominação trans- referente à direção oposta de ambos os substituintes com respeito ao anel de 5 membros. Verifica-se que, após a fervura do mosto, a razão cis-/trans- é em geral 7:3, uma vez que os diastereoisômeros cis- são 
termodinamicamente mais estáveis (configuração de menor energia), visto que os grupos laterais volumosos prenila e isohexenoila estão trans posicionadas ${ }^{9}$.

O valor de $\mathrm{pK}_{\mathrm{a}}$ varia sensivelmente para cada análogo de iso- $\alpha$-ácidos; porém, este pode ser aproximado para $3^{11,12}$. Sabe-se que o $\mathrm{pH}$ da maioria da cerveja gira em torno de 4,2 e 4,4, principalmente para cervejas do tipo large ${ }^{11,12}$. Desta forma, as isohumulonas encontram-se predominantemente na forma aniônica na bebida (aproximadamente 84\%), cuja fórmula estrutural está apresentada na Figura 4b. Evidentemente, esta afirmativa pode não ser verdadeira para cervejas mais ácidas, estando presentes, neste caso, os iso-a-ácidos em sua forma molecular, Figura 4a.

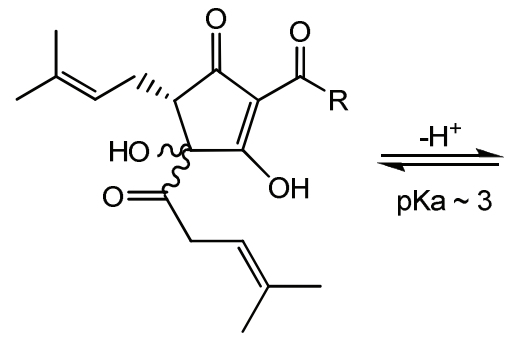

(a)

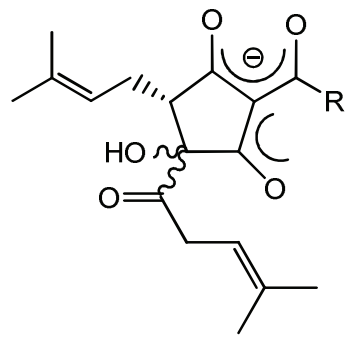

(b)

Figura 4. Estrutura química das isohumulonas em sua forma molecular (a) e aniônica (b).

A concentração de iso- $\alpha$-ácidos presentes no produto acabado varia entre 15 a $80 \mathrm{mg} \mathrm{L}^{-1}\left(4,110^{-5}\right.$ a $\left.2,210^{-4} \mathrm{~mol} \mathrm{~L}^{-1}\right)$, conferindo diferentes graus de amargor ${ }^{13}$. Desta forma, as isohumulonas representam aproximadamente $80 \%$ de todo componente derivado do lúpulo presente na cerveja ${ }^{10}$.

Quimicamente, a cerveja pode ser considerada uma solução alcoólica com concentração hidrogeniônica $\left(\mathrm{C}_{\mathrm{H}^{+}}\right)$de $10^{-4,2} \mathrm{~mol} \mathrm{~L}^{-1}$, contendo centenas de substâncias dissolvidas ${ }^{14}$. Entretanto, os constituintes de uma cerveja fresca, recém engarrafada, não estão em equilíbrio químico. Termodinamicamente, uma garrafa de cerveja é um sistema fechado e irá empenhar-se para alcançar uma condição de menor energia e máxima entropia. Por conseguinte, muitas conversões de seus 
constituintes são termodinamicamente possíveis, sendo que sua relevância para a qualidade de cerveja é, em sua maioria, determinada pelas velocidades de reação ${ }^{\dagger}$ em condições práticas de armazenamento do produto ${ }^{14}$.

Com o aumento da exportação da cerveja, principalmente devido à globalização do mercado, problemas relacionados ao tempo de prateleira do produto ("shelf-life") tornam-se de extrema importância para a indústria cervejeira. Sabe-se que a cerveja é suscetível a sofrer diversas reações durante o seu armazenamento, as quais levam a perda de amargor e frescor do produto, bem como o desenvolvimento de compostos que conferem aroma e sabor indesejáveis ${ }^{14}$. Desta forma, o conhecimento dos possíveis caminhos, mecanismos e constantes de velocidade específicas $^{\lambda}$ das reações que ocasionam a perda da qualidade sensorial do produto podem auxiliar no desenvolvimento de técnicas e métodos para a conservação do produto.

Neste aspecto, as isohumulonas são particularmente sensíveis a degradação durante o armazenamento ${ }^{15}$, o que leva não somente a perda sensorial de amargor, mas também à formação de compostos voláteis de aroma, tais como 4-metil-2pentanona e 3-penteno-2-ona ${ }^{14,15}$. Existem indícios fortes que apontam o envolvimento dos iso- $\alpha$-ácidos na formação de aromas indesejáveis típicos de cerveja "velha", podendo estes ácidos sofrerem degradação oxidativa, mesmo na ausência de oxigênio molecular ${ }^{12}$.

Diversos estudos reportaram que o envelhecimento da cerveja está diretamente relacionado com a degradação das trans-isohumulonas, visto que a configuração cis- mostrou-se mais estáveis e menos suscetíveis aos processos

\footnotetext{
${ }^{\dagger}$ A velocidade de cada reação irá determinar a viabilidade de cada caminho e está intrinsecamente relacionada a constante de velocidade específica da reação e ao teor dos reagentes.

${ }^{\lambda}$ Constante de velocidade específica refere-se à constante de velocidade determinada diretamente pelo decaimento ou formação da espécie de interesse.
} 
deteriorativos ${ }^{4,5,16}$. Todavia, produtos de oxidação de ambos os diastereoisômeros, cis- e trans-isohumulonas, formados durante o armazenamento da cerveja contida em garrafa PET, foram apontados em estudos recentes ${ }^{17,18}$. Estes compostos foram chamados de hidroperoxi-allo-isohumulonas e hidroxi-allo-isohumulonas e são decorrentes de reações de degradação dos iso- $\alpha$-ácidos via radicalóide, na presença de traços de metais de transição, tais como íons de ferro, e oxigênio molecular ${ }^{17}$.

Durante um tempo considerável a reação de degradação via foto-oxidação das isohumulonas foi estudada com muito afinco ${ }^{11,19-22}$. Neste contexto, verificou-se que os iso-a-ácidos sofrem degradação na presença de luz e riboflavina, fotosensibilizador naturalmente presente na cerveja ${ }^{19,20}$. Este tipo de reação tem impacto direto na qualidade sensorial da bebida não somente pela perda do amargor característico do produto, mas, sobretudo, pelo impacto negativo de alguns produtos de degradação.

A título de exemplificação, pode-se citar a formação do 3-metil-2-buteno-1-tiol $(\mathrm{MBT})^{19-22}$, cujo mecanismo de formação está ilustrado no Esquema 2. Verifica-se que após iniciada a reação com a transferência de 1 elétron do cromóforo $\beta$-tricarbonila das isohumulonas para a riboflavina no estado tripleto excitado $\left({ }^{3} \mathrm{FF}^{*}\right)$, excelente aceptor de elétrons $(E=+1,77 \vee v s . N H E)^{22}$, o radical alcoxila formado sofre uma clivagem de Norrish do Tipo I gerando o ácido dihidrohumulínico e o radical 4-metilpenta-3-enol. Este radical sofre rápida descarbonilação e, na presença de radicais tióis ( $\mathrm{SH}$ ) o $\mathrm{MBT}$ é então formado ${ }^{11,21}$. A presença desta substância confere um odor extremamente desagradável ao produto, lembrando o odor decorrente dos tióis secretados pelas glândulas anais do gambá listrado (Mustela Vison L.), fato este agravado pelo baixo limiar de percepção do produto formado (aproximadamente $\left.1 \mathrm{ng} \mathrm{L}^{-1}\right)^{19,22}$. 

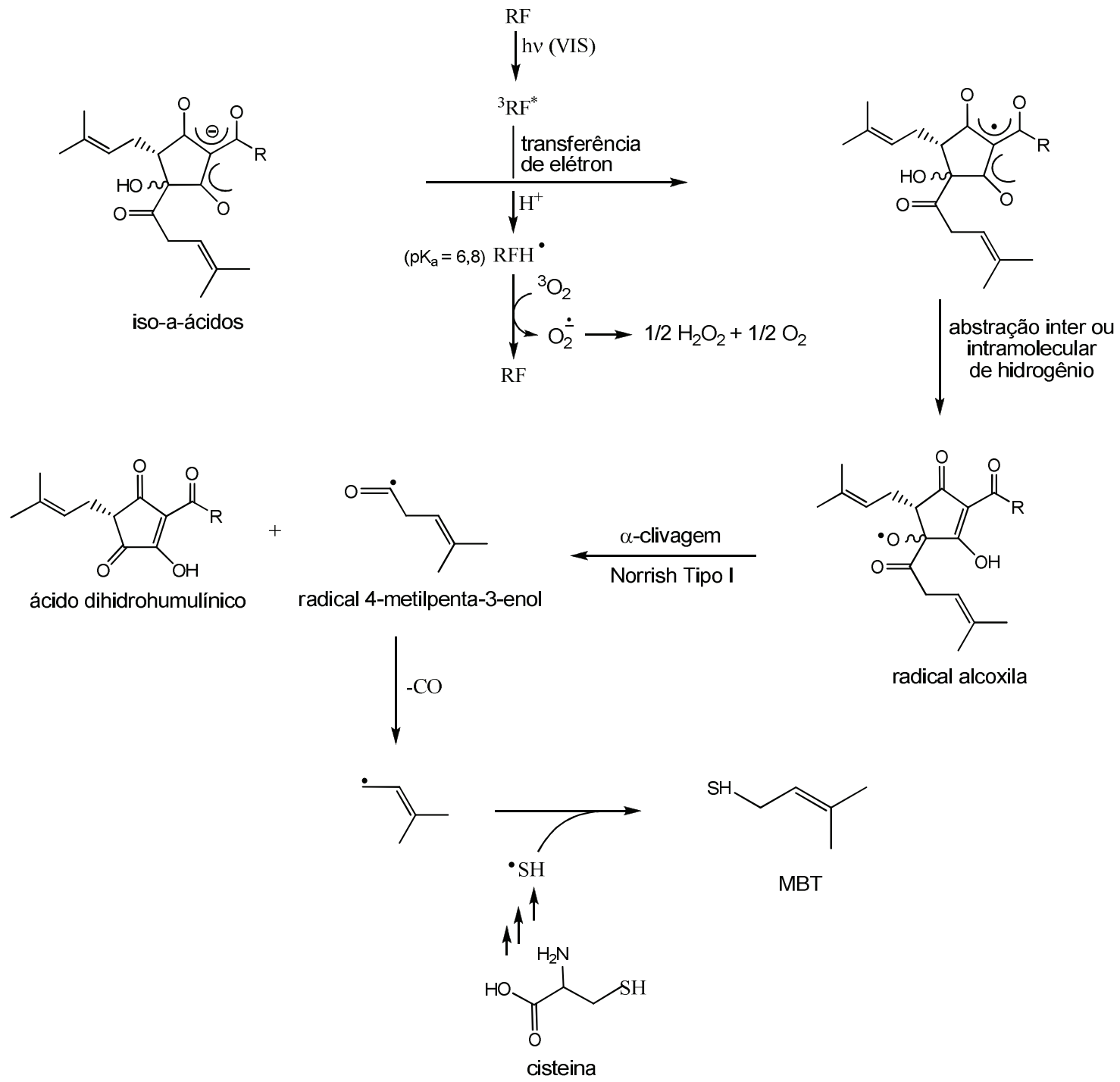

MBT

Esquema 2. Reação de degradação fotoquímica dos iso- $\alpha$-ácidos em cerveja ${ }^{11,21}$.

Em adição, Lusk e Murakami ${ }^{23}$ revelaram recentemente a existência de dois novos compostos formados a partir da exposição da cerveja à luz. Pouco se conhece sobre a estrutura destes compostos; no entanto, sabe-se que estes são decorrentes da fotodegradação dos iso- $\alpha$-ácidos sensibilizado pela riboflavina. Como resultado, através da análise sensorial dos mesmos, verificou-se que estas substâncias possuem aroma indistinguível ao conferido pelo MBT, além de apresentarem a mesma massa molecular. 
Verifica-se uma crescente busca pelas indústrias cervejeiras por aperfeiçoamento em seu processo industrial, cuja finalidade consiste em atribuir ao produto acabado melhorias referentes à estabilidade, qualidade sensorial e aumento do tempo de prateleira do mesmo. De fato, os derivados hidrogenados e reduzidos dos iso-a-ácidos, em especial tetrahidro-isohumulonas (2a-c, Figura 5) e dihidroisohumulonas (1a-c, Figura 5), vêm sendo empregados no processo industrial da cerveja por serem reconhecidamente menos sensíveis ${ }^{*}$ a degradação via fotoquímica que os seus precursores, isohumulonas.

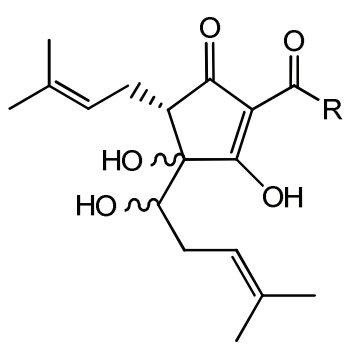

$(1 \mathrm{a}-\mathrm{c})$

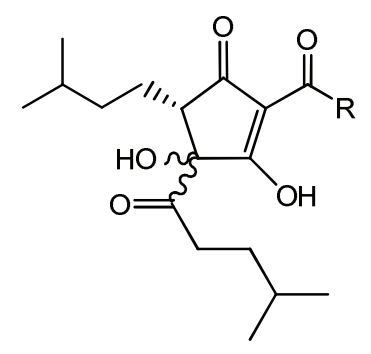

$(2 \mathrm{a}-\mathrm{c})$
$\mathrm{a}-\mathrm{R}=\mathrm{CH}_{2} \mathrm{CH}\left(\mathrm{CH}_{3}\right)_{2}$

$\mathrm{b}-\mathrm{R}=\mathrm{CH}\left(\mathrm{CH}_{3}\right)_{2}$

c - $\mathrm{R}=\mathrm{CH}\left(\mathrm{CH}_{3}\right) \mathrm{CH}_{2} \mathrm{CH}_{3}$

Figura 5. Estrutura química da dihidro-isohumulonas (1a-c) e tetrahidro-isohumulonas (2a-c), derivados reduzidos e hidrogenados dos iso- $\alpha$-ácidos, respectivamente. (1a) dihidro-iso-n-humulona, (1b) dihidro-isocohumulona, (1c) dihidro-isoadhumulona, (2a) tetrahidro-iso-n-humulona, (2b) tetrahidro-isocohumulona, $(2 \mathrm{c})$ tetrahidro-isoadhumulona.

Assim, o uso dos derivados reduzidos dos ácidos amargos do lúpulo vem de encontro à melhoria na qualidade sensorial do produto, uma vez há, em parte, uma minimização na formação de aromas indesejáveis e perda sensorial de amargor ${ }^{19-22}$. Entretanto, na prática, vários problemas são detectados, já que os derivados reduzidos também podem sofrer decomposição via radicalóide, levando a formação de produtos de degradação específicos, tais como 4-metil-3-pentenal, o qual lembra o odor de papelão e assim conferindo um aroma típico de cerveja "velha"22. A exposição das tetrahidro-isohumulonas à luz conduz a formação do composto

\footnotetext{
* O atributo menos sensível está relacionado ao menor impacto sensorial dos fotoprodutos de degradação e não a estabilidade química da espécie.
} 
4-metilpentanal, sendo, neste caso, a descarbonilação do radical 4-metil-pentanoil competitiva com a abstração de hidrogênio a partir de um doador apropriado ${ }^{22}$. Entretanto, os produtos de degradação dos derivados hidrogenados e reduzidos dos iso-a-ácidos não apresentam um impacto negativo tão expressivo quanto ao conferido ao MBT, formado a partir da isohumulonas.

Adicionalmente, a presença das tetrahidro-isohumulonas na cerveja resulta em uma maior estabilidade da espuma, bem como o aumento no poder de amargor do produto. Por outro lado, o uso das dihidro-isohumulonas no processo cervejeiro culmina em uma redução do amargor, bem como o decréscimo da estabilidade da espuma $^{5,24}$. Neste contexto, um aspecto importante a ser lembrado é o fato de que o uso dos derivados de iso-a-ácidos, os quais não são de origem natural, não é permitido na fabricação de cervejas destinadas ao mercado Alemão em decorrência do "Reinheitsgebot".

A partir desses exemplos de alterações que ocorrem durante o armazenamento da cerveja, segue que a natureza das mudanças do sabor é um processo complexo e depende principalmente do tipo da cerveja, concentração de oxigênio dissolvido e das variações de temperatura submetidas ao produto durante o transporte e estocagem.

Sabe-se que a concentração de radicais gerados durantes o processo de envelhecimento natural da cerveja aumenta com o teor de oxigênio dissolvido, com elevadas temperaturas de armazenamento ${ }^{14}$ ou com o aumento das concentrações de alguns metais de transição, tais como íons de ferro e cobre. Entretanto, pelo fato do radical hidroxila $\left({ }^{\circ} \mathrm{OH}\right)$ apresentar alta reatividade $\left(\mathrm{E}^{0}=+2,7 \mathrm{~V}\right.$ vs. $\left.\mathrm{NHE}\right)$ e baixa seletividade, Andersen e Skibsted ${ }^{25}$ demonstraram, através de experimentos de 
"spin-trapping" e ressonância paramagnética de elétrons, que o radical 1-hidroxietila (HER) é o radical predominante formado na cerveja.

O radical HER é proposto por originar-se da reação entre o etanol, cosolvente, com o radical hidroxila, conforme ilustrado o Esquema $3^{25,26}$. De fato, verificou-se que radicais hidroxila abstraem átomos de hidrogênio de moléculas de etanol com uma constante de velocidade de $1,910^{9} \mathrm{~L} \mathrm{~mol}^{-1} \mathrm{~s}^{-1}$. Esta abstração de átomo de hidrogênio ocorre preferencialmente no carbono C1 (85\%), formando o radical 1-hidroxietila, sendo em menor extensão no carbono C2 (13\%), resultando no radical 2-hidroxietila ${ }^{25}$. Sabe-se ainda que ambos os radicais formados durante a oxidação do etanol reagem com o oxigênio molecular $\left(\mathrm{O}_{2}\right)$, resultando na formação do radical hidroperoxila $\left({ }^{\circ} \mathrm{OOH}\right)$ e acetaldeído como produto principal ao final ${ }^{25}$.

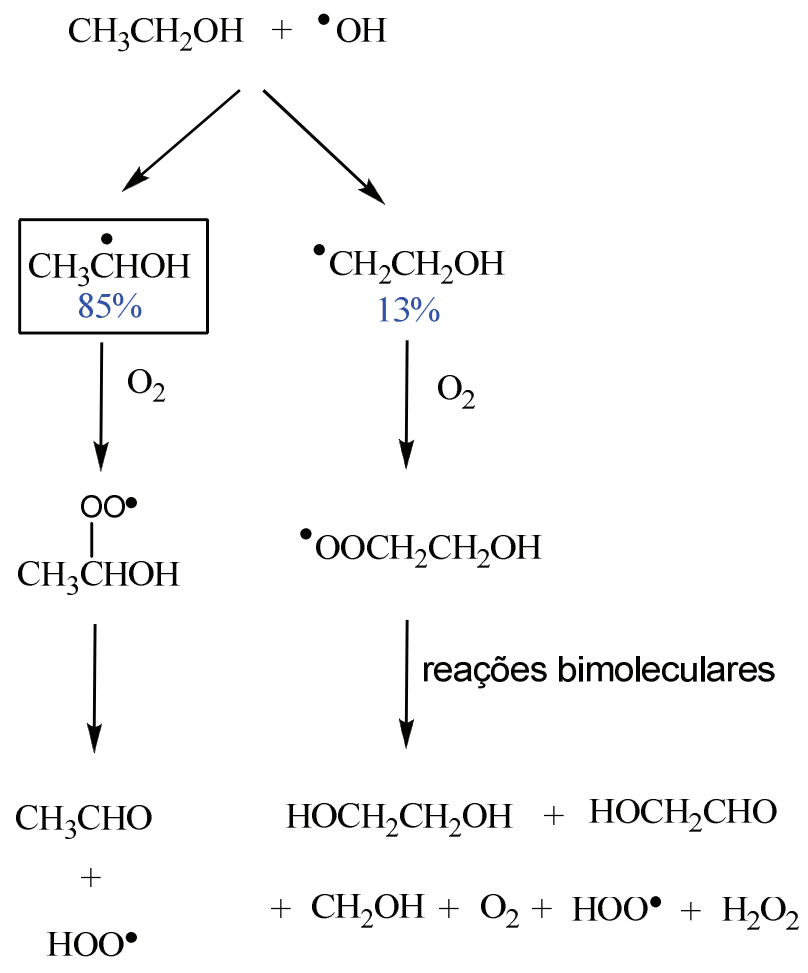

Esquema 3. Formação e reações subseqüentes dos radicais 1-hidroxietila, em destaque, e 2-hidroxietila em cerveja, de acordo com o proposto dor Andersen e Skibsted ${ }^{25}$.

Ainda, Elias e Andersen ${ }^{27}$ demonstraram recentemente que o radical HER é quantitativamente a espécie radical responsável pela oxidação do vinho. Desta 
forma, o radical 1-hidroxietila é formado a partir da oxidação do etanol pelo radical hidroxila decorrente da reação de Fenton ${ }^{25,28}$, Esquema 4.

$$
\mathrm{H}_{2} \mathrm{O}_{2}+\mathrm{Fe}^{+2} / \mathrm{Cu}^{+1} \longrightarrow \mathrm{OH}^{-}+{ }^{\circ} \mathrm{OH}+\mathrm{Fe}^{+3} / \mathrm{Cu}^{+2} \quad \mathrm{k}=63 \mathrm{~L} \mathrm{~mol}^{-1} \mathrm{~s}^{-1}
$$

Esquema 4. Reação de Fenton ${ }^{25,28}$.

É interessante ressaltar que compostos fenólicos, presentes tanto na cerveja quanto no mosto, são reativos frente ao radical 1-hidroxietila ${ }^{29,30}$. Estas substâncias fenólicas estão presentes na bebida em teores consideráveis, os quais giram em torno de $460 \mathrm{mg} \mathrm{L}^{-1}\left(2,710^{-3} \mathrm{~mol} \mathrm{~L}^{-1} \text { expresso em equivalente de ácido gálico }\right)^{30-32}$. Dentre estes compostos fenólicos, pode-se citar compostos pertencentes à classe dos flavonóides, tais como: quercetina, kaempferol e morina; bem como alguns ácidos cinâmicos como ácido cafeico, clorogênico e p-cumárico, cujas estruturas químicas estão apresentadas na Figura 6. 
<smiles>O=c1c(O)c(-c2ccc(O)c(O)c2)oc2cc(O)cc(O)c12</smiles>

(a)<smiles>O=c1c(O)c(-c2ccc(O)cc2)oc2cc(O)cc(O)c12</smiles>

(c)<smiles>C[C@@H]1CC(O)(O)C[C@@H](OC(=O)/C=C/c2ccc(O)c(O)c2)[C@@H]1O</smiles><smiles>O=c1c(O)c(-c2ccc(O)cc2O)oc2cc(O)cc(O)c12</smiles>

(b)<smiles>O=C(O)/C=C/c1ccc(O)cc1</smiles>

(d)<smiles>O=C(O)/C=C/c1ccc(O)c(O)c1</smiles>

(f)

Figura 6. Estrutura química de alguns fenóis presentes na cerveja. (a) quercetina, (b) morina, (c) kaempferol, (d) ácido p-cumárico, (e) ácido clorogênico, (f) ácido cafeico.

Substâncias fenólicas são conhecidas pela suas propriedades antioxidantes, sendo então de extrema importância na preservação de alimentos ao evitar ou inibir processos oxidativos que levam a deterioração o produto. Neste contexto, Marfak e Trouillas $^{30}$ determinaram as constantes de velocidade da reação entre o radical HER e alguns flavonóides, tais como quercetina $\left(4,010^{4} \mathrm{~L} \mathrm{~mol}^{-1} \mathrm{~s}^{-1}\right)$, kaempferol $\left(3,110^{4} \mathrm{~L} \mathrm{~mol}^{-1} \mathrm{~s}^{-1}\right)$ e morina $\left(2,910^{4} \mathrm{~L} \mathrm{~mol}^{-1} \mathrm{~s}^{-1}\right)$. Consequentemente, esta reatividade ocasiona a decomposição destes antioxidantes naturais e, portanto, a diminuição da capacidade redox do produto. 


\section{OBJETIVOS}

Aparte do melhor conhecimento a respeito do processo de deterioração oxidativa da cerveja, os principais objetivos e metas do presente trabalho podem ser resumidos conforme descrito a seguir:

- Estudo da reatividade de isohumulonas frente ao radical 1-hidroxietila;

- Estudo da reatividade dos derivados reduzidos e hidrogenados dos iso-a-ácidos, dihidro-isohumulonas e tetrahidro-isohumulonas respectivamente, frente ao radical 1-hidroxietila;

- Determinação dos produtos de reação;

- Estudo eletroquímico da forma molecular das trans-isohumulonas;

- Propor o mecanismo de degradação das isohumulonas via radicalóide, bem como elucidar o sítio de reação e verificar a dependência estereoquímica da reação;

- Estudo da reatividade de alguns fenóis, presentes na cerveja, frente ao radical 1-hidroxietila. 


\section{MATERIAL E MÉTODO}

\subsection{Reagentes.}

Acetonitrila, ácido clorídrico $36-38 \%$ e etanol foram obtidos da J. T. Baker; acetato de etila e metanol foram obtidos da Tedia, ácido fórmico 98-100\%, cloreto de ferro (II) $\left(\mathrm{FeCl}_{2} \cdot 4 \mathrm{H}_{2} \mathrm{O}\right)$, hidróxido de amônia e o peróxido de hidrogênio $30 \%$ foram obtidos da Merck; acetato de amônio, ácido p-cumárico, borohidreto de sódio, a-4-piridil-1-óxido-N-tert-butilnitrona (4-POBN), $\beta$-ciclodextrina 98\%, catalase de fígado bovino, catalisador paládio suportado em carbono 10\%, diciclohexilamina 99\%, ferroceno, quercetina e o perclorato de tetrabutilamônio foram obtidos da Sigma-Aldrich; sulfato de sódio (Hexis); clorofórmio deuterado (Acros Organics); gases argônio $(5,0)$, hidrogênio $(4,5)$, Helio $(5,0)$ e nitrogênio foram obtidos da White Martins. O extrato de lúpulo pré-isomerizado (30\% massa/volume) foi gentilmente cedido pela empresa Hopsteiner. A água de alta pureza (18 $\mathrm{M} \Omega \mathrm{cm}^{-1}$ ) utilizada foi previamente destilada e purificada utilizando um sistema de purificação Milli-Q (Millipore). Placas de TLC com matriz sílica gel suportadas em alumínio contendo $200 \mu \mathrm{m}$ de espessura de camada e indicador fluorescente $(254 \mathrm{~nm})$ foram obtidas da Fluka Analytical. Todos os reagentes utilizados foram de grau analítico e utilizados sem prévio tratamento. Os solventes foram de grau cromatográfico (HPLC) utilizados sem prévio tratamento, com exceção do acetato de etila que foi tratado seguindo procedimento descrito na literatura ${ }^{33}$. 
3.2. Isolamento das trans-isohumulonas.

Os diastereoisômeros trans- foram isolados utilizando metodologia proposta por Khatib e Verpoorte ${ }^{34}$, na qual se partiu de uma solução aquosa comercial contendo uma mistura de sais de potássio das isohumulonas na forma cis- e trans(6,6 g). A esta solução foi adicionada uma solução aquosa de $\beta$-ciclodextrina (1,5 g, em $12 \mathrm{~mL}$ de água), gota a gota, mantida a $70{ }^{\circ} \mathrm{C}$, utilizando-se a razão molar $\left(\mathrm{R}_{\text {iso-d-ácidos//-ciclodextrina) }}\right)$ 4:1. A mistura reacional foi mantida sob agitação a $70{ }^{\circ} \mathrm{C}$ durante 30 minutos, ocorrendo a complexação seletiva ao formar complexos de $\beta$-ciclodextrina com os trans-iso- $\alpha$-ácidos. A seguir, a mistura reacional foi devidamente armazenada a $4{ }^{\circ} \mathrm{C}$, sob o abrigo de luz e em repouso, por 48 horas.

Ao término da reação de complexação, formou-se um precipitado amarelo claro, o qual foi filtrado e lavado várias vezes com etanol/água (1:2 v/v) e acetato de etila. Na etapa seguinte, adicionou-se $50 \mathrm{~mL}$ de metanol ao complexo, sob agitação, para que houvesse a liberação das trans-isohumulonas, as quais ficaram em solução enquanto que a $\beta$-ciclodextrina precipitou. Por conseguinte, um novo processo de filtração foi realizado utilizando-se um filtro de placa porosa e o solvente removido por roto-evaporação a pressão reduzida. Então, adicionou-se acetato de etila $(25 \mathrm{~mL}$ ) para que resquícios de $\beta$-ciclodextrina fossem precipitados e, por fim, a solução resultante de uma nova filtração foi roto-evaporada até a secura. Obteve-se, desta forma, uma mistura contendo as trans-isohumulonas na sua forma aniônica, a qual foi posteriormente caracterizada por espectroscopia eletrônica de absorção (UV-vis), ressonância magnética nuclear $\left({ }^{1} \mathrm{H} R \mathrm{RMN}\right)$ e cromatografia líquida hifenada ao espectrômetro de massas (LC-ESI-MS ${ }^{\mathrm{n}}$ ). 
Adicionalmente, a trans-isocohumulona foi cromatograficamente separada da trans-iso-n-humulona utilizando-se um sistema de cromatografia líquida de alta eficiência (HPLC) semi-preparativo, detector de arranjo de diodos na região do UV-vis. A separação foi obtida através de uma coluna LUNA C-18 $10 \mu \mathrm{m}(20 \mathrm{~cm}$ x 0,7 cm); fluxo 2,5 mL min. ${ }^{-1}$; fase móvel solvente $A-\mathrm{H}_{2} \mathrm{O} /$ Ácido fórmico $(99: 1 \mathrm{v} / \mathrm{v})$ e solvente B - Etanol/Ácido fórmico (99:1 v/v); sistema isocrático, cuja relação da fase móvel foi $56 \%$ do solvente B em A. Uma solução alcoólica contendo apenas os diastereisômeros trans- (20 mg/injeção) foi então injetada para obter o perfil cromatográfico desejado, coletando as frações dos analitos de acordo com os respectivos tempos de retenção. As frações foram posteriormente caracterizadas por LC-ESI-MS

3.3. Isolamento das cis-isohumulonas.

Os cis-iso- $\alpha$-ácidos foram isolados partindo-se se uma solução comercial contendo sais de potássio dos diastereisômeros cis- e trans- (1,6 g). A esta solução contendo a mistura diastereoisomérica foi adicionada vagarosamente a uma solução aquosa equimolar de $\beta$-ciclodextrina $(1,5 \mathrm{~g}$, em $12 \mathrm{~mL}$ de água)

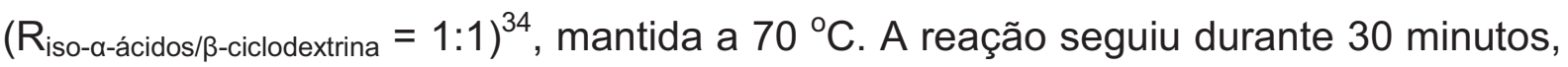
sob agitação a $70{ }^{\circ} \mathrm{C}$, havendo a complexação das trans-isohumulonas com a $\beta$-ciclodextrina. A mistura reacional foi armazenada a $4{ }^{\circ} \mathrm{C}$, sob o abrigo de luz e em repouso, por 48 horas e, após a precipitação do complexo, este foi isolado através de uma prévia filtração e o sobrenadante, contendo os cis-iso- $\alpha$-ácidos dissolvidos, foi centrifugado a $7.000 \mathrm{rpm}, 4{ }^{\circ} \mathrm{C}$, por 30 minutos, com o intuito de precipitar 
resquícios de complexo na solução. Em seguida, todo complexo foi retido no filtro de placa porosa e a solução resultante liofilizada. Adicionou-se cuidadosamente acetato de etila $(25 \mathrm{~mL})$ ao sólido resultante e $\beta$-ciclodextrina remanescente foi retida em um filtro de placa porosa, sendo a solução sobrenadante roto-evaporada até a secura. Por fim, obteve-se uma mistura contendo os diastereoisômeros cis- em sua forma aniônica, a qual foi caracterizada por UV-vis, ${ }^{1} \mathrm{H}$ RMN e LC-ESI-MS ${ }^{n}$.

Ainda, a cis-isocohumulona foi separada dos homólogos cis-isoadhumulona e cis-iso-n-humulona aplicando as mesmas condições experimentais empregadas na separação dos trans-iso-a-ácidos, partindo-se de uma solução alcoólica contendo os três análogos de cis-iso-a-ácidos. Em seguida, as frações foram caracterizadas por LC-ESI-MS ${ }^{n}$.

3.4. Preparo das dihidro-isohumulonas.

As dihidro-isohumuloonas foram preparadas partindo-se de uma mistura de cis- e trans-iso- $\alpha$-ácidos (400 mg; $\left.1,110^{-3} \mathrm{~mol}\right)$ em metanol $(27 \mathrm{~mL}$ ) e adicionandose borohidreto de sódio $(92,0 \mathrm{mg})$, sobre agitação, por 23 horas, a temperatura ambiente $\left(25^{\circ} \mathrm{C}\right)$. Após o término da reação, a mistura reacional foi acidificada com ácido clorídrico $\left(12 \mathrm{~mol} \mathrm{~L}^{-1}\right)$ a $\mathrm{pH} 1$ e o solvente foi removido por roto-evaporação a pressão reduzida. O resíduo foi então re-dissolvido em água $(20 \mathrm{~mL})$ e a solução resultando extraída com acetato de etila $(3 \times 20 \mathrm{~mL})$, sendo a fase orgânica posteriormente seca com $\mathrm{Na}_{2} \mathrm{SO}_{4}$. Após seca, o solvente da fase orgânica foi removido por roto-evaporação, obtendo uma mistura cis- e trans-dihidroisohumulonas, a qual foi caracterizada por UV-vis, ${ }^{1} \mathrm{H}$ RMN e LC-ESI-MS ${ }^{n}$. 
O desenvolvimento da reação foi monitorado através de cromatografia planar, TLC, utilizando-se placas de matriz sílica gel suportada em alumínio contendo $200 \mu \mathrm{m}$ de espessura de camada e indicador fluorescente (254 nm). Como solvente de eluição foram utilizados Hexano/Éter etílico (1:4 v/v) acidificado com ácido acético e como revelador foi utilizado o permanganato de potássio $\left(\mathrm{KMnO}_{4}\right)$.

\subsection{Preparo das tetrahidro-isohumulonas.}

Os derivados hidrogenados dos iso- $\alpha$-ácidos foram obtidos seguindo a rota sintética descrita por Verzele e De Keukeleire ${ }^{9}$. Assim, a hidrogenação das olefinas das cadeias laterais conectadas aos carbonos C5 e C4, referentes aos grupos prenila e isohexenoila respectivamente, foi obtida partindo-se de uma solução contendo os diastereisômeros cis- e trans- $\left(200 \mathrm{mg} ; 5,5210^{-4} \mathrm{~mol}\right)$ em metanol (25 mL), com adição do catalisador paládio suportando no carbono 10\% (59,0 mg), sob atmosfera de hidrogênio $\left(\mathrm{H}_{2}\right)$ (pressão ambiente). Depois de decorrido 6 horas de reação, sobre agitação vigorosa e a temperatura ambiente $\left(25^{\circ} \mathrm{C}\right)$, o catalisador foi retido e a mistura reacional roto-evaporada até a secura para a obtenção da mistura cis- e trans- tetrahidroisohumulonas. Os produtos da reação seguiram para posterior caracterização química por UV-vis, ${ }^{1} \mathrm{H}$ RMN e LC-ESI-MS ${ }^{\text {n. }}$

A reação foi monitorada através de cromatografia planar TLC, utilizando-se placas de sílica gel e solventes de eluição Hexano/Éter etílico (1:1 v/v) acidificado com ácido acético. 
3.6. Caracterização química dos compostos.

A pureza dos compostos isolados e sintetizados foi avaliada por Espectroscopia Eletrônica de Absorção (UV-vis), Cromatografia Líquida hifenada ao Espectrômetro de Massas (LC-ESI-MS ${ }^{n}$ ) e Ressonância Magnética Nuclear $\left({ }^{1} H\right.$ RMN).

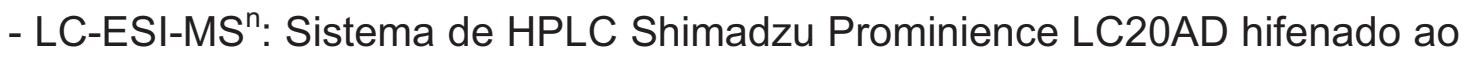
espectrômetro de massas de múltiplo estágio do tipo "ion-trap" Bruker modelo Esquire 4000.

Coluna: Agilent C-18 extended ( $5 \mu \mathrm{m}, 2,1 \times 150 \mathrm{~mm}$ ); fluxo $0,5 \mathrm{~mL} \mathrm{~min}{ }^{-1}$; fase móvel ${ }^{35}$ solvent $A$ - Acetato de Amônio $\left(510^{-3} \mathrm{~mol} \mathrm{~L}^{-1}\right) / \mathrm{H}_{2} \mathrm{O} /$ Etanol $(80: 20 \mathrm{v} / \mathrm{v}), \mathrm{pH}$ aparente ajustado a 9,4 com hidróxido de amônia, solvente B - Acetonitrila/Etanol $(60: 40 \mathrm{v} / \mathrm{v})$; gradiente $0,3 \mathrm{~min}: 0 \%$ B isocrático, 3 - 4 min.: 0 - 16\% B, 4 - 54 min.: 16 $-30 \%$ B, $54-57$ min.: $30-95 \%$ B, $57-65$ min.: 95\% B isocrático.

Espectrômetro de Massas (ESI-MS ${ }^{n}$ ): utilizou-se um divisor de fluxo na interface HPLC/MS, cujo fluxo que chegou até o espectrômetro de massas foi 150 $\mu \mathrm{L} \min ^{-1}$. Condições de nebulização: pressão 40 psi, fluxo do gás $\left(\mathrm{N}_{2}\right) 9 \mathrm{~L} \mathrm{~min}^{-1}$; temperatura de desolvatação $365^{\circ} \mathrm{C}$, voltagem do capilar $3500 \mathrm{~V}$; modo de detecção de íons negativo.

- ${ }^{1} \mathrm{H}$ RMN: para realizar as análises de ressonância magnética nuclear, os compostos foram previamente dissolvidos em uma solução etanol/ácido fórmico $(99: 1 \mathrm{v} / \mathrm{v})$ e todo solvente foi removido por roto-evaporação a pressão reduzida. Este procedimento foi requerido para garantir que os iso- $\alpha$-ácidos e seus derivados estivessem em sua forma protonada. Assim, os espectros de ressonância magnética nuclear foram obtidos utilizando-se clorofórmio deuterado $\left(\mathrm{CDCl}_{3}\right)$ como solvente, 
nos equipamentos: Bruker $200 \mathrm{MHz}, 4,7$ T, AC200, Instituto de Química de São Carlos (IQSC), Universidade de São Paulo (USP); Bruker, 400,21 MHz, DRX 400-9.4 T, Departamento de Química (DQ), Universidade Federal de São Carlos (UFSCar).

- UV-vis: os espectros eletrônicos de absorção na região do ultravioleta visível dos compostos foram obtidos em um espectrofotômetro Hitachi modelo U-3501. Utilizou-se uma cela de quartzo de caminho ótico $1,0 \times 1,0 \mathrm{~cm}$. As medidas de absorção foram efetuadas pela leitura direta dos espectros, sendo utilizado como referência o próprio solvente.

\subsubsection{Estudo eletroquímico das isohumulonas.}

As medidas eletroquímicas foram realizadas em um potenciostato AUTOLAB modelo PGSTAT100, utilizando-se o eletrodo de diamante dopado com boro como eletrodo de trabalho, fabricado pela Adamant Technologies S.A., Suíça, com dopagem 8.000 ppm de boro e área superficial $6,25 \mathrm{~mm}^{2}$. O contra-eletrodo utilizado foi uma rede de platina, cuja área superficial é de $3,0 \mathrm{~mm}^{2}$. O potencial do eletrodo de referência foi checado contra o potencial padrão do par de ferroceno $\left(\mathrm{Fe}^{+1} / \mathrm{Fe}\right)$. Neste caso, o potencial medido é relatado contra o Eletrodo Normal de Hidrogênio $(N H E)$ usando $\mathrm{E}^{\circ}=0,630 \mathrm{~V}$ vs. NHE para o $\mathrm{Fe}^{+1} / \mathrm{Fe}$, em acetonitrila ${ }^{36}$.

Variou-se a taxa de velocidade de varredura de $10 \mathrm{mV} \mathrm{s}^{-1}$ a $200 \mathrm{mV} \mathrm{s}^{-1}$. Ainda, as medidas foram efetuadas em meio orgânico (perclorato de tetrabutilamônio em acetonitrila $\left.-0,1 \mathrm{~mol} \mathrm{~L}^{-1}\right)$, a temperatura ambiente $\left(25^{\circ} \mathrm{C}\right)$, sob atmosfera inerte $\left(\mathrm{N}_{2}\right)$. 
3.7. Reatividade dos compostos de interesse frente ao radical 1-hidroxietila.

3.7.1. Estudos com o radical 1-hidroxietila: formação e estabilidade do aduto radical [4-POBN/CH$\left.\left(\mathrm{CH}_{3}\right) \mathrm{OH}\right]^{\circ}$.

O radical 1-hidroxietila foi gerado, conforme já demonstrado no Esquema 3, a partir do radical hidroxila, o qual resulta da Reação de Fenton ${ }^{25,28}$, Esquema 4. Entretanto, em função da dificuldade na detecção direta da maioria dos radicais devido seus baixos tempo de meia vida, a reação deste com os compostos de interesse, presentes na cerveja, foi estudada utilizando-se o 4-POBN como armadilha química ("spin-trap"), formando o aduto radical [4-POBN/CH$\left.\left(\mathrm{CH}_{3}\right) \mathrm{OH}\right]^{\bullet}$,

\section{Esquema 5.}

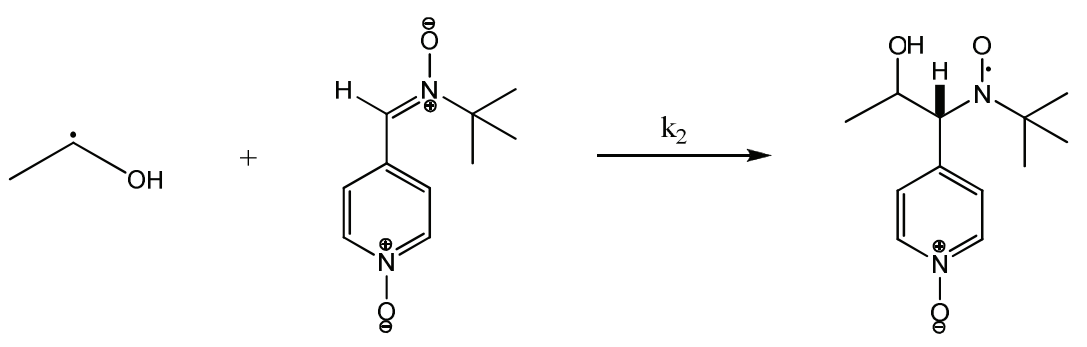

Esquema 5. Reação de formação do spin radical [4-POBN/CH( $\left.\left(\mathrm{CH}_{3}\right) \mathrm{OH}\right]^{\circ}$.

O valor da constante de velocidade específica da reação entre o 4-POBN e o radical 1-hidroxietila está relatada na literatura com o valor de $3,110^{7} \mathrm{~L} \mathrm{~mol}^{-1} \mathrm{~s}^{-1} 37$.

Como um todo, a reação foi conferida adicionando-se $60 \mu \mathrm{L}$ de uma solução de $\mathrm{FeCl}_{2} \cdot 4 \mathrm{H}_{2} \mathrm{O}\left(2,010^{-3} \mathrm{~mol} \mathrm{~L}^{-1}\right)$ levemente acidificada $(\mathrm{pH} \sim 4,5)$ a $1 \mathrm{~mL}$ de uma solução contendo o 4-POBN $\left(3,210^{-3} \mathrm{~mol} \mathrm{~L}^{-1}\right)$ a $6 \%$ de etanol (ca. $\left.1 \mathrm{~mol} \mathrm{~L}^{-1}\right)$. A mistura reacional foi cuidadosamente desgaseificada com argônio, seguida do acréscimo de $80 \mu \mathrm{L}$ de solução de $\mathrm{H}_{2} \mathrm{O}_{2} 30 \%\left(59,010^{-3} \mathrm{~mol} \mathrm{~L}^{-1}\right)$ para promover a 
formação do radical 1-hidroxietila e posterior geração do aduto radical. A reação foi monitorada até os 5 primeiros minutos após a adição do peróxido de hidrogênio, verificando as espécies formadas. Vale ressaltar que a concentração analítica do peróxido de hidrogênio foi determinada através do espectro eletrônico de absorção $\left(\lambda=240 \mathrm{~nm} ; \varepsilon_{240}=39,4 \mathrm{~L} \mathrm{~mol}^{-1} \mathrm{~cm}^{-1}\right)^{38}$.

A reação foi então monitorada através de duas técnicas: Espectroscopia de Ressonância Paramagnética de Elétrons (RPE) e Cromatografia Líquida hifenada ao Espectrômetro de Massas (LC-ESI-MS ${ }^{\mathrm{n}}$ ).

Parâmetros instrumentais:

- Espectrômetro de Ressonância Paramagnética de Elétrons (RPE): Espectrômetro Bruker modelo EMX operando na banda-X.

Campo magnético central: 3.378 G; freqüência: $9,53 \mathrm{GHz}$; atenuação: 23 dB; potência: $1 \mathrm{~mW}$; modulação da freqüência: $100 \mathrm{KHz}$; modulação da amplitude: $1 \mathrm{G}$.

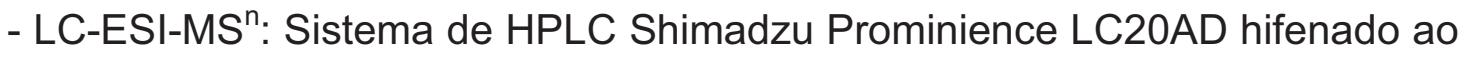
espectrômetro de massas de múltiplo estágio de tipo "ion-trap" Bruker Esquire 4000.

Coluna Agilente C-18 extended (5 $\mu \mathrm{m} ; 2,1 \times 150 \mathrm{~mm}$ ); fluxo 0,3 mL min. ${ }^{-1}$; fase móvel solvente $A-\mathrm{H}_{2} \mathrm{O} /$ Ácido Fórmico $(99,9: 0,1 \mathrm{v} / \mathrm{v})$, solvente $B$ Acetonitrila/Ácido Fórmico (99,9:0,1 v/v); gradiente 0 - $15 \min .: 0-25 \%$ B, $15-20$ $\min .: 25-100 \%$ B, $20-23 \min .:$ 100\% B isocrático, $23-25 \min .: 100-0 \%$ B.

Espectrômetro de Massas (ESI-MS ${ }^{n}$ ): utilizou-se um divisor de fluxo na interface HPLC/MS, cujo fluxo que chegou até o espectrômetro de massas foi $100 \mu \mathrm{L}$ min. $^{-1}$. As condições de nebulização foram pressão 30 psi, fluxo de gás $\left(\mathrm{N}_{2}\right)$ $9 \mathrm{~L} \mathrm{min.}{ }^{-1}$, temperatura $250{ }^{\circ} \mathrm{C}$, voltagem do capilar de $3.000 \mathrm{~V}$, operando no modo de detecção de íons positivo. 
Avaliou-se também a influência da adição de catalase na estabilidade do aduto radical, a qual decompõe o excesso de peróxido adicionado que supostamente pode interferir na quantificação do aduto [4-POBN/CH($\left.\left(\mathrm{CH}_{3}\right) \mathrm{OH}\right]^{*}$. Assim, foi realizado um estudo sobre a estabilidade do aduto radical na presença e ausência de catalase. Desta forma, para o estudo na presença de catalase, adicionou-se $100 \mu \mathrm{L}$ da enzima $\left(47,4 \mathrm{mg} \mathrm{mL}^{-1}\right)^{38}$ à mistura reacional após decorrido o tempo de amostragem da reação, seguindo para a análise por ESI-(+)-MS ${ }^{n}$, segundo os parâmetros instrumentais abaixo:

Espectrômetro de Massas (ESI-(+)-MS $\left.{ }^{n}\right)$ : utilizou-se um divisor de fluxo na interface HPLC/MS, cujo fluxo que chegou até o espectrômetro de massas foi $100 \mu \mathrm{L} \min ^{-1}$. As condições de nebulização foram pressão 30 psi, fluxo de gás $\left(\mathrm{N}_{2}\right)$ $9 \mathrm{~L} \mathrm{~min} .^{-1}$, temperatura de desolvatação $250{ }^{\circ} \mathrm{C}$, voltagem do capilar de $3000 \mathrm{~V}$. Modo de detecção de íons positivo.

3.7.2. Determinação das constantes de velocidade aparentes ${ }^{f}$ decorrentes das reações dos compostos de interesse frente ao radical 1-hidroxietila.

Para estimar as constantes de velocidade de segunda ordem de capitação do radical 1-hidroxietila pelos iso-a-ácidos e seus derivados, foi utilizada a abordagem de cinética de competição ${ }^{39,40}$. Neste contexto, o 4-POBN compete com os compostos de interesse pela captação do radical 1-hidroxietila formado, conforme ilustrado no Esquema 6.

\footnotetext{
${ }^{f}$ Constante de velocidade aparente refere-se à constante de velocidade determinada indiretamente através da utilização de uma sonda química.
} 

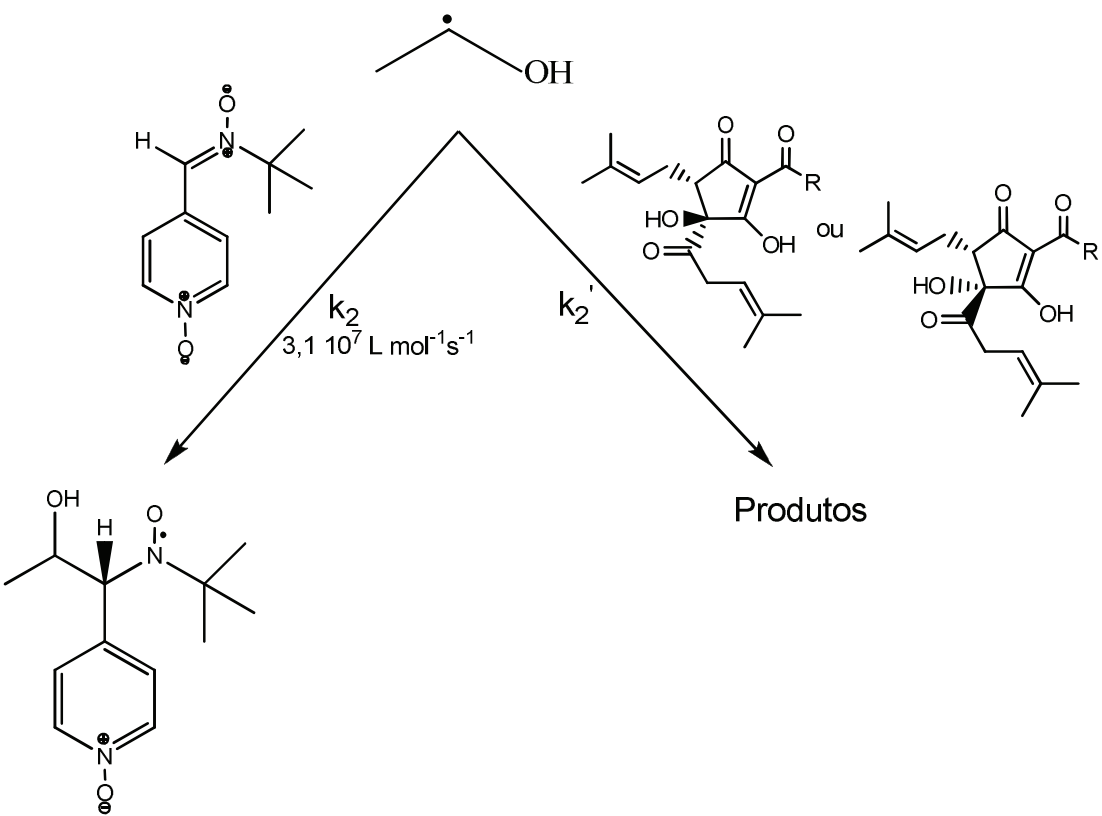

Produtos

Esquema 6. llustração da reação de competição entre a armadilha química 4-POBN e a isohumulonas pelo radical 1 -hidroxietila.

Desta forma, os compostos foram primeiramente dissolvidos em etanol. No caso dos ácidos amargos derivados do lúpulo, as concentrações destes foram determinadas através da leitura da solução pelo espectrofotômetro UV-vis, de acordo com os respectivos coeficientes de absortividade $\left(\varepsilon_{279} \mathrm{~nm}=11.150\right.$ $\mathrm{L} \mathrm{mol}{ }^{-1} \mathrm{~cm}^{-1}$, iso- $\alpha$-ácidos; $\varepsilon_{279} \mathrm{~nm}=11.150 \mathrm{~L} \mathrm{~mol}^{-1} \mathrm{~cm}^{-1}$, dihidro-isohumulonas; $\varepsilon_{254 \mathrm{~nm}}=17.690 \mathrm{~L} \mathrm{~mol}^{-1} \mathrm{~cm}^{-1}$, tetrahidro-isohumulonas) ${ }^{9}$.

Seguindo uma cinética de competição, volumes diferentes da solução de isoa-ácidos foram adicionados em $60 \mu \mathrm{L}$ de uma solução aquosa de $\mathrm{FeCl}_{2} \cdot 4 \mathrm{H}_{2} \mathrm{O}$ $\left(2,010^{-3} \mathrm{~mol} \mathrm{~L}^{-1}\right)$ levemente acidificada $(\mathrm{pH} \sim 4)$ e $1 \mathrm{~mL}$ de uma solução de 4-POBN $\left(3,210^{-3} \mathrm{~mol} \mathrm{~L}^{-1}\right)$ a $6 \%$ de etanol $\left(1 \mathrm{~mol} \mathrm{~L}^{-1}\right)$. Desgaseificou-se a mistura por 5 minutos para então acrescentar $80 \mu \mathrm{L}$ da solução de $\mathrm{H}_{2} \mathrm{O}_{2} 30 \%\left(59,010^{-3} \mathrm{~mol} \mathrm{~L}^{-1}\right)$. A reação foi monitorada pelo aduto radical [4-POBN/CH( $\left(\mathrm{CH}_{3}\right) \mathrm{OH}$ ] após decorrido 1 minuto da adição do peróxido de hidrogênio, acrescentando $100 \mu \mathrm{L}$ de catalase $\left(47,4 \mathrm{mg} \mathrm{mL}^{-1}\right)$ ao final. 
É interessante ressaltar que a sonda utilizada foi o aduto radical [4-POBN/CH$\left.\left(\mathrm{CH}_{3}\right) \mathrm{OH}\right]^{\circ}$, sendo este monitorado pelas técnicas RPE e ESI-(+)-MS/MS.

Parâmetros instrumentais:

Espectrômetro de Ressonância Paramagnética de Elétrons (RPE): Espectrômetro Bruker modelo EMX operando na banda-X.

Campo magnético central: 3.378 G; frequência: $9,53 \mathrm{GHz}$; atenuação: $23 \mathrm{~dB}$; potência: $1 \mathrm{~mW}$; modulação da frequência: $100 \mathrm{KHz}$; modulação da amplitude: $1 \mathrm{G}$.

Espectrômetro de Massas (ESI-(+)-MS/MS): utilizou-se um divisor de fluxo na interface HPLC/MS, cujo fluxo que chegou até o espectrômetro de massas foi $100 \mu \mathrm{L} \min ^{-1}$. As condições de nebulização foram pressão 30 psi, fluxo de gás $\left(\mathrm{N}_{2}\right)$ $9 \mathrm{~L} \mathrm{min.}{ }^{-1}$, temperatura de desolvatação $250{ }^{\circ} \mathrm{C}$, voltagem do capilar de $3000 \mathrm{~V}$. Modo de detecção de íons positivo.

3.8. Cálculo quântico, ab initio $D F T$, na determinação das propriedades eletrônicas das isohumulonas.

Para a determinação das configurações espaciais mais estáveis das moléculas dos diastereoisômeros cis- e trans-isohumulonas foi utilizado o cálculo de dinâmica molecular por DFT (Teoria de Densidade do Funcional), com o método B3LYP, base $6-311+G(d, p)$, otimizando em um contínuo dielétrico simulado em etanol com o formalismo da equação integral como modelo contínuo polarizado $(I E F-P C M)$. Por outro lado, as entalpias de dissociação dos hidrogênios $(B D E)$, 
momento dipolo elétrico e energia dos orbitais de fronteira HOMO foram obtidas através de cálculo usando o método DFT utilizando a base $M 06 / 6-31+G(d)$.

3.9. Caracterização química dos produtos da reação entre o radical 1-hidroxietila e os iso- $\alpha$-ácidos.

Os produtos da reação entre os iso- $\alpha$-ácidos e o radical 1-hidroxietila foram caracterizados por LC-ESI-MS ${ }^{n}$.

- LC-ESI-MS ${ }^{n}$ : Sistema de HPLC Shimadzu Prominience LC20AD hifenado ao espectrômetro de massas de múltiplo estágio do tipo "íon-trap" Bruker modelo Esquire 4000.

Coluna: Agilent C-18 extended (5 $\mu \mathrm{m}, 2,1 \times 150 \mathrm{~mm})$; fluxo 0,3 $\mathrm{mL} \mathrm{min}^{-1}$; fase móvel solvente $\mathrm{A}-\mathrm{H}_{2} \mathrm{O} /$ Ácido fórmico $(99,9: 0,1 \mathrm{v} / \mathrm{v})$, solvente $\mathrm{B}-$ Acetonitrila/Ácido fórmico $(99,9: 0,1 \mathrm{v} / \mathrm{v})$; gradiente $0-5 \min : 0-30 \%$ B, $5-20 \min .: 30-50 \%$ B, 20 $35 \min .: 50-65 \%$ B, $35-55 \min .: 65-100 \%$ B, $55-60 \min .: 100-0 \%$ B.

Espectrômetro de Massas (ESI-MS $\left.{ }^{n}\right)$ : utilizou-se um divisor de fluxo na interface HPLC/MS, cujo fluxo que chegou até o espectrômetro de massas foi $100 \mu \mathrm{L} \min ^{-1}$. Condições de nebulização: pressão 30 psi, fluxo do gás $\left(\mathrm{N}_{2}\right) 9 \mathrm{~L} \mathrm{~min} \mathrm{~m}^{-1}$; temperatura de desolvatação $365^{\circ} \mathrm{C}$, voltagem do capilar $3500 \mathrm{~V}$; modo de detecção de íons negativo. 


\section{RESULTADOS E DISCUSSÃO}

4.1. Isolamento das isohumulonas.

Primeiramente, foi testada uma metodologia clássica consolidada por Verzele e De Keukeleire ${ }^{9}$ para promover o isolamento dos diastereoisômeros cis- e trans-. De acordo com este procedimento, formam-se sais de diciclohexilamina das transisohumulonas ao final. No entanto, este método é eficaz somente na situação em que se tem ao menos $30 \%$ das espécies trans- em solução comparado com a forma cis-. Como não se obteve os sais de diciclohexilamina dos diastereoisômeros trans-, supôs ser devido à presença de contaminantes oriundo da oxidação do extrato, o que em princípio pode inibir a precipitação dos sais de deciclohexilamina. Deve-se dizer que não se obteve sucesso mesmo após exaustivas tentativas.

As trans- e cis-isohumulonas foram isoladas e purificadas eficientemente com o emprego da $\beta$-ciclodextrina para promover a complexação estéreo-seletiva dos diastereoisomeros trans $^{32}{ }^{32}$. A Figura 7 ilustra esquematicamente o processo de separação dos iso- $\alpha$-ácidos por complexação seletiva com $\beta$-ciclodextrina, o qual se dá pelas interações hidrofóbicas entre a cavidade interior da $\beta$-ciclodextrina (hidrofóbica) com as cadeias laterais isohexenoila e prenila dos isômeros trans-, conectadas aos carbonos $\mathrm{C} 4$ e C5, respectivamente. 


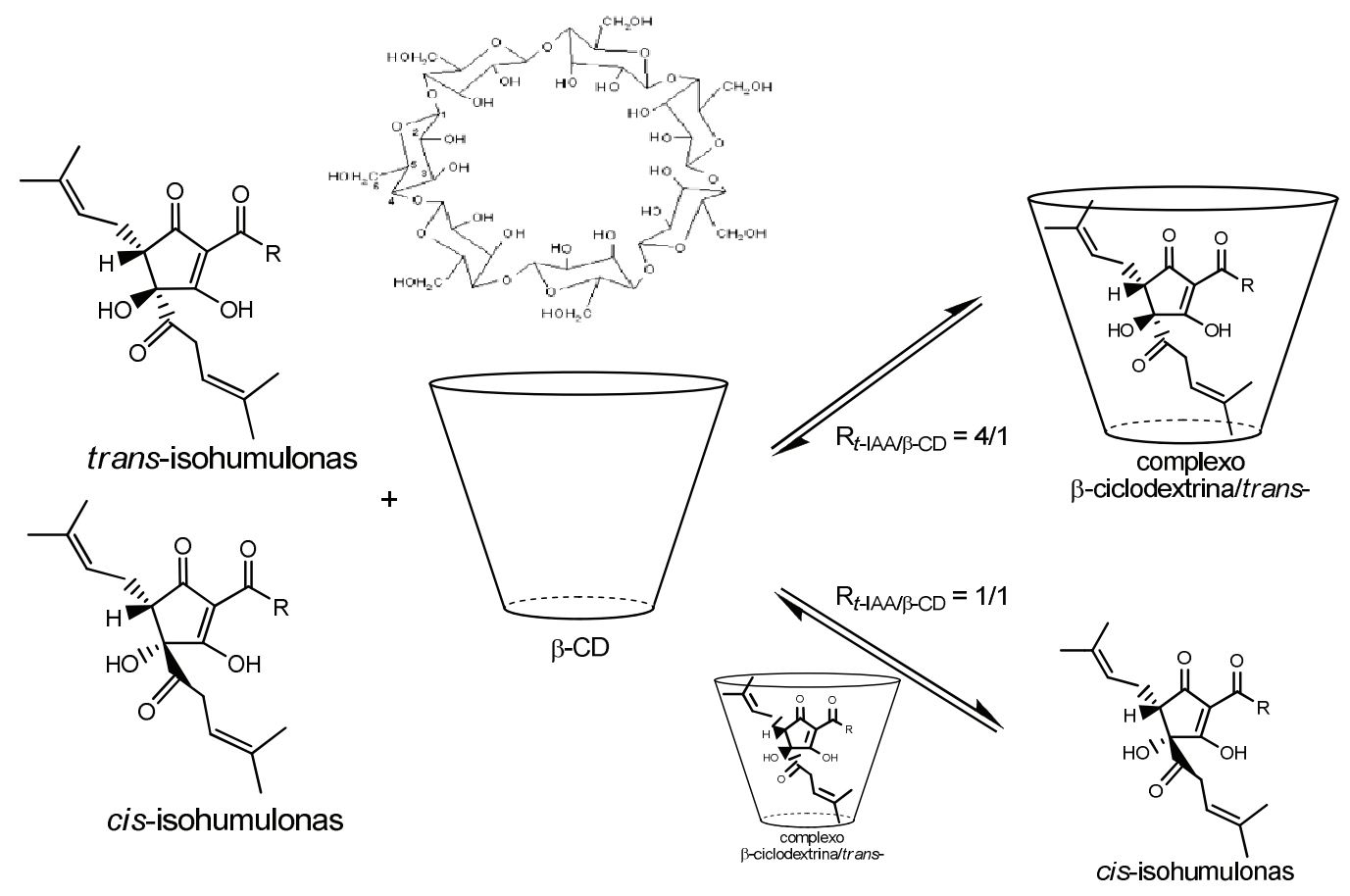

Figura 7. Ilustração esquemática da separação dos diastereoisômeros por complexação com a $\beta$-ciclodextrina.

4.2. Preparo dos derivados reduzidos/hidrogenados das isohumulonas.

\subsubsection{Preparo das dihidro-isohumulonas.}

Os derivados reduzidos dos iso- $\alpha$-ácidos foram preparados de acordo com a metodologia descrita anteriormente no item 3.4. A evolução da reação foi monitorada através de cromatografia planar (TLC). Desta forma, através da evolução dos compostos na placa de sílica gel, apresentada na Figura 8, constatou-se que a reação foi completada com 23 horas de amostragem. Neste caso, os precursores representado pela letra "P" - apresentaram um fator de retenção (Rf) igual a 0,35, ao passo que o fator de retenção (Rf) verificado para os produtos da reação representado pela letra "R" - foi igual a 0,32. O rendimento final obtido para a reação de redução foi de $87 \%$. 


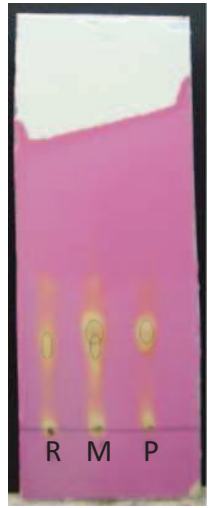

Figura 8. Evolução dos precursores - isohumulonas - e produtos da reação - dihidro-isohumulonas no sistema de cromatografia planar utilizando sílica gel como fase estacionária e hexano/éter etílico (1:4 v/v) acidificado com ácido acético como fase móvel. (R) reação; $(M)$ mistura; (P) precursores.

4.2.2. Preparo das tetrahidro-isohumulonas.

Os derivados hidrogenados dos iso-a-ácidos foram preparados de acordo com a metodologia proposta por Verzele e De Keukeleire ${ }^{9}$. A reação foi acompanhada utilizando-se uma placa de sílica gel (TLC), em um sistema de cromatografia planar, conforme consta na Figura 9. Desta forma, de acordo com os fatores de retenção $(\mathrm{Rf})$ dos precursores e produtos da reação, 0,11 e 0,20 respectivamente, após 6 horas de amostragem todos precursores foram consumidos, sendo então a reação finalizada. O rendimento verificado para a reação de hidrogenólise foi de $89 \%$. 


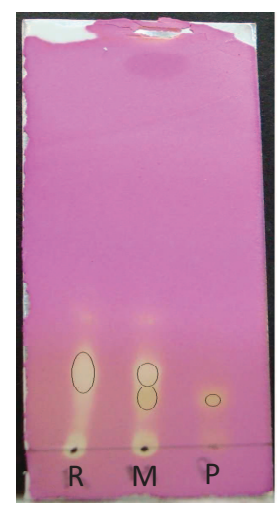

Figura 9. Evolução dos precursores - isohumulonas - e produtos da reação - tetrahidroisohumulonas - no sistema de cromatografia planar utilizando sílica gel como fase estacionária e hexano/éter etílico $(1: 1 \mathrm{v} / \mathrm{v})$ acidificado com ácido acético como fase móvel.(R) reação; $(M)$ mistura; (P) precursores.

4.3. Caracterização química das isohumulonas isoladas e seus derivados reduzidos/hidrogenados.

4.3.1. Caracterização química das trans-isohumulonas isoladas.

Primeiramente, os diastereoisômeros trans- foram caracterizados por espectrofotometria UV-vis pela leitura direta das trans-isohumulonas isoladas em solução contendo $10 \mathrm{~mL}$ de etanol e $1 \mathrm{~mL}$ de solução aquosa de $\mathrm{HCl}\left(2,0 \mathrm{~mol} \mathrm{~L}{ }^{-1}\right)$. Desta forma, através da leitura do espectro eletrônico de absorção, Figura 10, notase a presença de duas bandas centradas em 227 e 279 nm, cujos coeficientes de absortividade molar são 10.200 e $11.150 \mathrm{~L} \mathrm{~mol}^{-1} \mathrm{~cm}^{-1}$, respectivamente. Estes valores estão de acordo com os reportados na literatura ${ }^{9}$ para a espécie transisohumulona. 


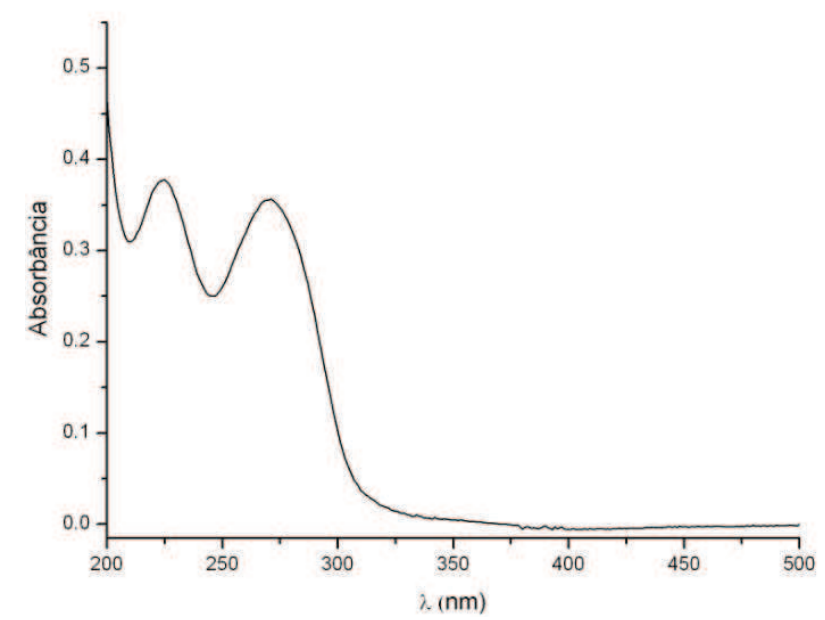

Figura 10. Espectro eletrônico de absorção das trans-isohumulonas isoladas em solução contendo $10 \mathrm{~mL}$ de etanol e $1 \mathrm{~mL}$ de solução aquosa de $\mathrm{HCl}\left(2,0 \mathrm{~mol} \mathrm{~L}^{-1}\right)$. Concentração de trans-isohumulonas de $3,210^{-5} \mathrm{~mol} \mathrm{~L}^{-1}$.

A segunda técnica utilizada na caracterização química das transisohumulonas isoladas foi a LC-ESI-MS ${ }^{n}$. Comparando-se o perfil cromatográfico dos diastereoisômeros trans- isolados (em azul) com o cromatograma da solução comercial de iso- $\alpha$-ácidos contendo as formas cis- e trans- (em vermelho), Figura 11, constata-se que há uma sobreposição do segundo pico do cromatograma inerente a solução das isohumulonas com o primeiro pico do cromatograma das trans-isohumulonas, cujo tempo de retenção $\left(t_{r}\right)$ é 11,4 minutos. Estes picos são referentes aos diastereoisômeros trans-, sendo o pico em 10,5 minutos $\left(t_{r}\right)$ do cromatograma da solução de isohumulonas referente à forma cis-. Esta informação deve-se ao fato de que os compostos trans- estão presentes em menor proporção que as formas cis-, pois a formação deste último é termodinamicamente favorecida ${ }^{9}$. 


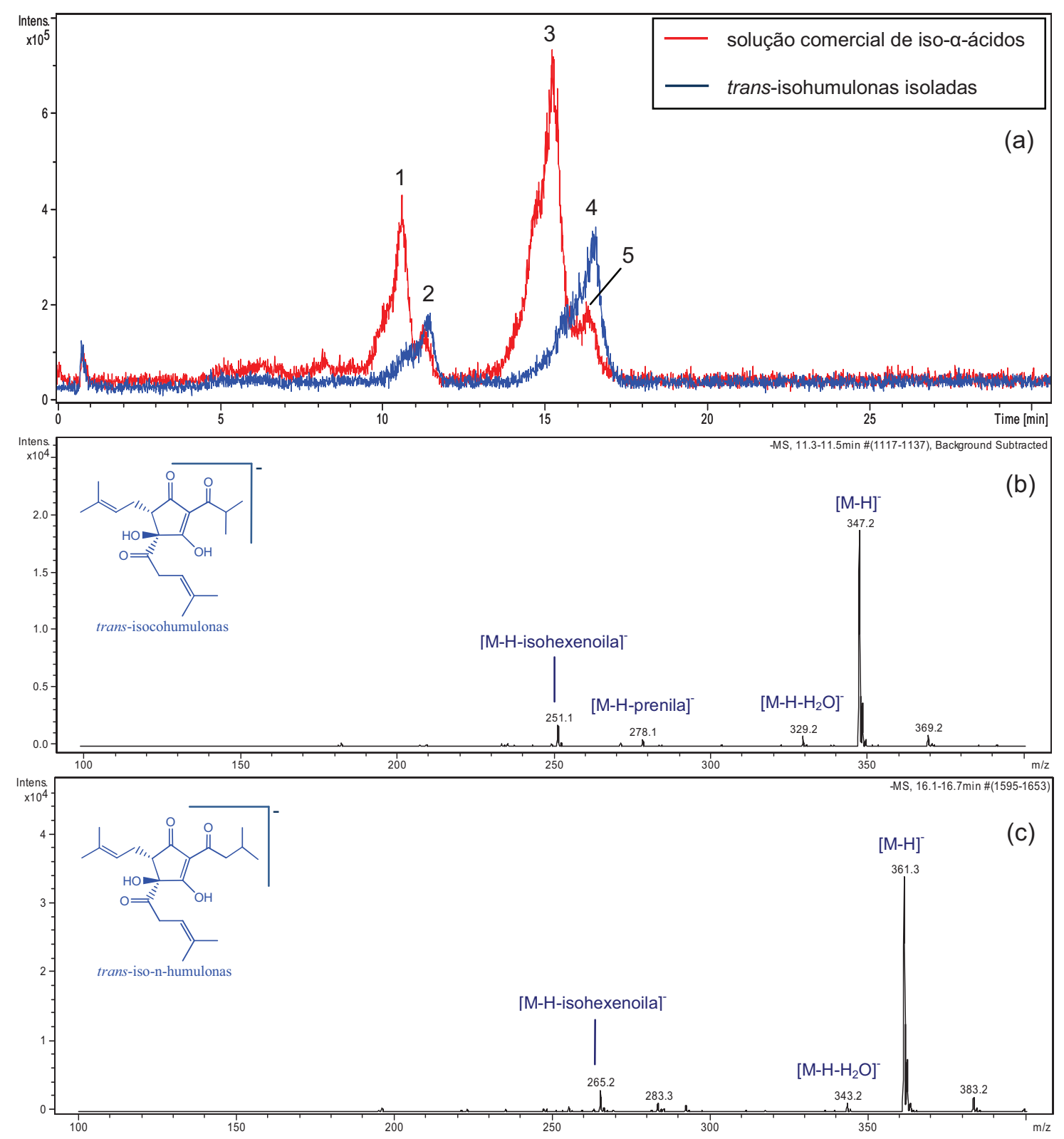

Figura 11. (a) Cromatograma de íons total da amostra comercial contendo as isohumulonas, formas cis- e trans- (em vermelho) e das trans-isohumulonas isoladas (em azul). (b) Espectro de massas (ESI(-)MS) da espécie trans-coisohumulona referente ao pico 2, $\mathrm{t}_{\mathrm{r}}=11,4 \mathrm{~min}$. (c) Espectro de massas (ESI(-)MS) da espécie trans-iso-n-humulona referente ao pico $4, \mathrm{t}_{\mathrm{r}}=16,5 \mathrm{~min}$.

A Figura 11b apresenta o espectro de massas do pico 2 do cromatograma das trans-isohumulonas isoladas, no qual se observa o íon [M-H] $347 \mathrm{~m} / \mathrm{z}$ referente à molécula desprotonada. Este íon é referente à espécie trans-isocohumulona, a qual apresenta uma massa molecular igual a $348 \mathrm{~g} \mathrm{~mol}^{-1}$.

Por outro lado, o pico $4, \mathrm{t}_{\mathrm{r}}=16,5$ minutos, refere-se a trans-iso-n-humulona, cuja massa molecular é $362 \mathrm{~g} \mathrm{~mol}^{-1}$, resultando no íon referente à molécula 
desprotonada $[\mathrm{M}-\mathrm{H}]^{-}=361 \mathrm{~m} / \mathrm{z}$, Figura 11c. É interessante ressaltar que a transisoadhumulona, por estar presente inicialmente no extrato de lúpulo isomerizado em pequena quantidade, sua complexação não foi efetiva; consequentemente, não foi detectada a trans-isoadhumulona na solução final das trans-isohumulonas isoladas.

Ainda, pela da análise cromatográfica do extrato de lúpulo pré-isomerizado (cromatograma em vermelho apresentada na Figura 11a), concedido gentilmente pela Hopsteiner, constatou-se um excesso de $70 \%$ dos isômeros cis- em relação aos trans-iso-a-ácidos, sendo os percentuais dos compostos apresentados na Tabela 1. Como um todo, a pureza verificada para a solução aquosa comercial contendo as formas cis- e trans-iso-a-ácidos foi de $90 \%$.

Tabela 1. Percentuais de isohumulonas no extrato de lúpulo pré-isomerizado.

\begin{tabular}{cccc}
\hline $\begin{array}{c}\text { cis- } \\
\text { isocohumulona }\end{array}$ & $\begin{array}{c}\text { trans- } \\
\text { isocohumulona }\end{array}$ & $\begin{array}{c}\text { iso-n-humulona } \\
(\text { cis- e trans- })\end{array}$ & $\begin{array}{c}\text { isoadhumulona } \\
\text { (cis- e trans-) }\end{array}$ \\
\hline $25,9 \%$ & $3,6 \%$ & $66,0 \%$ & $4,5 \%$ \\
\hline
\end{tabular}

As trans-isohumulonas isoladas foram caracterizadas ainda por ${ }^{1} \mathrm{H} R \mathrm{RMN}$, cujo espectro obtido encontra-se na Figura 12. A partir deste, foram identificados alguns sinais característicos dos diastereoisômeros trans ${ }^{-9,13}$, cujos deslocamentos químicos ( $\delta$ ) são: 2,14 ppm (1H, m); 2,40 ppm (2H, m); 2,70 ppm (2H, d, J = $7 \mathrm{~Hz})$; 3,27 ppm $(2 \mathrm{H}, \mathrm{d}, \mathrm{J}=7 \mathrm{~Hz}) ; 5,00 \mathrm{ppm}(1 \mathrm{H}, \mathrm{t}, \mathrm{J}=7 \mathrm{~Hz}) ; 5,18 \mathrm{ppm}(1 \mathrm{H}, \mathrm{t}, \mathrm{J}=7 \mathrm{~Hz})$. Ainda, é interessante ressaltar que o sinal em 2,70 ppm é característico das transisohumulonas, sendo este parâmetro utilizado para a distinção destes compostos dos seus isômeros cis- pela leitura dos espectros de ressonância magnética nuclear. 


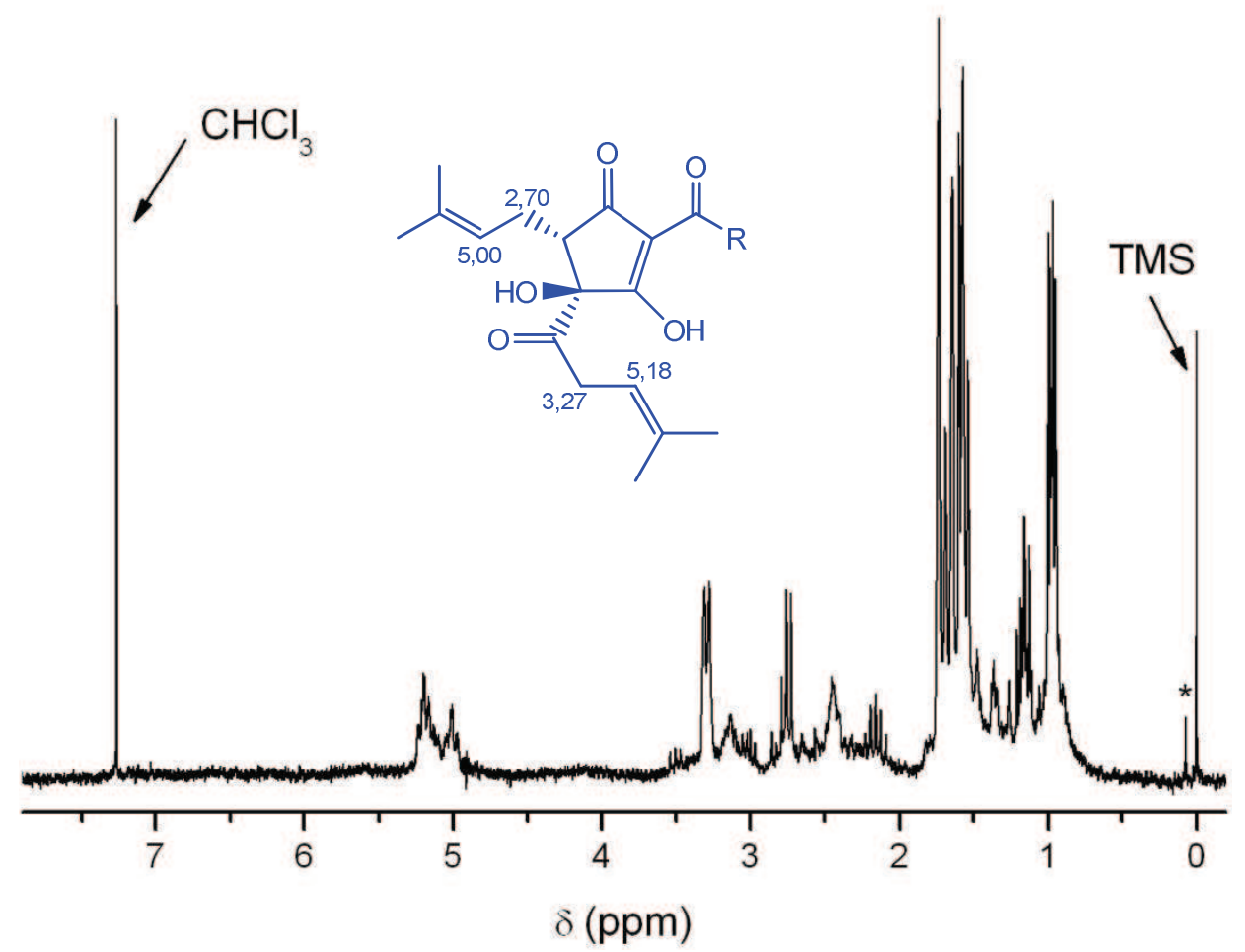

Figura 12. Espectro de $1 \mathrm{H} \mathrm{RMN}(200 \mathrm{MHz})$ das trans-isohumulonas isoladas, em $\mathrm{CDCl}_{3}$. Os sinais marcados com $\left({ }^{*}\right)$ indicam impurezas presentes na amostra.

Portanto, constata-se que as formas trans- foram isoladas com sucesso a partir da complexação seletiva utilizando a $\beta$-ciclodextrina, resultando em uma pureza estimada de $95 \%$.

Utilizando um sistema HPLC semi-preparativo, buscou-se isolar os análogos trans-isocohumulona e trans-iso-n-humulona. Para tal, testou-se várias condições cromatográficas, variando-se desde a composição da fase móvel até o tipo de coluna utilizada. Referente à fase móvel, testou-se diversos solventes de eluição, acidificados ou não, bem como a aplicação de gradiente de eluição ou no modo isocrático, variando, neste último, a proporção entre os solventes empregados. Dentre as colunas testadas, Waters X-Bridge C18 $5 \mu \mathrm{m}(10 \mathrm{~mm} \times 250 \mathrm{~mm})$ e LUNA C-18 $10 \mu \mathrm{m}(20 \mathrm{~cm} \times 0,7 \mathrm{~cm})$, a coluna LUNA foi aquela que apresentou maior eficiência na separação dos análogos. Desta forma, as melhores condições obtidas 
na separação estão descritas no item 3.2, na qual foi empregado um sistema isocrático com a relação de fase móvel de $56 \%$ do solvente B sobre o solvente A.

O cromatograma resultante está apresentado na Figura 13, no qual se pode notar a presença de dois picos majoritários - P.1 e P.2. De fato, o primeiro pico apresenta o tempo de retenção de 15,0 minutos e refere-se à trans-isocohumulona, ao passo que o pico 2, $\mathrm{t}_{\mathrm{r}}=18,6$ minutos, é referente à eluição da trans-iso-nhumulona.

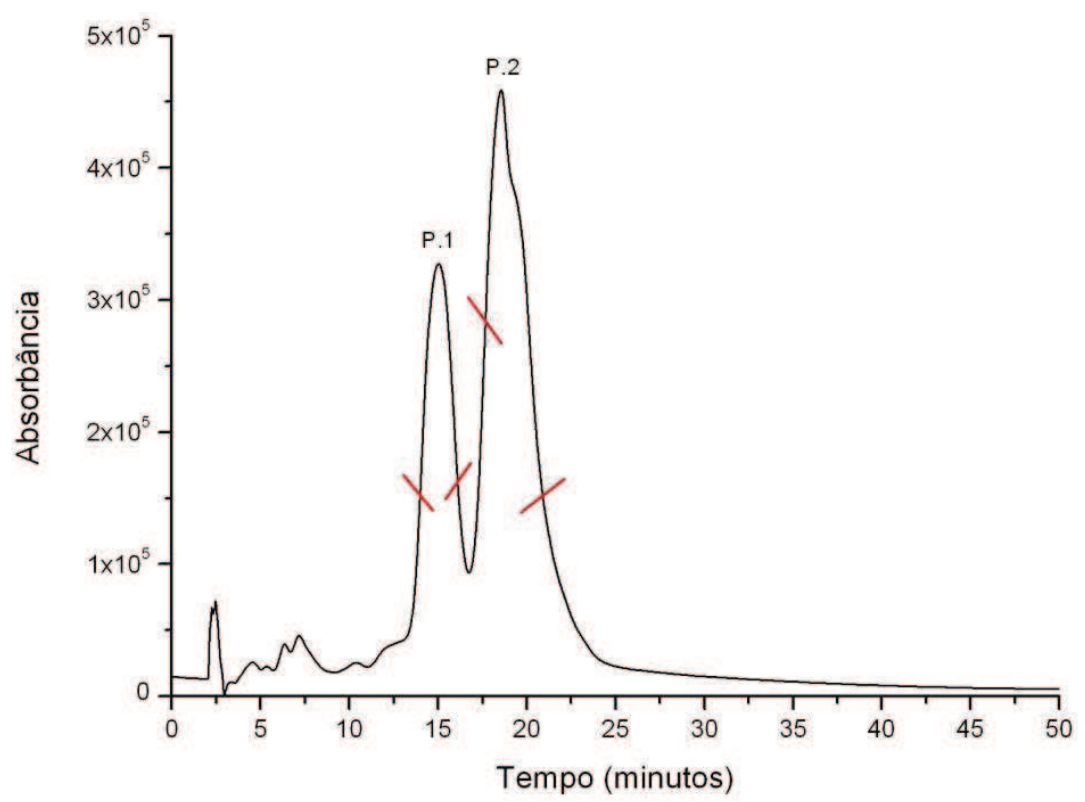

Figura 13. Cromatograma característico das trans-isohumulonas em meio alcoólico $\left(5,010^{-3} \mathrm{~mol} \mathrm{~L}^{-1}\right)$ submetido a separação em uma coluna LUNA C-18 e eluição isocrática $56 \%$ do solvente $B$. Vazão da fase móvel 2,5 mL min. ${ }^{-1}$ Volume de injeção $500 \mu \mathrm{L}$. Comprimento de onda de monitoramento $\lambda=270 \mathrm{~nm}$.

Assim, os compostos foram coletados em duas frações respectivas aos picos P.1 e P.2. No espectro de massas da fração 1, Figura 14, verificou-se a presença dos íons das moléculas desprotonadas [M-H] 347 e $361 \mathrm{~m} / \mathrm{z}$, os quais são referentes a trans-isocohumulona, $\left[\mathrm{M}_{\mathrm{a}}-\mathrm{H}\right]^{-}$, e resquícios da trans-iso-n-humulona, $\left[\mathrm{M}_{\mathrm{b}}-\mathrm{H}\right]^{-}$, respectivamente. Ainda, os íons 379 e 393 remetem a produtos (impurezas na amostra) decorrentes da oxidação dos iso-a-ácidos. Como um todo, o percentual 
verificado para a trans-isocohumulona foi de $55 \%$ com relação aos demais compostos presentes, não obtendo uma boa separação cromatográfica.

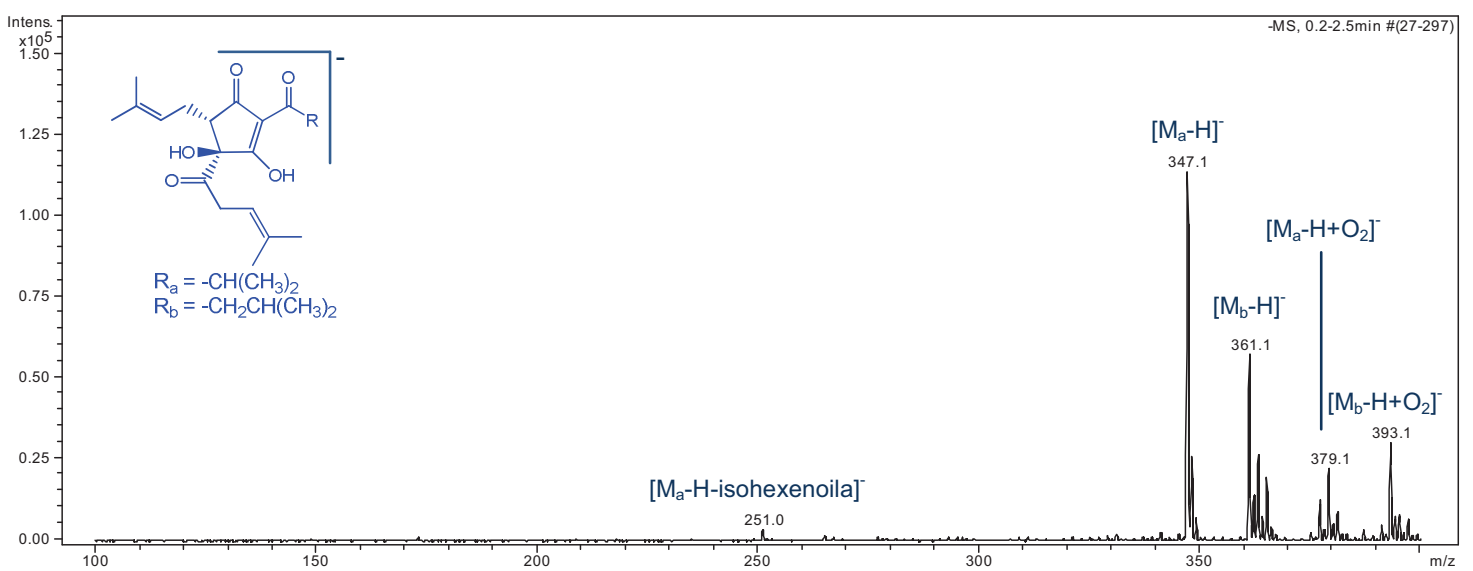

Figura 14. Espectro de massas (ESI(-)MS) resultante de injeção direta da fração 1 contendo transisohumulona.

Por outro lado, pelo espectro de massas da fração 2, apresentado na Figura 15, obteve-se um percentual de $85 \%$ referente a trans-isocohumulona. Aqui, nota-se a presença dos mesmos íons contidos no espectro de massas da fração 1; entretanto, a intensidade relativa ao íon da molécula desprotonada $[\mathrm{M}-\mathrm{H}]^{-} 361 \mathrm{~m} / \mathrm{z}$, respectivo a trans-isocohumulona, é bem maior que os demais íons.

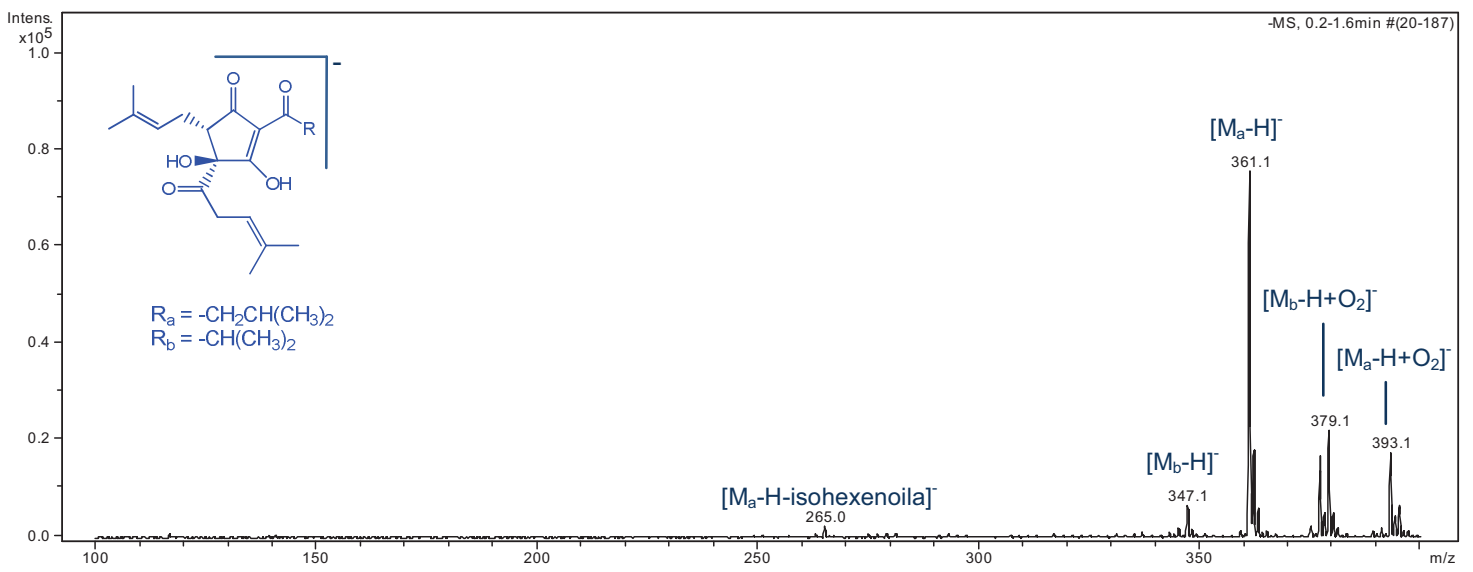

Figura 15. Espectro de massas (ESI(-)MS) resultante de injeção direta da fração 2 contendo transisohumulonas. 
4.3.2. Caracterização química das cis-isohumulonas isoladas.

O espectro eletrônico de absorção da solução contendo as cis-isohumulonas isoladas, apresentado na Figura 16, foi similar ao espectro apresentado pelas transisohumulonas, Figura 10. De fato, as bandas centradas em 227 e $279 \mathrm{~nm}$ aqui apresentadas são condizente com os dados reportados na literatura ${ }^{9}$, sendo os coeficientes de absortividade molar $\left(\varepsilon_{227 \mathrm{~nm}}=10.200\right.$ e $\left.\varepsilon_{279 \mathrm{~nm}}=11.150 \mathrm{~L} \mathrm{~mol}^{-1} \mathrm{~cm}^{-1}\right)$ iguais para ambos os diastereoisômeros cis- e trans-iso- $\alpha$-ácidos.

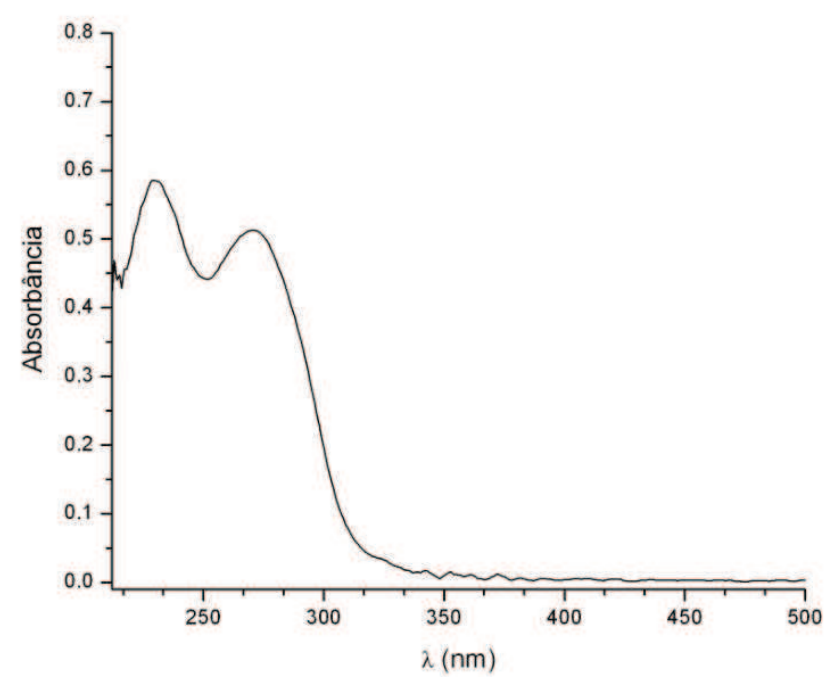

Figura 16. Espectro eletrônico de absorção das cis-isohumulonas isoladas em solução contendo 10 $\mathrm{mL}$ de etanol e $1 \mathrm{~mL}$ de solução aquosa de $\mathrm{HCl}\left(2,0 \mathrm{~mol} \mathrm{~L}^{-1}\right)$. Concentração de 4,6 $10^{-5} \mathrm{~mol} \mathrm{~L}^{-1}$.

Caracterizou-se as cis-isohumulonas isoladas por LC-ESI-MS ${ }^{n}$, obtendo então o perfil cromatográfico apresentado na Figura 17. Neste, é possível observar a sobreposição do primeiro pico do cromatograma de íons total inerente á solução comercial de iso- $\alpha$-ácidos (em vermelho) com o pico 1 do cromatograma de íons total dos diastereoisômeros cis- isolados (em azul). Conforme já mencionado no texto, estes picos, cujo tempo de retenção é 10,5 minutos, são referentes às formas cis-, sendo que as formas trans- eluem em 11,4 minutos, representado pelo pico 2 . 


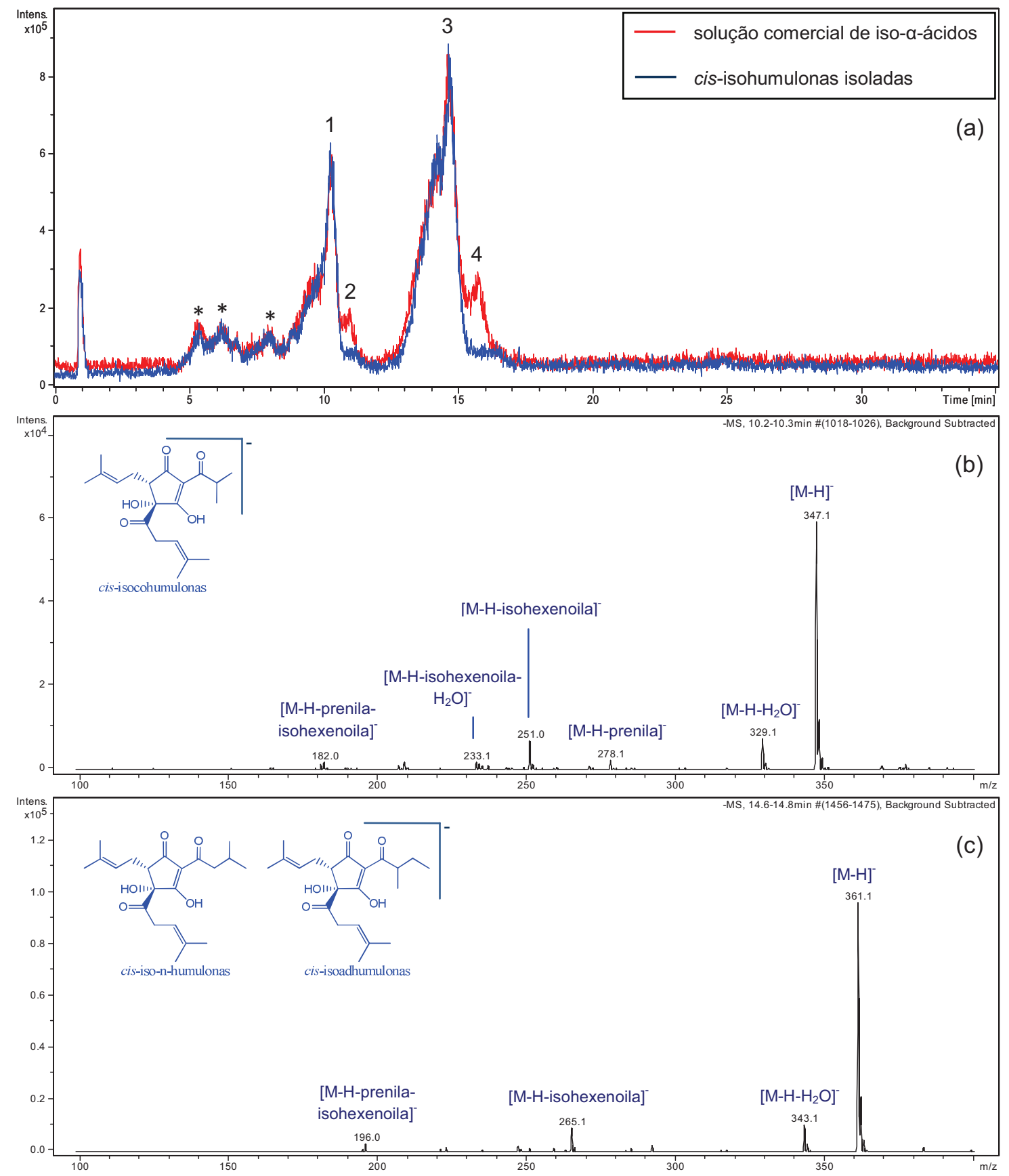

Figura 17. (a) Cromatograma de íons total da amostra comercial contendo as isohumulonas, formas cis- e trans-, (em vermelho) e das cis-isohumulonas isoladas (em azul). (b) Espectro de massas (ESI(-)MS) da espécie cis-isocohumulona referente ao pico 1, $t_{r}=10,5$ min. (c) Espectro de massas (ESI(-)MS) das espécies cis-isoadhumulona e cis-iso-n-humulona referente ao pico 3, $\mathrm{t}_{r}=14,7 \mathrm{~min}$. Os sinais marcados com $\left(^{*}\right)$ indicam impurezas presentes na amostra.

Pelo espectro de massas do pico 1 contido cromatograma das cisisohumulonas isoladas, nota-se o íon $[\mathrm{M}-\mathrm{H}]^{-} 347 \mathrm{~m} / \mathrm{z}$ respectivo à molécula desprotonada referente à forma cis-isocohumulona, Figura 17b. Por outro lado, o espectro de massas do pico 3, Figura 17c, cujo tempo de retenção é 14,7 minutos, 
aponta o íon $361 \mathrm{~m} / \mathrm{z}$ como sendo o íon das moléculas desprotonadas. Este é referente às formas cis-isoadhumulona e cis-iso-n-humulona.

Por fim, as cis-isohumulonas isoladas foram caracterizadas por ${ }^{1} \mathrm{H}$ RMN, sendo possível identificar alguns sinais característicos destes $\operatorname{compostos}^{9,13}$, conforme consta na Figura 18. Pela leitura do espectro, pode-se identificar alguns sinais característicos das espécies cis-, cujos deslocamentos químicos $(\delta)$ são: 2,43 ppm (2H, m); 3,30 ppm (2H, d, J = 6,5 Hz); 5,01 ppm (1H, t, J = 6,5 Hz); $5,19 \mathrm{ppm}(1 \mathrm{H}, \mathrm{t}, \mathrm{J}=6,5 \mathrm{~Hz})$. Ainda, podem ser notados alguns sinais referentes a impurezas presentes na amostra, os quais estão marcados no espectro e são referentes a possíveis produtos de oxidação advindos do extrato de lúpulo.

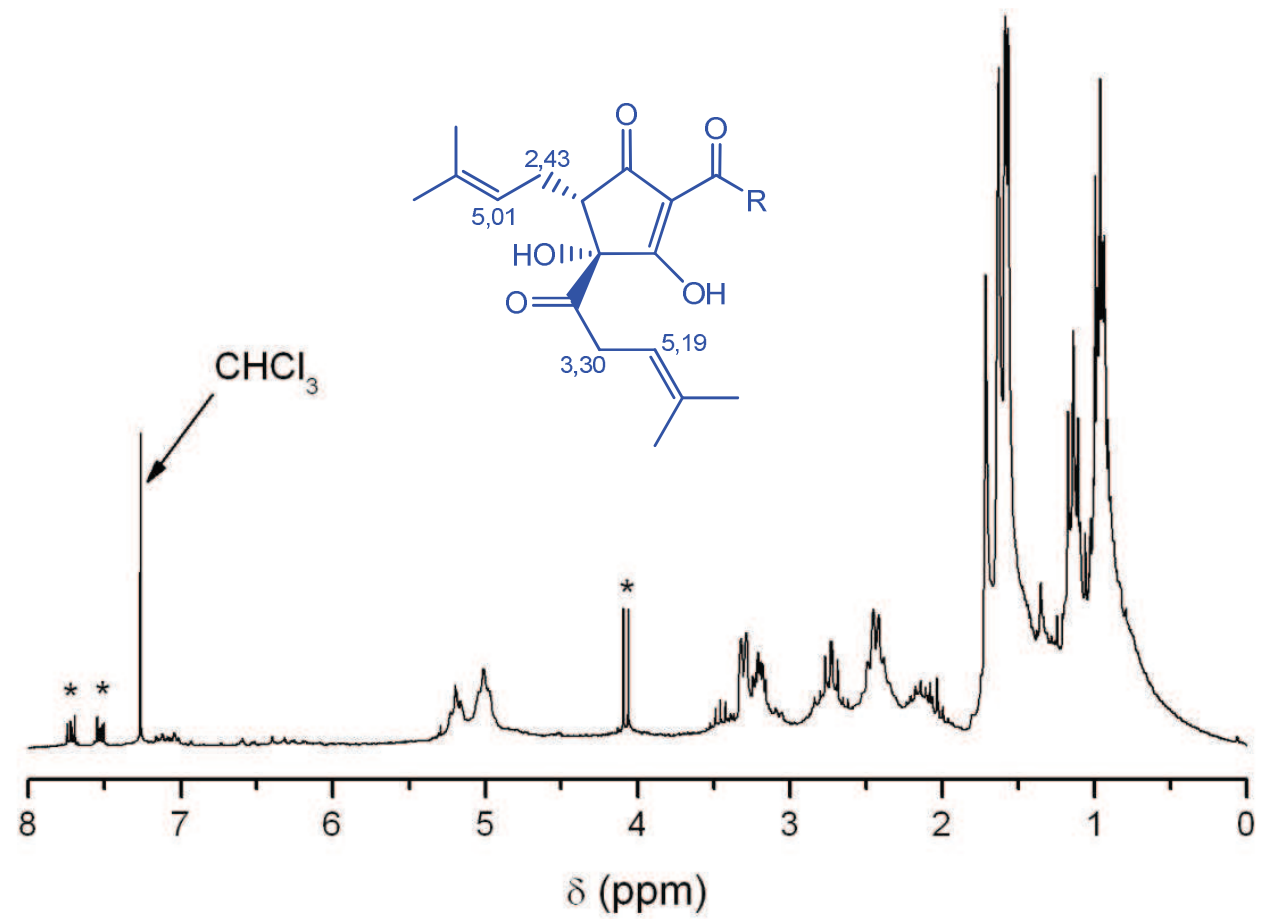

Figura 18. Espectro de $1 \mathrm{H}$ RMN $(200 \mathrm{MHz})$ das cis-isohumulonas isoladas, em $\mathrm{CDCl}_{3}$. Os sinais marcados com $\left({ }^{*}\right)$ indicam impurezas presentes na amostra.

Logo, constata-se que as cis-isohumulonas foram isoladas de forma eficaz ao empregar a complexação seletiva com a $\beta$-ciclodextrina, obtendo uma pureza estimada de $90 \%$. 
Empregando a mesma metodologia utilizada ao buscar isolar cada análogo das trans-isohumulonas isoladas, os análogos dos diastereoisômeros cis- foram tentativamente isolados através do sistema HPLC semi-preparativo. Pela leitura do cromatograma contido na Figura 19, verifica-se que os picos P.2 e P.3 referem-se à eluição dos homólogos cis-iso-n-humulona e cis-isoadhumulona da coluna, em 16,9 e 18,6 minutos $\left(\mathrm{t}_{\mathrm{r}}\right)$, respectivamente. O pico P.1 remete a cis-isocohumulona, cujo tempo de retenção é 13,9 minutos.

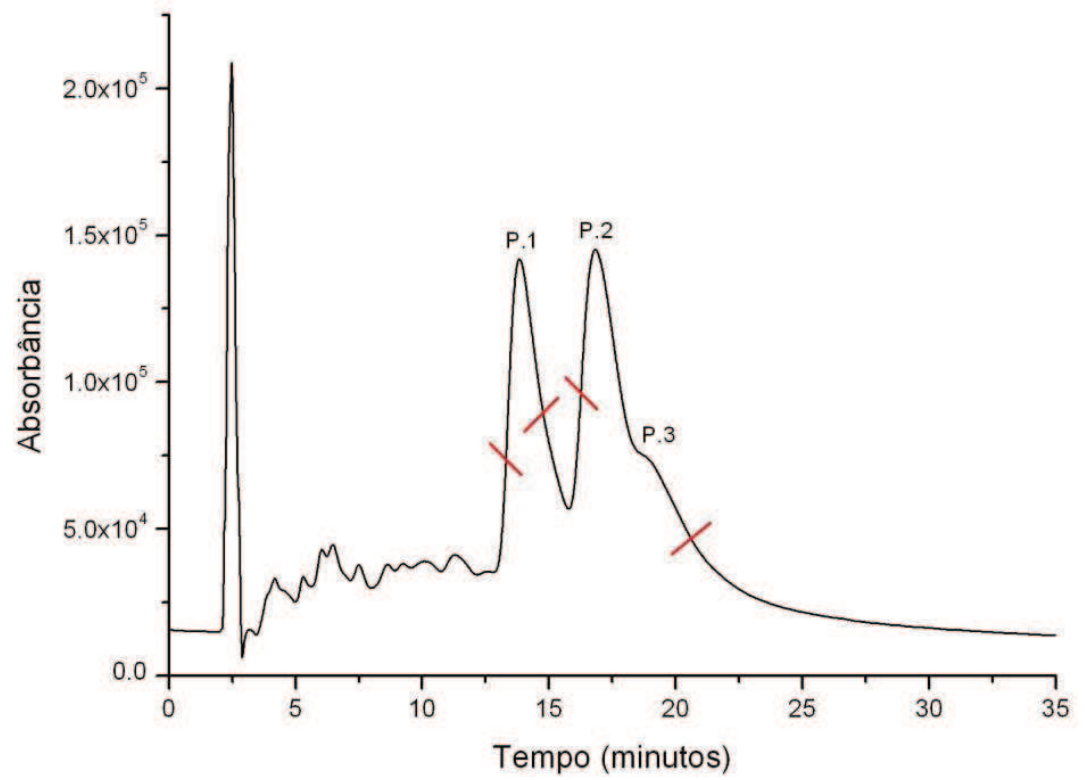

Figura 19. Cromatograma característico das cis-isohumulonas em meio alcoólico $\left(1,010^{-3} \mathrm{~mol} \mathrm{~L}^{-1}\right)$ submetido a separação em uma coluna LUNA C-18 e eluição isocrática $56 \%$ do solvente $B$. Vazão da fase móvel $2,5 \mathrm{~mL} \mathrm{~min} .^{-1}$ Volume de injeção $500 \mu \mathrm{L}$. Comprimento de onda de monitoramento $\lambda=270$ $\mathrm{nm}$.

O espectro de massas do pico P.1, Figura 20, apresenta os íons majoritários das moléculas desprotonadas $[\mathrm{M}-\mathrm{H}]^{-} 361 \mathrm{~m} / \mathrm{z},\left[\mathrm{M}_{\mathrm{b}}-\mathrm{H}\right]^{-}$, e $347 \mathrm{~m} / \mathrm{z},\left[\mathrm{M}_{\mathrm{a}}-\mathrm{H}\right]^{-}$, os quais são referentes à cis-iso-n-humulona e cis-isocohumulona, respectivamente. Logo, o percentual verificado da cis-isocohumulona foi estimado em $60 \%$ com relação aos demais compostos presentes; portanto, não se obteve uma separação cromatográfica eficiente. 


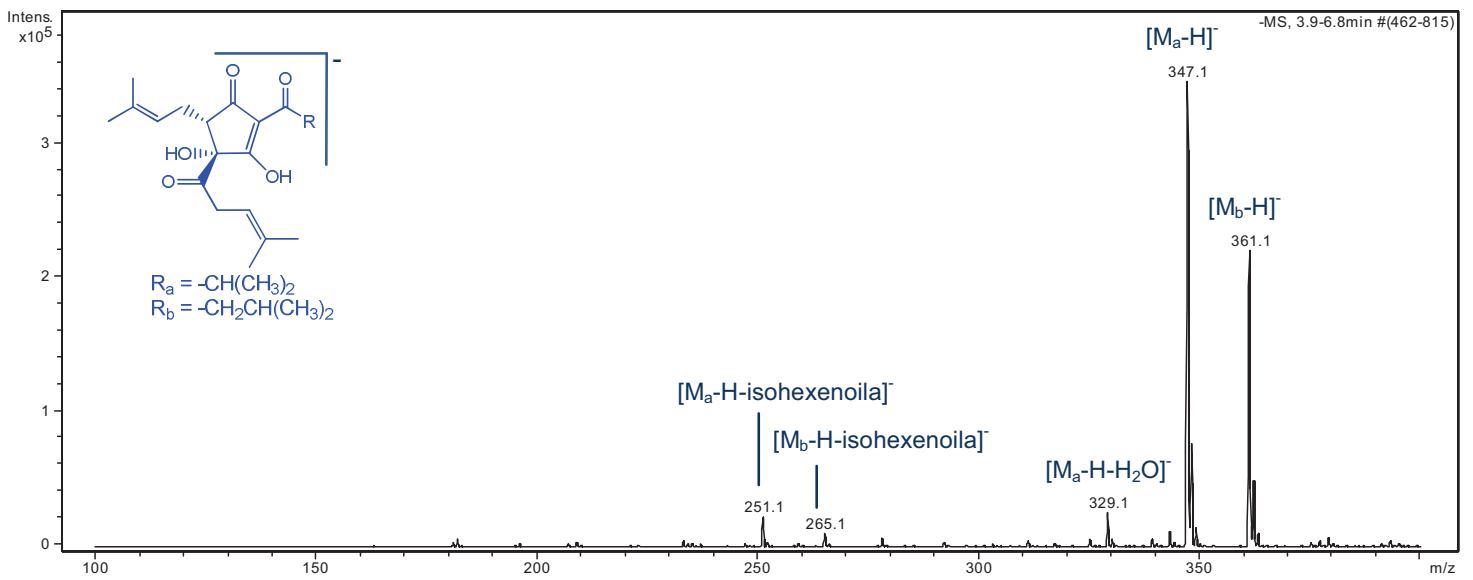

Figura 20. Espectro de massas (ESI(-)MS) resultante de injeção direta da fração 1 contendo cisisohumulonas.

No espectro de massas dos picos P.2 e P.3, Figura 21, o íon $361 \mathrm{~m} / \mathrm{z}$ consiste no íon das moléculas desprotonadas, o qual é referente aos homólogos cisisoadhumulona e cis-iso-n-humulona. De fato, a amostra apresentou uma pureza estimada em 95\%, verificando uma boa separação cromatográfica.

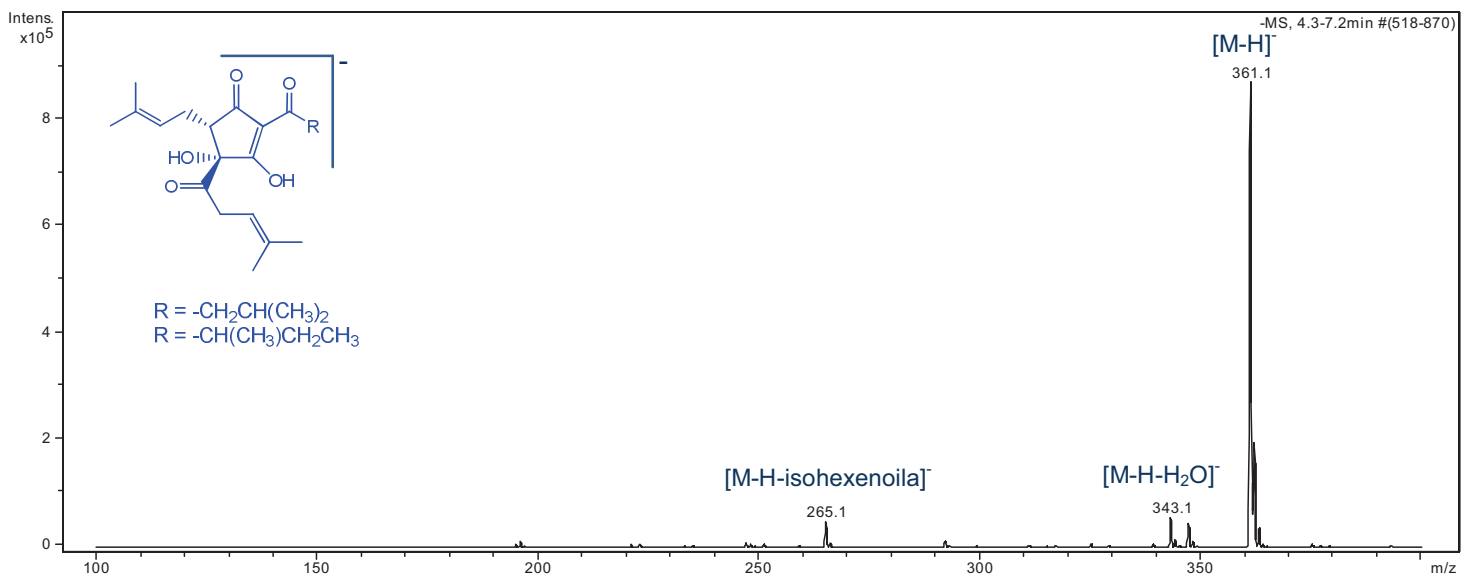

Figura 21. Espectro de massas (ESI(-)MS) resultante de injeção direta da fração 2 contendo cisisohumulonas.

4.3.3. Caracterização química das dihidro-isohumulonas.

Conforme já exposto, a redução da função carbonila do isohexenoila dos isoa-ácidos conduz a formação dos dihidro-iso- $\alpha$-ácidos. Logo, verifica-se que estes 
compostos reduzidos apresentam um centro quiral a mais na molécula, o qual se situa no carbono contendo o grupo hidroxila formado.

Pela leitura do espectro eletrônico de absorção dos dihidro-iso-a-ácidos, contido na Figura 22, nota-se uma similaridade com os espectros apresentado pelos precursores, iso- $\alpha$-ácidos. Este resultado está de acordo com relatos na literatura ${ }^{9}$, sendo então os coeficientes de absortividade molar 10.200 e $11.150 \mathrm{~L} \mathrm{~mol}^{-1} \mathrm{~cm}^{-1}$ respectivos às bandas centradas em 227 e $279 \mathrm{~nm}$.

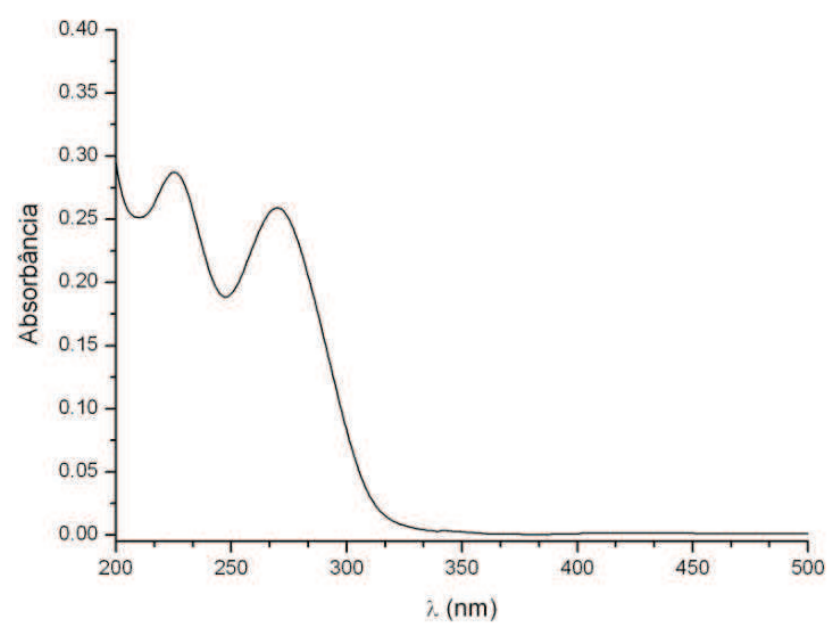

Figura 22. Espectro eletrônico de absorção das dihidro-isohumulonas, formas cis- e trans-, em solução contendo $10 \mathrm{~mL}$ de etanol e $1 \mathrm{~mL}$ de solução aquosa de $\mathrm{HCl}\left(2,0 \mathrm{~mol} \mathrm{~L}^{-1}\right)$. Concentração de $2,310^{-5} \mathrm{~mol} \mathrm{~L}^{-1}$.

O perfil cromatográfico resultante da caracterização dos derivados reduzidos dos iso- $\alpha$-ácidos por LC-ESI-MS ${ }^{n}$ está apresentado na Figura 23. Nota-se a presença de 6 picos majoritários, cujos tempos de retenção são: 6,3 minutos, pico 1; 7,6 minutos, pico 2; 8,2 minutos, pico 3; 10 minutos, pico 4; 11,7 minutos, pico 5; 15,1 minutos, pico 6 . 


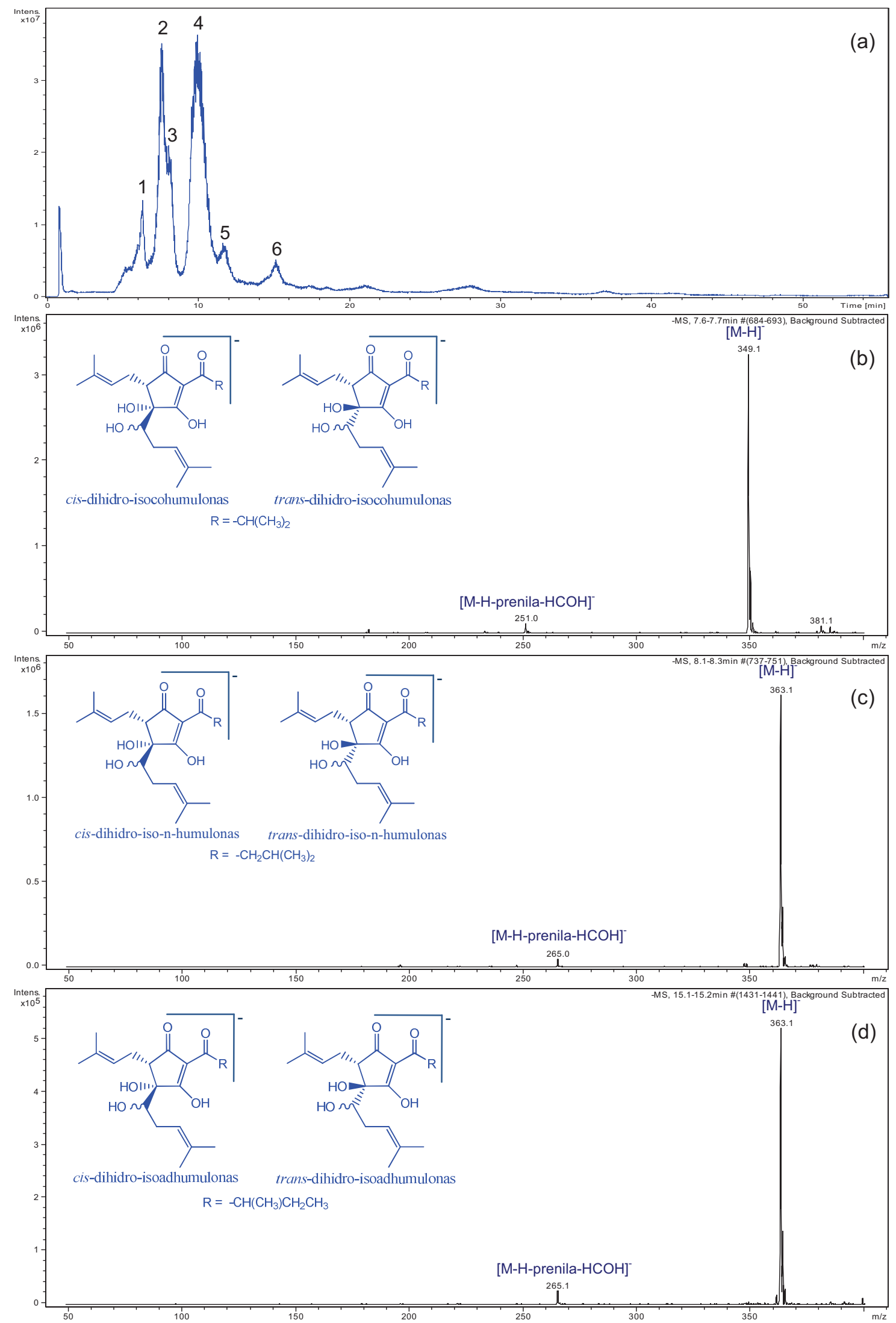

Figura 23. (a) Cromatograma de íons total das dihidro-isohumulonas. (b) Espectro de massas (ESI(-)MS) da espécie trans- e cis-dihidro-isocohumulona referente aos picos 1 e 2, $\mathrm{t}_{\mathrm{r}}=6,3$ e 7,6 min. (c) Espectro de massas (ESI(-)MS) da espécie trans- e cis-dihidro-iso-n-humulona referente aos picos 3 e 4, $\mathrm{t}_{\mathrm{r}}=8,2$ e 10,0 min. (d) Espectro de massas (ESI(-)MS) da espécie cis- e trans-dihidroisoadhumulona referente aos picos 5 e $6, \mathrm{t}_{\mathrm{r}}=11,7$ e 15,1 min. 
Os espectros de massas dos picos 1 e 2 encontram-se na Figura 23b. De fato, os picos supracitados apresentaram o mesmo íon das moléculas desprotonadas $[\mathrm{M}-\mathrm{H}]^{-} 349 \mathrm{~m} / \mathrm{z}$, sendo estes resultantes das eluições das dihidroisocohumulonas, cuja massa molecular é igual a $350 \mathrm{~g} \mathrm{~mol}^{-1}$. Ainda, pela comparação das áreas referentes aos picos, constatou-se que o primeiro pico remete a trans-dihidro-isocohumulona, pois a área é relativamente menor que a área apresentada pelo segundo pico, sendo este decorrente da eluição da espécie cis-.

Os espectros de massas referentes aos demais picos, contidos na Figura 23c-d, apresentaram perfis similares, cujo íon das moléculas desprotonadas é igual a $363 \mathrm{~m} / \mathrm{z}$. Logo, constata-se que os picos 3, 4, 5 e 6 são inerentes aos homólogos dihidro-iso-n-humulonas e dihidro-isoadhumulonas, os quais possuem massa molecular igual a $364 \mathrm{~g} \mathrm{~mol}^{-1}$. Através da comparação entre as áreas dos picos e sabendo que os derivados das iso-n-humulonas estão presentes em maior concentração, constatou-se que os picos 3 e 4 são referentes aos diastereoisômeros trans-dihidro-iso-n-humulona e cis-dihidro-iso-n-humulona, respectivamente. Por outro lado, os picos 5 e 6 remetem aos compostos cis-dihidro-isoadhumulona e trans-dihidro-isoadhumulona.

O espectro de ressonância magnética nuclear ( ${ }^{1} \mathrm{H}$ RMN) obtido do produto da reação decorrente da redução dos iso-a-ácidos está apresentado na Figura 24. Apesar da baixa resolução do espectro, verifica-se uma diferença nítida entre o presente espectro e o apresentado pelos precursores iso- $\alpha$-ácidos. Esta diferença diz respeito a sinal alargado em 6,3 ppm, o qual está diretamente relacionado com a nova função hidroxila presente na molécula, uma vez que átomos de hidrogênios ligados à alcoóis são, no geral, facilmente trocáveis com átomos de deutério presentes no meio $\left(\mathrm{CDCl}_{3}\right)$. Todavia, outro aspecto que contribui para o alargamento 
do sinal é a presença de 12 compostos em solução, os quais apresentam deslocamentos químicos ligeiramente distintos. Este resultado está de acordo com o relatado por Verzele e De Keukeleire ${ }^{9}$.
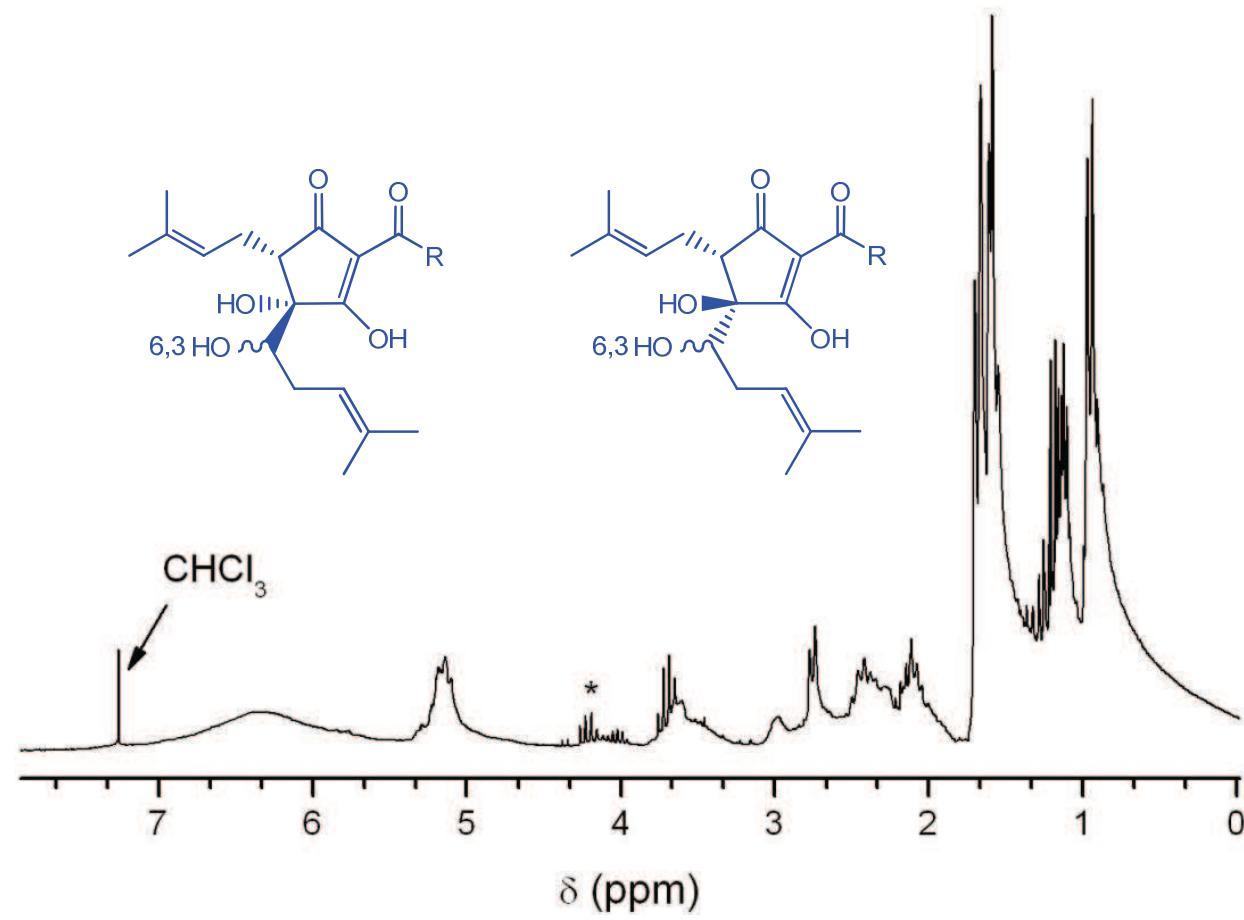

Figura 24. Espectro de $1 \mathrm{H}$ RMN (200 MHz) das dihidro-isohumulonas, formas cis- e trans-, em $\mathrm{CDCl}_{3}$. Os sinais marcados com $\left(^{*}\right)$ indicam impurezas presentes na amostra.

Como um todo, através das análises dos produtos da reação de redução dos iso- $\alpha$-ácidos, constatou-se que o preparo das dihidro-isohumulonas foi bem sucedida, obtendo uma pureza estimada de $98 \%$.

4.3.4. Caracterização química das tetrahidro-isohumulonas.

As tetrahidro-isohumulonas foram preparadas a partir da hidrogenação das olefinas das cadeiras laterais conectadas aos carbonos C5 e C4, referentes aos grupos prenila e isohexenoila dos iso- $\alpha$-ácidos. Os produtos da reação foram 
primeiramente caracterizados por espectrofotometria UV-vis. Assim, pela leitura direta da solução alcoólica contendo os derivados hidrogenados, obteve-se o espectro contido na Figura 25, o qual apresenta uma banda centrada em 254 nm e um ombro em 273 cujos coeficientes de absortividade molar são 17.690 e 13.730 $\mathrm{L} \mathrm{mol}^{-1} \mathrm{~cm}^{-1}$, respectivamente. Este conjunto de dados está de acordo com o relatado por Verzele e De Keukeleire ${ }^{9}$.

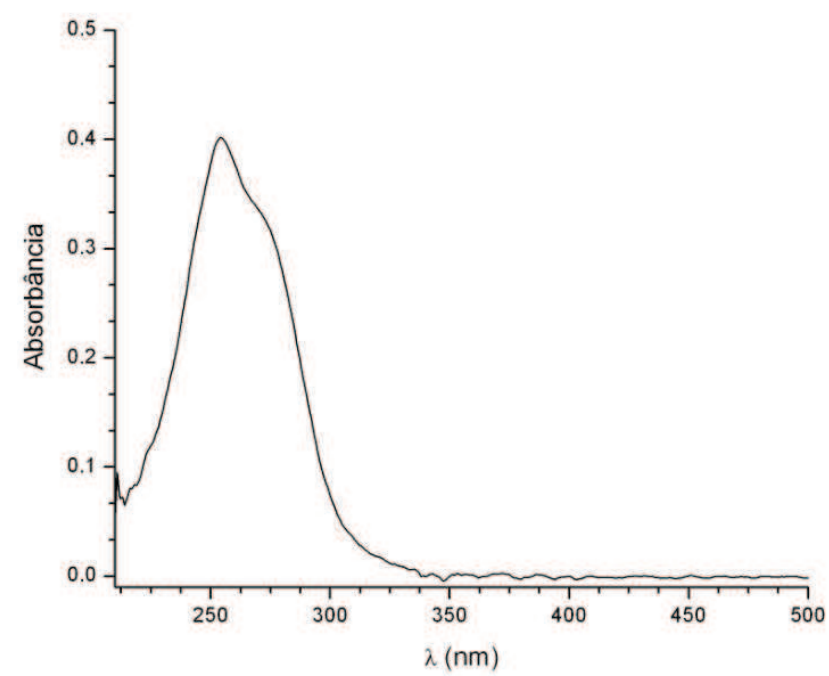

Figura 25. Espectro eletrônico de absorção das tetrahidro-isohumulonas, formas cis- e trans-, em meio etanol. Concentração de $2,310^{-5} \mathrm{~mol} \mathrm{~L}^{-1}$.

Em seguida, as tetrahidro-isohumulonas foram analisadas por LC-ESI-MS ${ }^{n}$. Assim, conforme pode ser verificado na Figura 26a, o cromatograma obtido apresenta 4 picos, cujos $t_{r}$ são: 19,2 minutos - pico 1; 21,5 minutos - pico 2; 26,0 minutos - pico 3; 29,6 minutos - pico 4.

Através da leitura dos espectros de massas de cada pico em questão, observou-se que os espectros dos picos 1 e 2 apresentam o mesmo íon das moléculas desprotonadas $[\mathrm{M}-\mathrm{H}]^{-} 351 \mathrm{~m} / \mathrm{z}$, conforme está apresentando na Figura 26b. De fato, este íon é referente às tetrahidro-isocohumulonas, cuja massa molecular é $352 \mathrm{~g} \mathrm{~mol}^{-1}$. Ainda, pelo cálculo das áreas destes picos, constatou-se 
que o primeiro pico refere-se aos distereoisômeros cis-, ao passo que a transtetradhidro-isocohumulona elue da coluna em 21,5 minutos, pico 2.

Analogamente, os picos 3 e 4 apresentam espectros de massas similares, Figuras 26c-d, sendo o íon $365 \mathrm{~m} / \mathrm{z}$ o íon das moléculas desprotonadas [M-H]. Estes picos referem-se aos homólogos tetrahidro-iso-n-isohumulonas e tetrahidroisoadhumulonas, os quais apresentam massa molecular igual a $366 \mathrm{~g} \mathrm{~mol}^{-1}$. Através do cálculo das áreas, verificou-se que o pico 3 remete à mistura das tetrahidro-iso-nhumulonas, cis- e trans-, as quais são majoritárias no extrato de lúpulo utilizado. Por outro lado, o último pico é resultado da eluição da mistura cis- e trans-tetrahidroisoadhumulona, minoritárias no extrato de lúpulo pré-isomerizado. 

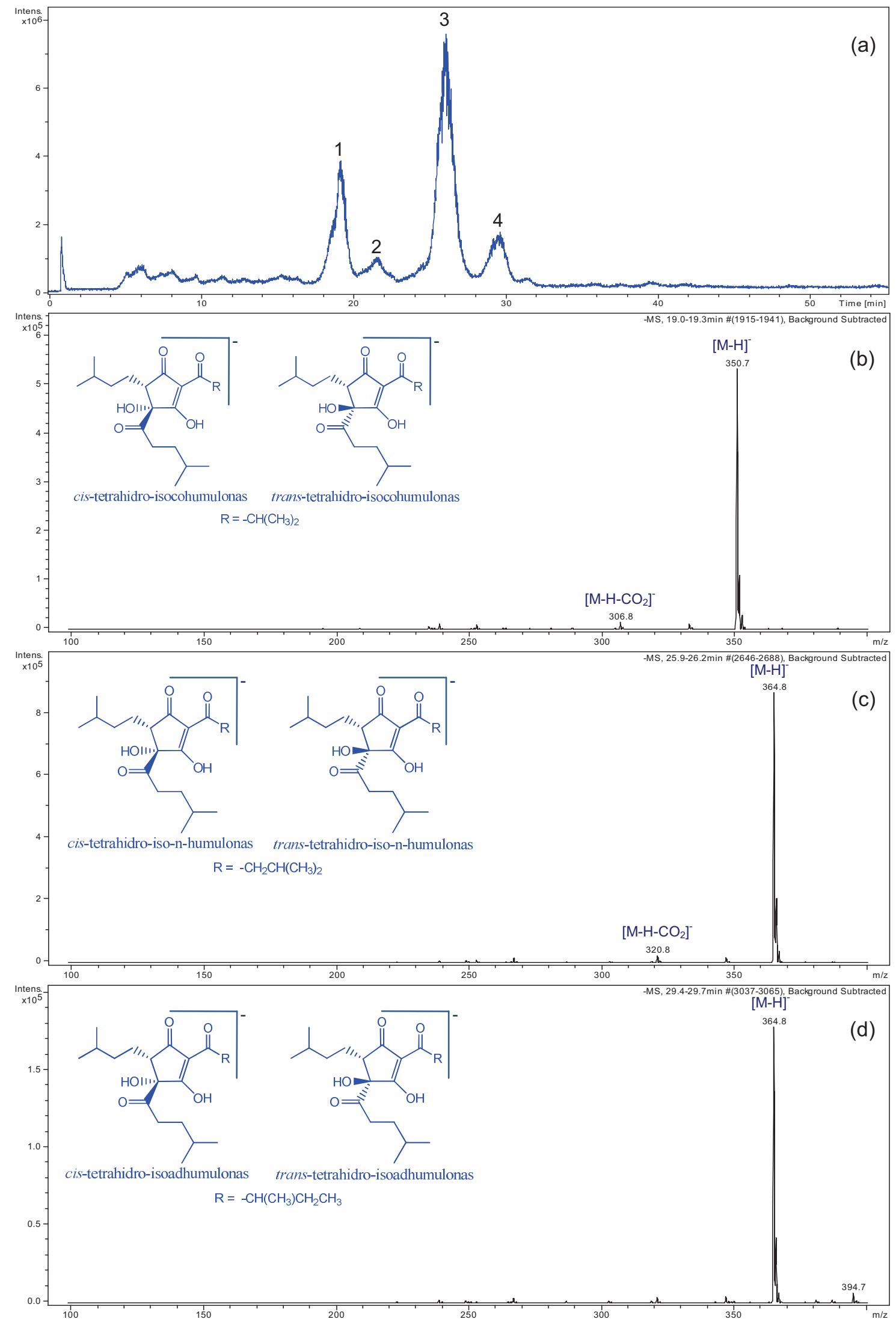

Figura 26. (a) Cromatograma de íons total das tetrahidro-isohumulonas, formas cis- e trans-. (b) Espectro de massas (ESI(-)MS) da espécie cis- e trans-tetrahidro-isocohumulona referente aos picos 1 e 2, $t_{r}=19,2$ e 21,5 min., respectivamente. (c) Espectro de massas (ESI(-)MS) das espécies cis- e trans-tetrahidro-iso-n-humulona referente ao pico 3, $\mathrm{t}_{\mathrm{r}}=26,0 \mathrm{~min}$. (d) Espectro de massas (ESI(-)MS) das espécies cis- e trans-tetrahidro-isoadhumulona referente ao pico $4, \mathrm{t}_{\mathrm{r}}=29,6 \mathrm{~min}$. 
Por fim, caracterizou-se as tetrahidro-isohumulonas por ${ }^{1} \mathrm{H}$ RMN, obtendo o espectro apresentado a seguir, Figura 27. Neste, apesar da baixa resolução, notase a ausência do duplo tripleto na região de 5,00 e 5,17 ppm, referentes aos hidrogênio das olefinas das cadeiras laterais em C4 e C5, presentes inicialmente nos precursores isohumulonas. Desta forma, constatou-se que a síntese foi bem sucedida, havendo a hidrogenação das olefinas das cadeiras laterais referentes aos grupos prenila e isohexenoila.

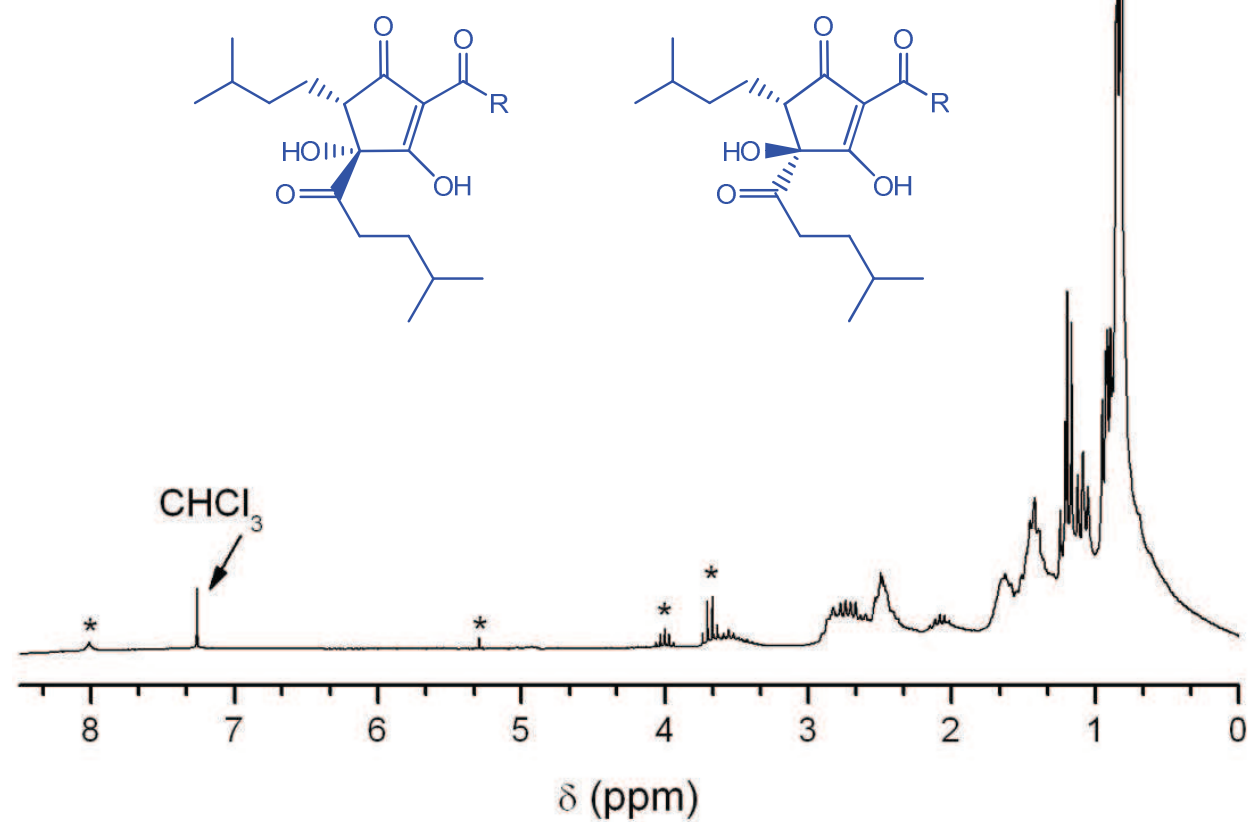

Figura 27. Espectro de $1 \mathrm{H}$ RMN (200 MHz) das tetrahidro-isohumulonas, formas cis- e trans-, em $\mathrm{CDCl}_{3}$. Os sinais marcados com $\left(^{*}\right)$ indicam impurezas presentes na amostra.

Em suma, verificou-se que as tetrahidro-isohumulonas foram preparadas a partir da hidrogenação dos iso- $\alpha$-ácidos, resultando em uma pureza estimada de $90 \%$. 
4.3.5. Estudo eletroquímico das isohumulonas.

Sabe-se que o cromóforo $\beta$-tricarbonílico dos iso- $\alpha$-ácidos é suscetível a sofrer oxidação ${ }^{12}$. Este grupo contém um número significativo de elétrons $\pi \mathrm{e}$ orbitais $\mathrm{p}$ deslocalizados em um sistema conjugado, o qual é compostos por 3 átomos de oxigênio e 4 átomos de carbono, comum a todos os ácidos amargos derivados do lúpulo. Desta forma, aparte dos processos oxidativos verificados nos iso- $\alpha$-ácidos, a degradação destes via transferência de elétrons se deve a oxidação do grupo $\beta$-tricarbonílico, sendo o mesmo potencial de oxidação verificado para ambas as espécies trans- e cis-isohumulonas em suas formas aniônicas. Analogamente, o mesmo potencial foi verificado para os derivados dihidroisohumulonas e tetrahidro-isohumulonas, em sua forma desprotonada ${ }^{12}$.

No entanto, o potencial de oxidação da forma molecular destes compostos não foi ainda relatado devido ao alto potencial de oxidação destas espécies e a limitação da janela dos eletrodos comumente utilizados. Desta forma, o intuito principal do estudo eletroquímico foi determinar o potencial de oxidação dos iso- $\alpha$-ácidos em sua forma molecular. Para tanto, o potencial de oxidação das transisohumulonas foi obtido utilizando-se o eletrodo de diamante dopado com boro como eletrodo de trabalho. Ainda, experimentos foram direcionados para comprovar 0 potencial de oxidação das formas aniônicas da configuração trans-. Neste contexto, realizaram-se experimentos de voltametria cíclica em uma janela de potencial de 0,0 a 2,2 V vs. NHE, obtendo voltamogramas em diferentes velocidades de varredura $\left(10,50,100\right.$ e $\left.200 \mathrm{mV} \mathrm{s}^{-1}\right)$.

Nos experimentos eletroquímicos utilizando as trans-isohumulonas em sua forma aniônica, obteve-se o voltamograma apresentado na Figura 28, cujo potencial 
de oxidação foi igual a $1,4 \mathrm{~V}$ vs. NHE. Ainda, verificou-se a existência de um processo irreversível decorrente da oxidação de 1 elétron, pela ausência de onda de varredura catódica. Estes resultados estão de acordo com o descrito na literatura ${ }^{12}$.

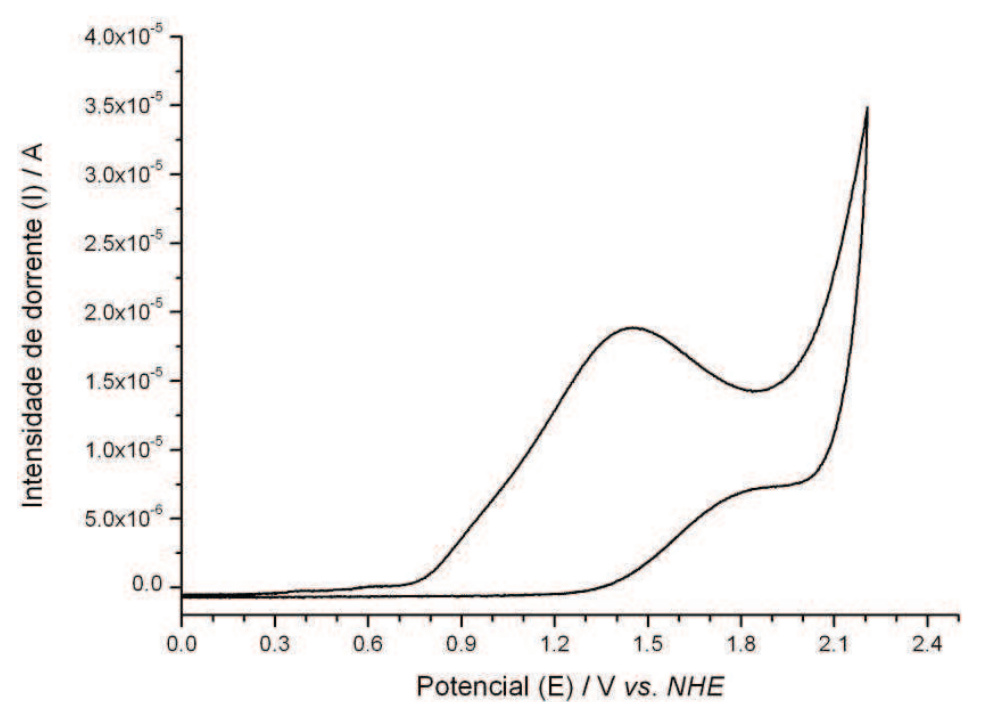

Figura 28. Voltamograma cíclico das trans-isohumulonas em sua forma aniônica, em acetonitrila contendo $0,2 \mathrm{~mol} \mathrm{~L}^{-1}$ de perclorato de tetrabutilamônio como eletrólito suporte. Eletrodos: diamante dopado com boro (trabalho), platina (contra-eletrodo), ferroceno (referência interna). A velocidade de varredura foi $50 \mathrm{mV} \mathrm{s}^{-1}$.

Utilizando a forma protonada das trans-isohumulonas, experimentos de voltametria cíclica foram conduzidos, obtendo voltamogramas em diferentes velocidades de varredura $\left(10,50,100\right.$ e $\left.200 \mathrm{mV} \mathrm{s}^{-1}\right)$, os quais se encontram na Figura 29. Aqui, verificou-se que o pico de oxidação para os compostos foi $1,8 \mathrm{~V}$ vs. NHE, bem como a presença de um processo irreversível. Também, observou-se que os potenciais de pico deslocam com o aumento da velocidade de varredura. Neste caso, através do gráfico da corrente de pico anódico vs. a raiz quadrada da velocidade de varredura $\left(\mathrm{v}^{1 / 2}\right)$ presente na Figura 29, constatou-se uma dependência linear, cujo coeficiente de correlação é igual a 0,9987. Desta forma, foi evidenciado um processo difusional, no qual o transporte de massa na oxidação das trans-isohumulonas é controlado cineticamente por transferência heterogênea de elétrons do substrato para o eletrodo. 


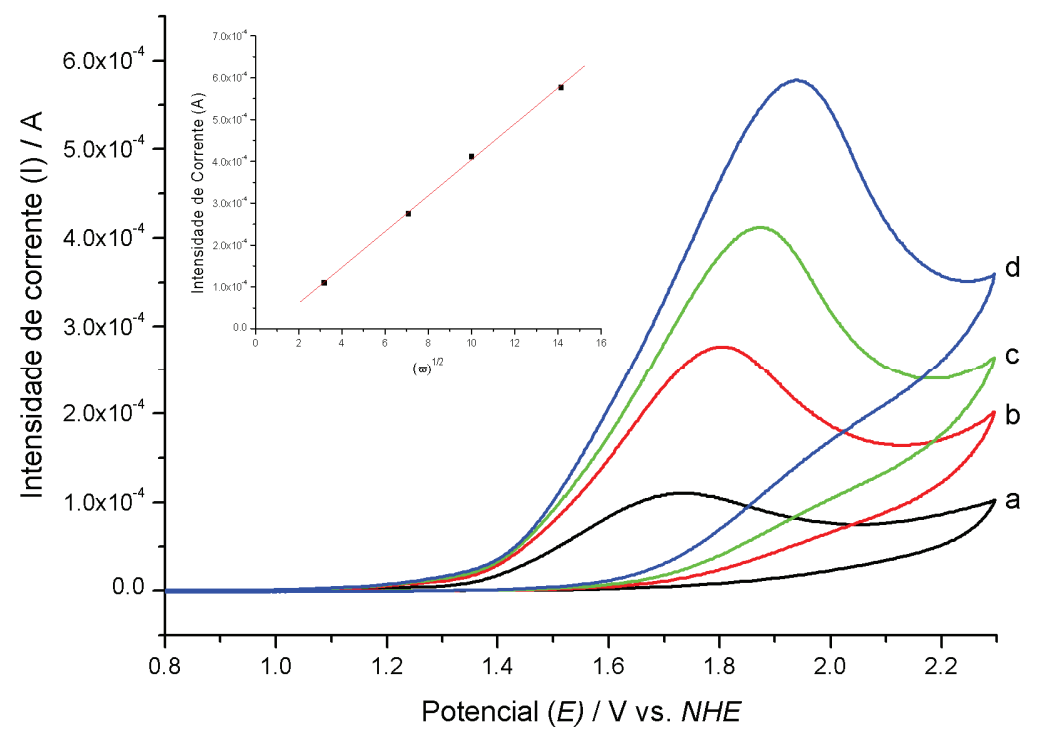

Figura 29. Voltamograma cíclico das trans-isohumulonas em sua forma molecular, em acetonitrila contendo $0,2 \mathrm{~mol} \mathrm{~L}^{-1}$ de perclorato de tetrabutilamônio como eletrólito suporte. Eletrodos: diamante dopado com boro (trabalho), platina (contra-eletrodo), ferroceno (referência interna). As velocidades de varredura foram: $a=10 \mathrm{mV} \mathrm{s}^{-1}, \mathrm{~b}=50 \mathrm{mV} \mathrm{s}^{-1}, \mathrm{c}=100 \mathrm{mv} \mathrm{s}^{-1}, \mathrm{~d}=200 \mathrm{mV} \mathrm{s}^{-1}$.

De fato, constatou-se que as isohumulonas em sua forma aniônica são mais suscetíveis a sofrerem oxidação que os compostos em sua forma molecular. Conforme mencionado anteriormente no texto, as iso- $\alpha$-ácidos estão presentes na cerveja, em sua maioria, na forma desprotonada, o que deixa patente a deterioração destes compostos na bebida. 
4.4. Reatividade dos iso- $\alpha$-ácidos e seus derivados e alguns fenóis frente o radical 1 -hidroxietila.

4.4.1. Estudos com o radical 1-hidroxietila: formação do aduto radical [4-POBN/CH$\left.\left(\mathrm{CH}_{3}\right) \mathrm{OH}\right]^{\circ}$.

Primeiramente, avaliou-se a influência do oxigênio dissolvido no meio reacional quanto à captação do radical 1-hidroxietila pela armadilha química 4-POBN. Conforme pode ser observado no cromatograma contido na Figura 30a, apenas um composto foi detectado, em 6 minutos $\left(t_{r}\right)$, o qual, pelo espectro de massas $\left(E S I-M S^{n}\right)$, é referente à eluição do 4-POBN da coluna, cujo íon da molécula protonada $[\mathrm{M}+\mathrm{H}]^{+}$é igual a $195 \mathrm{~m} / \mathrm{z}$, Figura 30b. Observa-se também os íons fragmentos em 139, 122 e 95 m/z referentes à perda do grupo tert-butil, tert-butil e $\mathrm{H}_{2} \mathrm{O}$ e dos fragmentos $-\mathrm{C}\left(\mathrm{CH}_{3}\right)_{3}$ e $\mathrm{H}_{2} \mathrm{CNO}^{+}$respectivamente. 


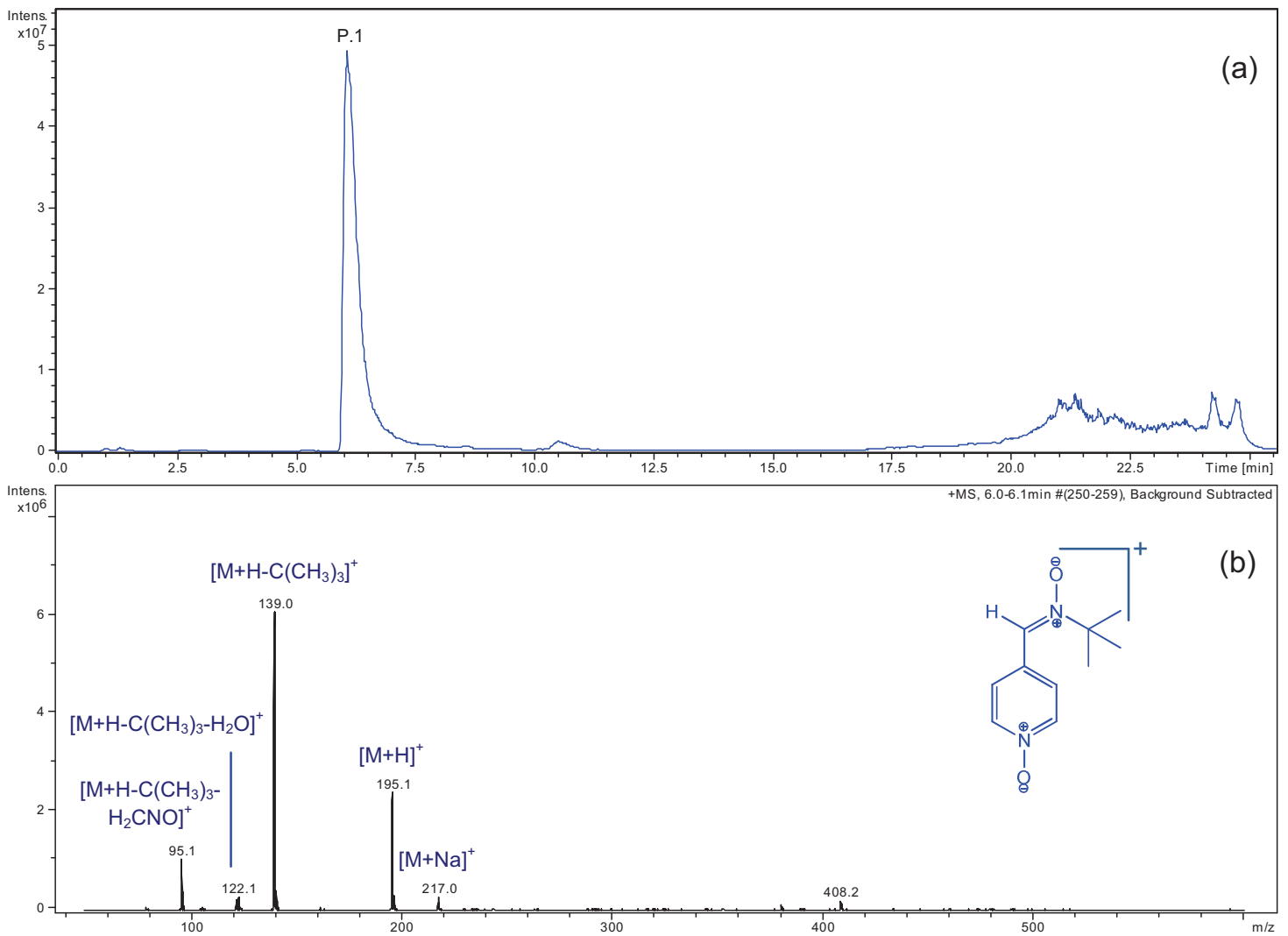

Figura 30. (a) Cromatograma de íons total dos produtos decorrentes da reação de formação do aduto radical [4-POBN/CH$\left.\left(\mathrm{CH}_{3}\right) \mathrm{OH}\right]^{\circ}$ sob atmosfera de $\mathrm{O}_{2}$. $\mathrm{T}=25^{\circ} \mathrm{C} ; \mathrm{t}=5$ minutos. (b) Espectro de massas $(\mathrm{ESI}(+) \mathrm{MS})$ do eluato em $\mathrm{t}_{\mathrm{r}}=6 \mathrm{~min}$ referente à espécie 4-POBN.

Segundo a literatura ${ }^{25,41}$, o oxigênio reage com o radical 1-hidroxietila com constante de velocidade próxima ao limite difusional, gerando acetaldeido como produto principal, conforme ilustrado no Esquema 3. Consequentemente, a formação do aduto radical [4-POBN/CH( $\left.\left(\mathrm{CH}_{3}\right) \mathrm{OH}\right]^{\bullet}$ não foi observada em condições aeróbicas em função desta reação paralela.

Por outro lado, ao analisar a mistura reacional após 5 minutos de amostragem e sob atmosfera de argônio, observa-se a formação de quatro novos picos decorrentes da reação entre a armadilha química e o radical 1-hidroxietila, denominados pico 2 (P.2), pico 3 (P.3), pico 4 (P.4) e pico 5 (P.5) na Figura 31a.

$\mathrm{O}$ pico $2, \mathrm{t}_{\mathrm{r}}=7,9$ minutos, refere-se à forma oxidada do aduto, resultando no íon da molécula protonada $[\mathrm{M}+\mathrm{H}]^{+} 239 \mathrm{~m} / \mathrm{z}$, conforme pode ser observado no 
fragmentograma contido na Figura 31b. Adicionalmente, o espectro de massas por CID (Colision Induced Dissociation) deste íon encontra-se na Figura A1 do Apêndice A.

O pico 3 consiste na eluição do aduto radical [4-POBN/CH( $\left.\left(\mathrm{CH}_{3}\right) \mathrm{OH}\right]^{\bullet}$ em 8,6 minutos $\left(t_{r}\right)$. Pela leitura do espectro de massas referente a este pico, Figura 31c, nota-se o íon da molécula protonada $[\mathrm{M}+\mathrm{H}]^{+} 240 \mathrm{~m} / \mathrm{z}$. O espectro de massas por $\mathrm{CID}$ deste íon está apresentado no Apêndice A Figura A2.

O pico 4, referente ao eluato em 9,2 minutos $\left(t_{r}\right)$, remete ao 4-POBN ligado a duas moléculas do radical 1-hidroxietila, cujo íon da molécula protonada $[\mathrm{M}+\mathrm{H}]^{+}$ apresentado é $285 \mathrm{~m} / \mathrm{z}$, Figura 31d. Pelo espectro de massas por CID, fragmentograma, deste íon referente a este pico, Apêndice A Figura A3, observase que a fragmentação do íon da molécula protonada gera o íon secundário $241 \mathrm{~m} / \mathrm{z}$, o qual consiste no aduto em sua forma reduzida.

Da mesma forma, o fragmentograma obtido para o pico $5, t_{r}=12,8$ minutos, contido na Figura 31e, apresenta o íon da molécula protonada $[\mathrm{M}+\mathrm{H}]^{+} 285 \mathrm{~m} / \mathrm{z}$. Conforme citado anteriormente, este íon remete ao 4-POBN contendo duas moléculas do radical 1-hidroxietila. Neste espectro, verifica-se a presença do íon secundário $241 \mathrm{~m} / \mathrm{z}$ decorrente da fragmentação secundária do íon da molécula protonada, conforme pode ser observado na Figura A4 do Apêndice A. 


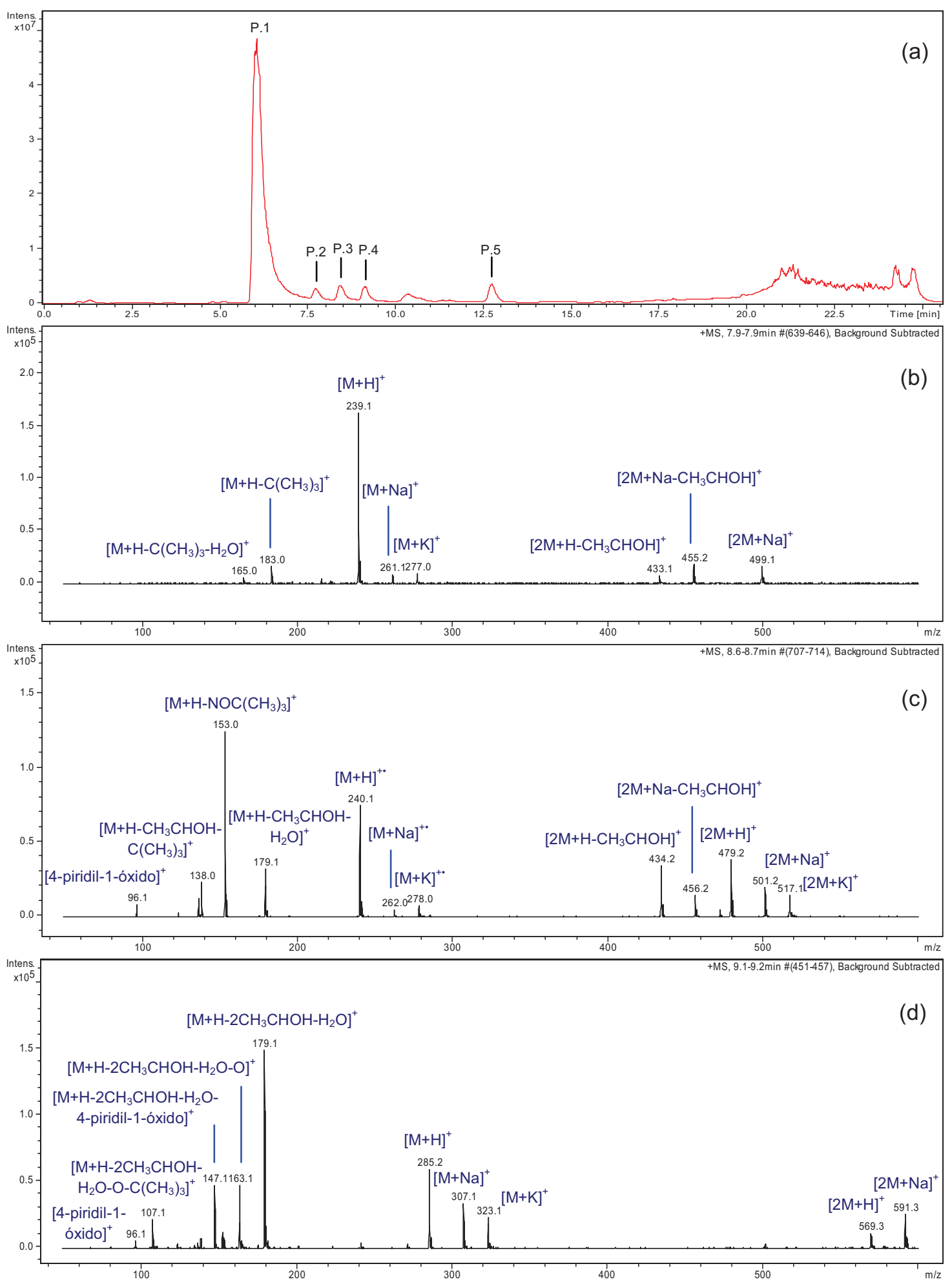


(conclusão da figura)

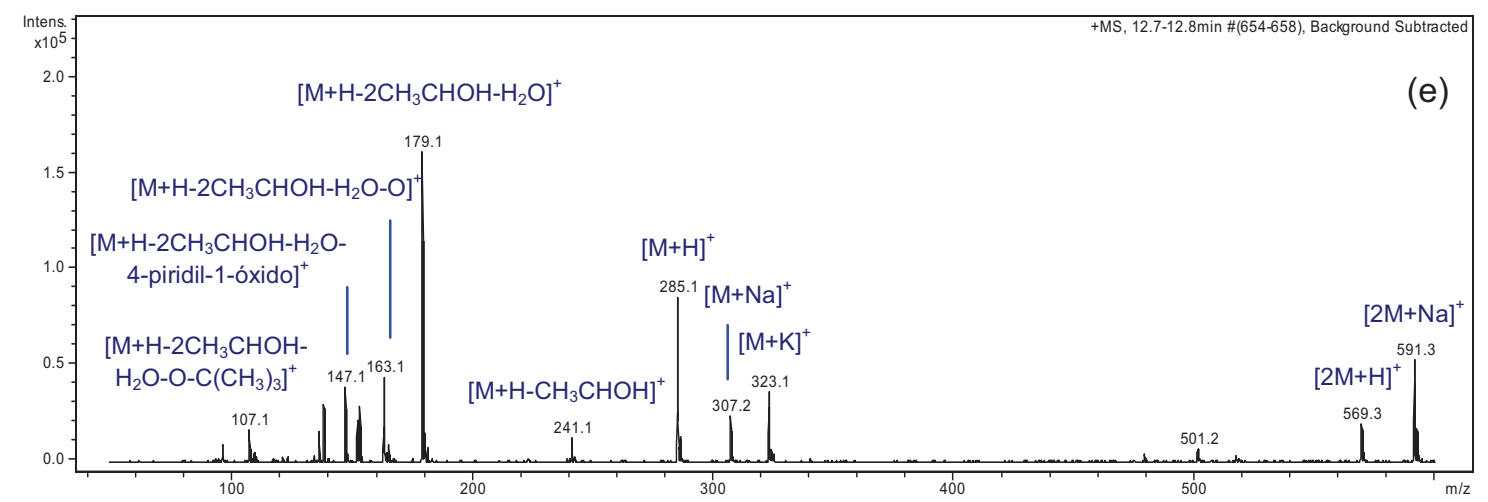

Figura 31. (a) Cromatograma de íons total dos produtos decorrentes da reação de formação do aduto radical [4-POBN $\left./ \mathrm{CH}\left(\mathrm{CH}_{3}\right) \mathrm{OH}\right]^{\circ}$ sob atmosfera de $\mathrm{Ar}$. $\mathrm{T}=25^{\circ} \mathrm{C} ; \mathrm{t}=5$ minutos. (b) Espectro de massas $(E S I(+) M S)$ com atribuição dos íons do eluato em $t_{r}=7,9$ min. (c) Espectro de massas $(E S I(+) M S)$ com atribuição dos íons do eluato em $\mathrm{t}_{\mathrm{r}}=8,6 \mathrm{~min}$. (d) Espectro de massas $(\mathrm{ESI}(+) \mathrm{MS})$ com atribuição dos íons do eluato em $t_{r}=9,2$ min. (e) Espectro de massas (ESI(+)MS) com atribuição dos íons do eluato em $\mathrm{t}_{\mathrm{r}}=12,8 \mathrm{~min}$.

De fato, pelo cromatograma apresentado na Figura 31a, observa-se que as espécies que eluem em 9,2 e 12,8 minutos não são quimicamente idênticas, pois possuem tempos de retenção bem distintos, apesar de apresentarem fragmentogramas similares. No entanto, não se pode afirmar a estrutura química exata referentes a cada pico somente utilizando-se a técnica LC-MS/MS.

A título ilustrativo, as estruturas químicas dos compostos supracitados estão apresentadas na Figura 32.<smiles>CC(O)C(c1cc[n+]([O-])cc1)=[N+]([O-])C(C)(C)C</smiles>

(a)<smiles>CC(O)[C@H](c1cc[n+]([O-])cc1)N([O-])C(C)(C)C</smiles>

(b)<smiles>CC(O)ON([C@H](c1cc[n+]([O-])cc1)C(C)(C)C)C(C)(C)C</smiles>

(c)<smiles>CC(O)C(c1cc[n+]([O-])cc1)(C(C)O)N(O)C(C)(C)C</smiles>

(d)<smiles>CC(O)[C@H](c1cc[n+]([O-])cc1)N(O)C(C)(C)C</smiles>

(e)

Figura 32. Estruturas químicas das quatro espécies formadas da reação entre 4-POBN e o radical 1-hidroxietila: (a) aduto oxidado; (b) aduto radical; (c) e (d) 4-POBN ligado a duas moléculas do radical 1-hidroxietil; (e) aduto reduzido. 
Em suma, verifica-se a existência de 4 espécies em solução decorrentes da reação entre a armadilha química e o radical 1-hidroxietila: a forma oxidada do aduto, dois compostos relacionados ao 4-POBN ligado a duas moléculas do radical, além do próprio aduto radical. É interessante ressaltar que, exceto o aduto radical, os demais compostos verificados não foram ainda relatados na literatura, uma vez que os produtos da reação foram analisados utilizando-se somente a técnica RPE, a qual detecta apenas substâncias paramagnéticas. Desta forma, o método tradicional descrito na literatura para se detectar e dosar radicais consiste em utilizar espectroscopia de ressonância paramagnética de elétrons (RPE). Assim, o aduto radical [4-POBN/CH$\left.\left(\mathrm{CH}_{3}\right) \mathrm{OH}\right]^{\circ}$ foi monitorado através desta técnica, cujo espectro está apresentado na Figura 33.

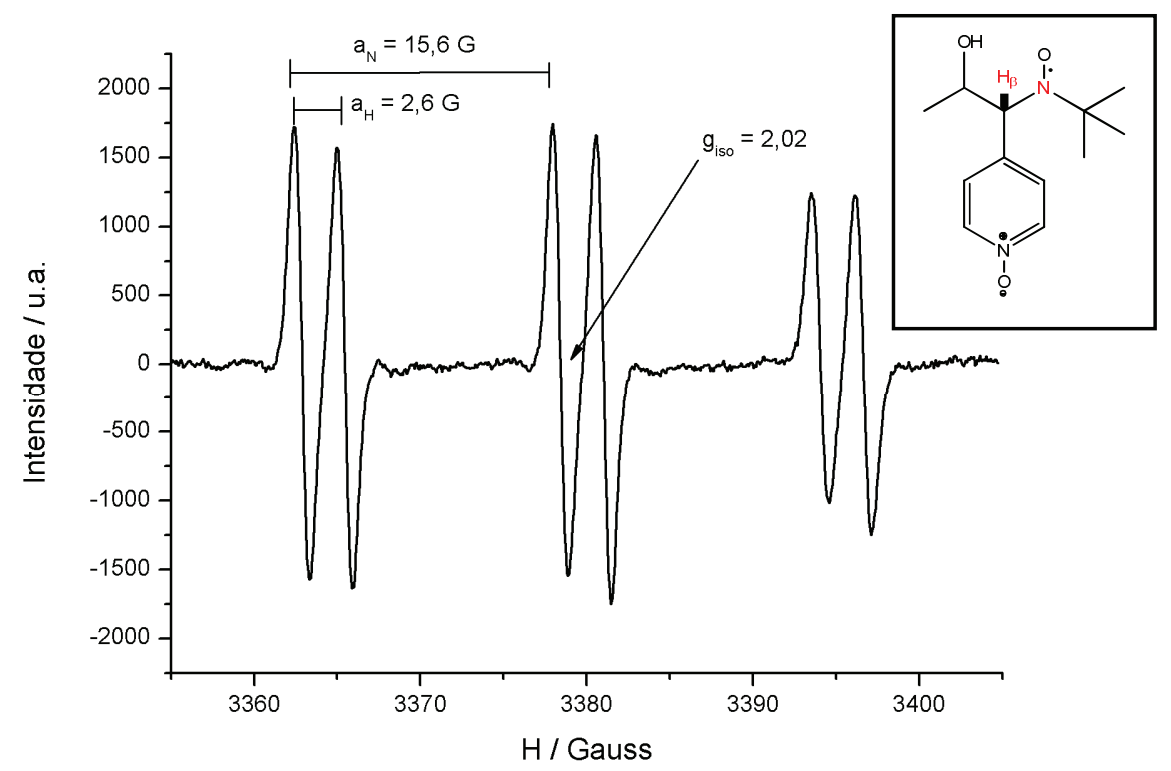

Figura 33. Espectro de ressonância paramagnética de elétrons (RPE) registrado em banda-X $(9,521 \mathrm{GHz})$ do aduto radical [4-POBN/CH$\left.\left(\mathrm{CH}_{3}\right) \mathrm{OH}\right]^{\circ}$ obtido em solução aquosa água/etanol $(\cong 5 \%)$ a temperatura de $25^{\circ} \mathrm{C}$.

Conforme pode ser observado, o espectro trata de um triplo dubleto decorrente do acoplamento hiperfino (contato de Fermi) do elétron desemparelhado com o átomo de nitrogênio $(I=1)$ e o desdobramento deste tripleto em dubleto pelo acoplamento super hiperfino com o átomo de hidrogênio beta $\left(H_{\beta}\right)(I=1 / 2)$. Do 
espectro, obteve-se uma constante de acoplamento entre o elétron desemparelhado e o núcleo do átomo de nitrogênio $\left(a_{N}\right)$ igual a $15,6 \mathrm{G}$, bem como uma constante de acoplamento entre este mesmo elétron com o núcleo do átomo de hidrogênio $\left(\mathrm{a}_{\mathrm{H} \beta}\right)$ igual a 2,6 G. Estas constantes de acoplamento e padrão de desdobramento hiperfino estão de acordo com a literatura ${ }^{25}$ e corroboram com a comprovação da existência do aduto radical [4-POBN/CH( $\left.\left(\mathrm{CH}_{3}\right) \mathrm{OH}\right]^{\circ}$.

4.4.2. Estudos com o radical 1-hidroxietila: estabilidade do aduto radical [4-POBN/CH$\left.\left(\mathrm{CH}_{3}\right) \mathrm{OH}\right]^{\circ}$.

Avaliou-se também a estabilidade do aduto radical por ESI-(+)-MS/MS em solução com o intuito de verificar o decaimento cinético deste, bem como para ajustar o tempo de amostragem da reação. Neste contexto, investigou-se a influência da adição de catalase no decaimento do radical ao analisar o tempo de meio vida ( $\left.\mathrm{t}_{1 / 2}\right)$ deste na presença e ausência da enzima. Assim, constatou-se que, de fato, a catalase tem efeito sobre a estabilidade do aduto radical, uma vez que esta consome o excesso de peróxido de hidrogênio em solução, o qual se supõe estar envolvido em reações paralelas que ocasionam um decaimento mais acentuado do aduto radical, conforme pode ser observado na Figura 34. 


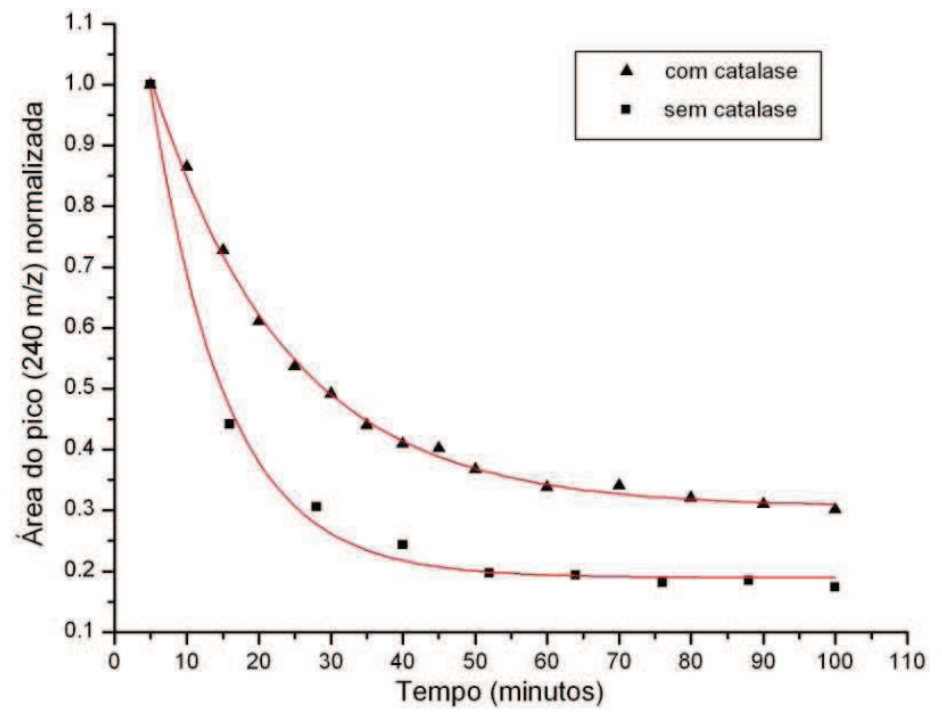

Figura 34. Decaimento do aduto radical [4-POBN/CH$\left.\left(\mathrm{CH}_{3}\right) \mathrm{OH}\right]^{\circ}$ na presença e ausência de catalase $\left(47,4 \mathrm{mg} \mathrm{mL}^{-1}\right) . \mathrm{T}=25^{\circ} \mathrm{C}$.

Na Tabela 2 são apresentadas as constantes de decaimento do aduto radical, bem como os respectivos tempos de meia vida $\left(t_{1 / 2}\right)$ obtidos na presença e ausência de catalase. Aqui, observa-se tempos de meia vida bem distintos, o que leva a concluir que o uso da catalase é de suma importância neste tipo de reação, principalmente quando se deseja quantificar o aduto radical [4-POBN/CH$\left.\left(\mathrm{CH}_{3}\right) \mathrm{OH}\right]^{\circ}$ formado, como no caso da utilização da cinética de competição.

Tabela 2. Dados cinéticos com respeito ao decaimento do aduto radical [4-POBN/CH$\left.\left(\mathrm{CH}_{3}\right) \mathrm{OH}\right]^{*}$ no meio reacional e a temperatura de $25^{\circ} \mathrm{C}$.

\begin{tabular}{ccc}
\hline & Sem Catalase & Com Catalase \\
\hline $\mathrm{k}_{\text {obs }}\left(\mathrm{s}^{-1}\right)$ & $1,610^{-3}$ & $9,010^{-4}$ \\
$\mathrm{t}_{1 / 2}(\mathrm{~s})$ & 432 & 774 \\
\hline
\end{tabular}

Desta forma, avaliou-se o comportamento dos íons das moléculas protonadas $[\mathrm{M}+\mathrm{H}]^{+}$239, 240 e $285 \mathrm{~m} / \mathrm{z}$ adicionando-se catalase ao final do tempo de amostragem estabelecido para a reação. Assim, estes íons foram monitorados durantes os 5 primeiros minutos de reação, obtendo o gráfico presente na Figura 
35. Observa-se uma evolução em função do tempo de reação da forma oxidada do aduto $\left([\mathrm{M}+\mathrm{H}]^{+}=239 \mathrm{~m} / \mathrm{z}\right)$ e das espécies formadas pela ligação do 4-POBN com duas moléculas do radical 1-hidroxietila $\left([\mathrm{M}+\mathrm{H}]^{+}=285 \mathrm{~m} / \mathrm{z}\right)$, ao passo que a concentração do aduto radical $\left([\mathrm{M}+\mathrm{H}]^{+}=240 \mathrm{~m} / \mathrm{z}\right)$ manteve-se praticamente constante durante os 5 minutos. É sabido que, nas condições experimentais utilizadas, era esperado que houvesse um acréscimo da concentração do aduto radical em solução. Assim, este comportamento está provavelmente relacionado às reações subseqüentes envolvendo o aduto radical, as quais geram as espécies referentes aos íons das moléculas protonadas $[\mathrm{M}+\mathrm{H}]^{+} 239$ e $285 \mathrm{~m} / \mathrm{z}$ pelo consumo do aduto radical.

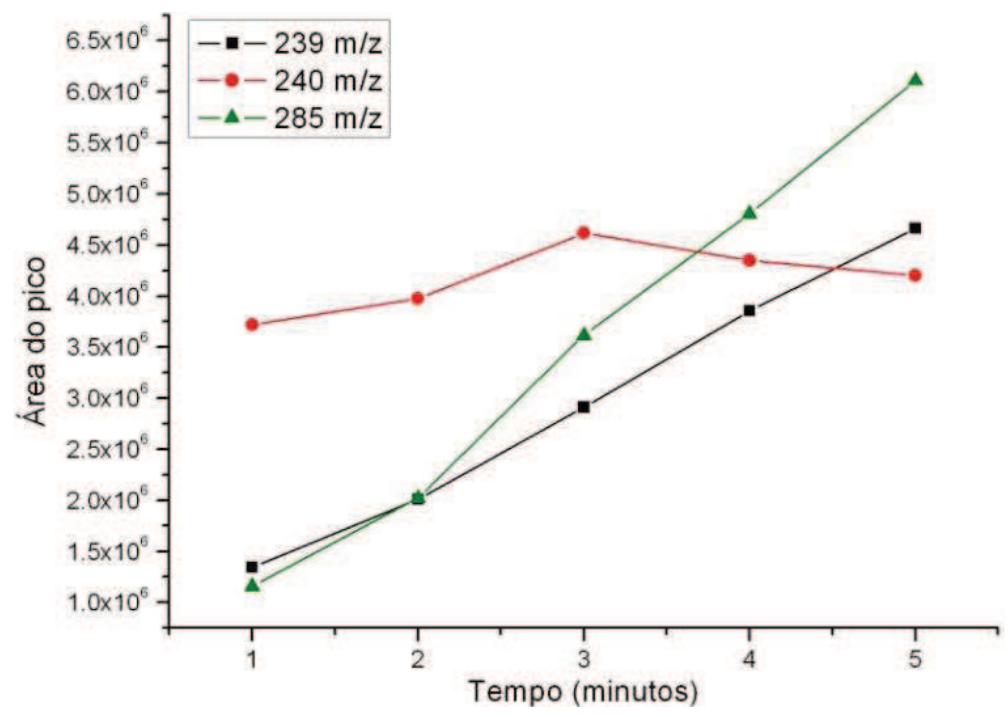

Figura 35. Área dos picos cromatográficos referentes às espécies aduto oxidado, aduto radical [4-POBN/CH$\left.\left(\mathrm{CH}_{3}\right) \mathrm{OH}\right]^{*}$ e 4-POBN contendo duas moléculas do radical 1-hidroxietila em função do tempo de reação e na presença de catalase.

Neste caso é interessante notar que em 1 minuto de reação as concentrações das espécies do aduto oxidado e 4-POBN ligado as duas moléculas do radical são significativamente inferiores à concentração do aduto radical. Isto é indício de que neste tempo de amostragem, as reações subsequentes podem ser, em parte, consideradas desprezíveis. Desta forma, para a obtenção das constantes de 
velocidade aparentes da reação dos compostos de interesse frente o radical 1-hidroxietila, através da abordagem cinética de competição, o tempo de amostragem utilizado foi 1 minuto.

O mecanismo de reação proposto para as reações subsequentes observadas encontra-se no Esquema 7, onde aduto radical é oxidado pelo meio, cuja constante de velocidade está representada por $\mathrm{k}_{20 x}$. Por outro lado, a segunda reação subsequente se dá pela ligação de uma molécula do radical 1-hidroxietila ao aduto radical, com a constante de velocidade $\mathrm{k}_{2 \mathrm{rad}}$. Aqui, cabe ressaltar que as constantes de velocidades decorrentes das reações de formação do aduto oxidado e 4-POBN ligado a duas moléculas do radical, $\mathrm{k}_{20 x}$ e $\mathrm{k}_{2 \mathrm{rad}}$ respectivamente, não são conhecidas.

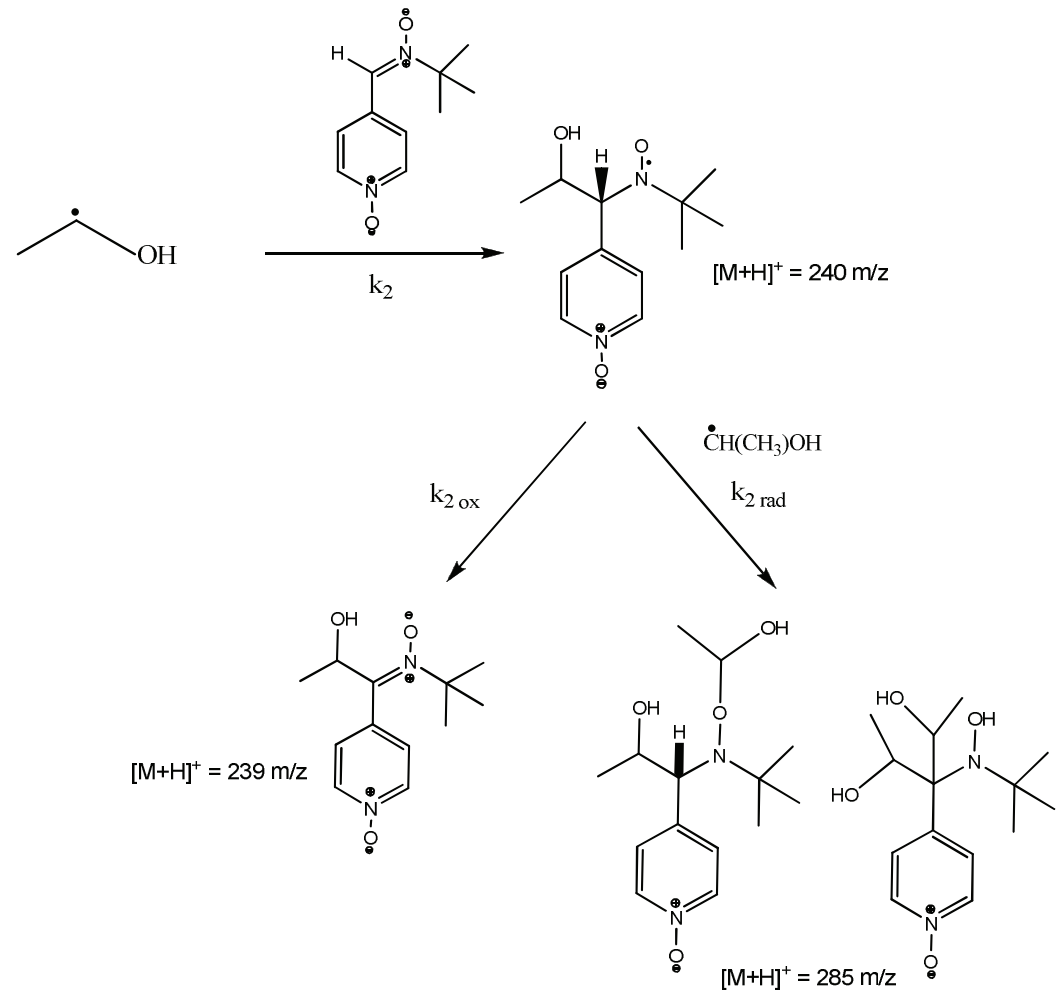

Esquema 7. Reação de formação das espécies aduto oxidado e 4-POBN ligado a duas moléculas de radical 1-hidroxietila. 
4.4.3. Estudos com o radical 1-hidroxietila: determinação das constantes de velocidades aparentes da reação entre o radical 1-hidroxietila e os compostos de interesse.

A reatividade dos ácidos amargos presentes na cerveja, derivados do lúpulo, bem como alguns fenóis presentes na bebida frente o radical 1-hidroxietila foi obtidada pela determinação das constantes de velocidade de segunda ordem das reações. Assim, conforme já mencionado no texto, as constantes de velocidade foram determinadas através de uma abordagem cinética de competição, obtendo então constantes de velocidade aparentes.

Desta forma, através da Equação 1:

$$
\left(\frac{F}{1-F}\right) * k_{2}{ }^{*}[4-P O B N]=k_{2}{ }^{*}[\mid A A]
$$

é possível estimar as constantes de velocidade da reação entre o radical 1-hidroxietila e os compostos em estudo - isohumulonas e derivados, bem como os fenóis de interesse.

$\mathrm{Na}$ expressão, $(\mathrm{F})$ representa o percentual de captação do radical pelos iso- $\alpha$-ácidos, [4-POBN] e [IAA] consistem nas concentrações da armadilha química 4-POBN e do composto de interesse aqui representado pelos iso- $\alpha$-ácidos, respectivamente. $k_{2}$ representa a constante de velocidade específica da reação entre o radical e a armadilha química 4-POBN e $k_{2}$ ' consiste na constate de velocidade aparente da reação envolvendo o radical e iso- $\alpha$-ácidos. A dedução para a Equação 1 encontra-se no Apêndice B.

Assim, variando-se a concentração dos compostos de interesse na reação, no caso representado pelos iso- $\alpha$-ácidos, um gráfico $(\mathrm{F} / \mathrm{F}-1)^{*} \mathrm{k}_{2}{ }^{*}[4-\mathrm{POBN}]$ vs. 
concentração do composto em estudo [IAA] foi construído obtendo um comportamento linear, no qual cada ponto da curva foi obtido a partir da média da análise em triplicata do aduto radical [4-POBN/CH( $\left.\left(\mathrm{CH}_{3}\right) \mathrm{OH}\right]$ para cada concentração do composto adicionado. Consequentemente, sabendo a concentração da armadilha química [4-POBN] e $\mathrm{k}_{2}\left(3,110^{7} \mathrm{~L} \mathrm{~mol}^{-1} \mathrm{~s}^{-1}\right)^{37}$, calculou-se as constantes de velocidade aparente de segunda ordem $\left(k_{2}{ }^{\prime}\right)$.

Como um todo, os compostos de interesse no estudo da reatividade com o radical 1-hidroxietila englobaram em primeira instância os iso-a-ácidos e os derivados dihidro-iso- $\alpha$-ácidos e tetrahidro-iso- $\alpha$-ácidos, dada a importância na qualidade sensorial da cerveja destes. Em uma segunda etapa, buscou-se avaliar a reatividade de alguns fenóis presentes também na cerveja. Adicionalmente, avaliouse a reatividade de cada diastereisômeros cis- e trans-isocohumulonas, bem como dos análogos iso-n-humulonas e isocohumulonas, nas formas cis- e trans-, frente ao radical de interesse, isolando os ácidos amargos do lúpulo através de um sistema HPLC semi-preparativo.

Um estudo comparativo foi desenvolvido utilizando as técnicas RPE e ESI-(+)-MS/MS com o intuito de analisar a reatividade do radical 1-hidroxietila perante os compostos em estudo. Desta forma, as reações foram monitoradas por estas duas técnicas, sob as mesmas condições reacionais e instrumentais.

Da cinética de competição e pela análise da Equação 1, sabe-se que o coeficiente angular da reta fornece a constante de velocidade de interesse. A título de exemplificação, a Figura $\mathbf{3 6}$ apresenta o gráfico obtido na cinética da reação entre as trans-isohumulonas e o radical 1-hidroxietila. 


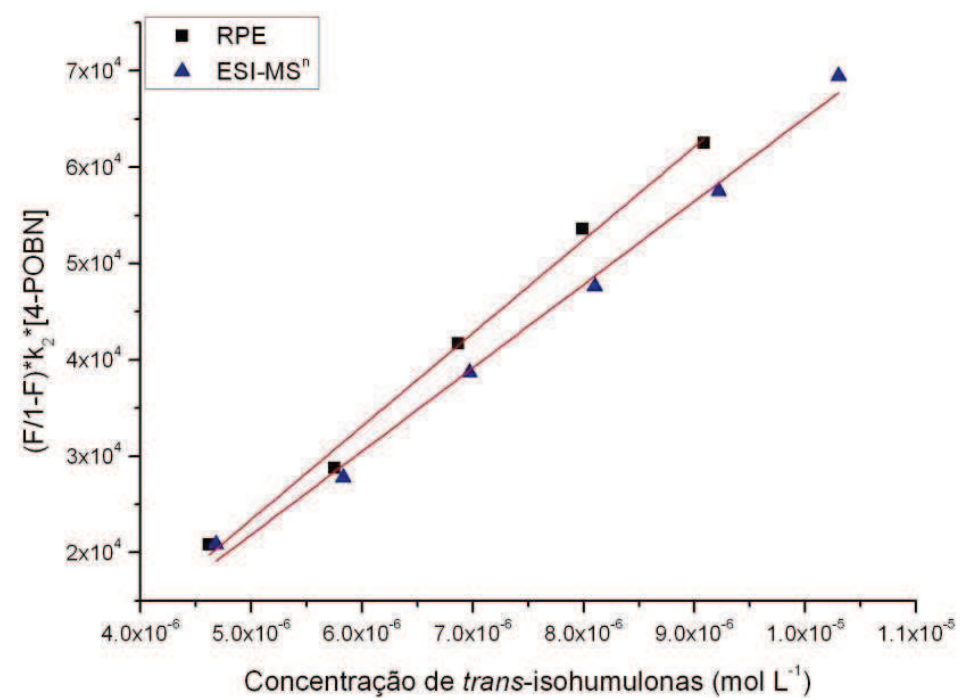

Figura 36. Gráfico $(\mathrm{F} / \mathrm{F}-1)^{*} \mathrm{k}_{2}{ }^{*}[4-\mathrm{POBN}]$ vs. concentração de trans-isohumulonas. Medidas obtidas por espectrometria de massas (ESI-(+)-MS/MS e espectroscopia de ressonância paramagnética de elétrons (EPR). $\mathrm{T}=25^{\circ} \mathrm{C} ; 1$ minuto de reação.

De fato, verificou-se que as técnicas ESI-(+)-MS/MS e RPE mostraram-se bastantes compatíveis para tal finalidade, pois os perfis de captação do radical foram similares. Consequentemente, as constantes de velocidade aparentes obtidas foram estatisticamente iguais no intervalo de confiança de $95 \%(p=0,05)$.

4.4.3.1. Reatividade dos iso- $\alpha$-ácidos e seus derivados frente o radical 1-hidroxietila.

Um estudo inerente à reatividade das formas naturais e reduzidas/hidrogenadas dos iso- $\alpha$ - frente o radical 1-hidroxietila foi efetuado com o intuito de verificar o grau de degradação destes compostos perante as reações radicalares, bem como verificar o mecanismo e sítio de reação envolvido na processo. 
Conforme já mencionado, o radical 1-hidroxietila pode reagir com o oxigênio dissolvido $\left(\mathrm{O}_{2}\right)$; por conseguinte, não teríamos uma cinética de competição do radical entre apenas dois compostos, que no caso consiste no 4-POBN e as isohumulonas. Portanto, as reações foram conduzidas sob atmosfera inerte de argônio, suprimindo o oxigênio no meio reacional e eliminando desta forma quaisquer reações paralelas decorrentes deste.

Assim, através da cinética de competição, obteve-se as constantes de velocidades aparentes da reação. Neste contexto, a Tabela 3 apresenta as constantes de velocidade aparentes obtidas da reação do radical 1-hidroxietila envolvendo os diastereoisômeros cis- e trans-isohumulonas, bem como as misturas cis- e trans-dihidro-isohumulonas, e cis- e trans-tetrahidro-isohumulonas, todos em sua forma aniônica.

Tabela 3. Constantes de velocidade aparentes da reação entre o radical 1-hidroxietila e os iso- $\alpha$-ácidos e seus derivados, em sua forma aniônica, determinadas por EPR e ESI-(+)-MS/MS, em 1 minuto de amostragem.

\begin{tabular}{ccc}
\hline & $\begin{array}{c}\text { EPR } \\
\left(\mathrm{L} \mathrm{mol}^{-1} \mathrm{~s}^{-1}\right)\end{array}$ & $\begin{array}{c}\text { ESI-(+)-MS/MS } \\
\left(\mathrm{L} \mathrm{mol}^{-1} \mathrm{~s}^{-1}\right)\end{array}$ \\
\hline trans-isohumulonas & $9,710^{9}$ & $8,610^{9}$ \\
cis-isohumulonas & $1,810^{8}$ & $1,710^{8}$ \\
$\begin{array}{c}\text { isohumulonas } \\
\text { (cis- e trans-) }\end{array}$ & $1,310^{9}$ & $1,210^{9}$ \\
$\begin{array}{c}\text { dihidro-isohumulonas } \\
\text { (cis- e trans-) }\end{array}$ & $1,510^{9}$ & $1,410^{9}$ \\
$\begin{array}{c}\text { tetrahidro-isohumulonas } \\
\text { (cis- e trans-) }\end{array}$ & reação não observada \\
\hline
\end{tabular}

Conforme pode ser observado, as trans-isohumulonas apresentaram maior reatividade perante o radical 1-hidroxietila que os demais compostos apresentados, sendo as constantes de velocidade aparentes destas 50 vezes maior que as 
apresentadas pelos diastereoisômeros cis-. Considerando os percentuais de iso- $\alpha$-ácidos presentes no extrato de lúpulo utilizado, bem como as constantes de velocidade aparentes obtidas para cada diastereoisômero cis- e trans-iso- $\alpha$-ácidos, pode-se inferir matematicamente a constante de velocidade aparente ( $k_{\text {obs }}$ ') verificada para a reação decorrente da mistura destes compostos, mantendo a mesma razão cis-/trans- presente no extrato de lúpulo isomerizado.

$$
\mathrm{k}_{\mathrm{obs}}{ }^{\prime}=\frac{\left(\mathrm{k}_{\text {trans }}{ }^{*} \% \text { trans- }\right)+\left(\mathrm{k}_{\text {cis }}{ }^{*} \% \text { cis- }\right)}{2}
$$

Assim, pela Equação 2 e sabendo os teores (\%) de diastereisômeros cis- e trans- presentes no extrato de lúpulo, $70 \%$ e $30 \%$ respectivamente, o valor de kobs' calculado foi aproximadamente $1,410^{9} \mathrm{~L} \mathrm{~mol}^{-1} \mathrm{~s}^{-1}$. Este valor está de acordo com as constantes de velocidade aparentes verificadas na reação entre o radical e as isohumulonas, formas cis- e trans-, advindas no extrato de lúpulo.

Em adição, foi efetuado um estudo com respeito à reatividade dos derivados reduzidos e hidrogenados dos iso- $\alpha$-ácidos frente o radical 1-hidroxietila. Neste contexto, da cinética de competição, verificou-se que as constantes de velocidades aparentes determinadas na reação entre as dihidro-isohumulonas, contendo a mistura distereisomérica, e o radical 1-hidroxietila foram estatisticamente iguais $(p=0,05)$ às constantes obtidas utilizando a mistura cis- e trans-isohumulonas. No entanto, as tetrahidro-isohumulonas, contendo mistura cis- e trans-, não se mostraram reativas frente o radical 1-hidroxietila. Isto é um indício de que o sítio reacional envolvido na reação apresenta uma dependência com as insaturações presentes nas cadeias laterais em $\mathrm{C} 5$ e $\mathrm{C} 4$ referentes aos grupos prenila e isoxehenoila, uma vez que os derivados hidrogenados dos iso- $\alpha$-ácidos possuem suas cadeias laterais saturadas. 
Paralelamente, a reatividade das frações 2 isoladas do sistema HPLC semipreparativo contendo os diastereoisômeros, cis- e trans-iso- $\alpha$-ácidos, foi investigada frente o radical 1-hidroxietila utilizando-se o espectrômetro de massas (ESI-(+)-MS/MS). Conforme mencionado no texto, estas frações continham as iso-nhumulonas em considerável grau de pureza (95\% para cis-iso-a-ácidos e 85\% para trans-iso-a-ácidos). Entretanto, não se testou a reatividade da fração 1 de cada configuração devido ao fato destas apresentarem elevado grau de impurezas. Ainda, é interessante salientar que as iso-n-humulonas contidas nas frações 2 estão presentes em sua forma molecular, uma vez que os solventes de eluição utilizados estavam acidificados com ácido fórmico (1\%), conforme pode ser constatado no procedimento experimental.

Desta forma, de acordo com a Tabela 4, verifica-se que, de fato, as constantes de velocidade aparentes obtidas utilizando os iso- $\alpha$-ácidos protonados são estatisticamente iguais $(p=0,05)$ às constantes de velocidade aparentes verificadas para estes compostos em sua forma desprotonada. Sendo assim, podese inferir que o mecanismo da reação em questão independe dos grupos substituintes R (isobutila, isopropila, sec-butila).

Tabela 4. Constantes de velocidade aparentes da reação entre o radical 1-hidroxietila e as iso-n-humulonas, em sua forma molecular, determinadas ESI-(+)-MS/MS, em 1 minuto de amostragem.

\begin{tabular}{cc}
\hline & $\mathrm{ESI}-(+)-\mathrm{MS} / \mathrm{MS}\left(\mathrm{L} \mathrm{mol}^{-1} \mathbf{~ s}^{-1}\right)$ \\
\hline trans-iso-n-humulonas & $8,710^{9}$ \\
cis-iso-n-humulonas & $1,610^{8}$ \\
\hline
\end{tabular}


As constantes de velocidade obtidas da reação entre as isohumulonas e o radical 1-hidroxietla estão próximas ao limite da difusão em meio aquoso, no qual as constantes de velocidade são da ordem de $10^{10} \mathrm{~L} \mathrm{~mol}^{-1} \mathrm{~s}^{-1}$, sendo o encontro das espécies em solução suficiente para que a reação se processe. Portanto, os dados demonstram a alta reatividade destes compostos frente ao radical estudado.

Para um maior entendimento do mecanismo envolvido neste tipo de reação, principalmente no que se refere à diferença de reatividade verificada entre os diastereisômeros com o radical de interesse, efetuou-se cálculos quânticos $a b$ initio com as estruturas químicas dos iso-a-ácidos com o intuito de determinar as propriedades eletrônicas dos compostos. Desta forma, os dados obtidos encontramse na Tabela 5.

Tabela 5. Propriedades eletrônicas dos diastereisômeros cis- e trans-iso-a-ácidos, em sua forma molecular, calculadas usando o método $M 06 / 6-31+G(d)$.

\begin{tabular}{|c|c|c|}
\hline & cis- & trans- \\
\hline Momento Dipolo (Debye) & 2,2 & 2,4 \\
\hline $\begin{array}{l}\left.\text { Energia do orbital HOMO ( } \mathrm{E}_{\text {номо }}\right) \\
\text { (u.a.) }\end{array}$ & $-0,2453$ & $-0,2394$ \\
\hline $\begin{array}{l}\text { Entalpia de Dissociação da Ligação } \\
\qquad \text { C- } \mathrm{H}_{\mathrm{Ca}}(\mathrm{BDE})\left(\mathrm{kcal} \mathrm{mol} \mathrm{mo}^{-1}\right)\end{array}$ & 75,1 & 75,5 \\
\hline $\begin{array}{l}\text { Entalpia de Dissociação da Ligação } \\
\text { C- } \mathrm{H}_{\mathrm{Cb}}(\mathrm{BDE}) \text { (kcal mol') }\end{array}$ & 77,6 & 75,5 \\
\hline
\end{tabular}

Neste contexto, através da leitura da Tabela 5, verifica-se que as transisohumulonas apresentam um maior dipolo elétrico que os diastereoisômeros cis-, sugerindo uma maior influência do solvente nas reações envolvendo as espécies trans-. A Figura 37 apresenta as configurações espaciais mais estáveis para as moléculas dos iso- $\alpha$-ácidos, bem como uma representação vetorial dos momentos de dipolo elétrico verificados. 

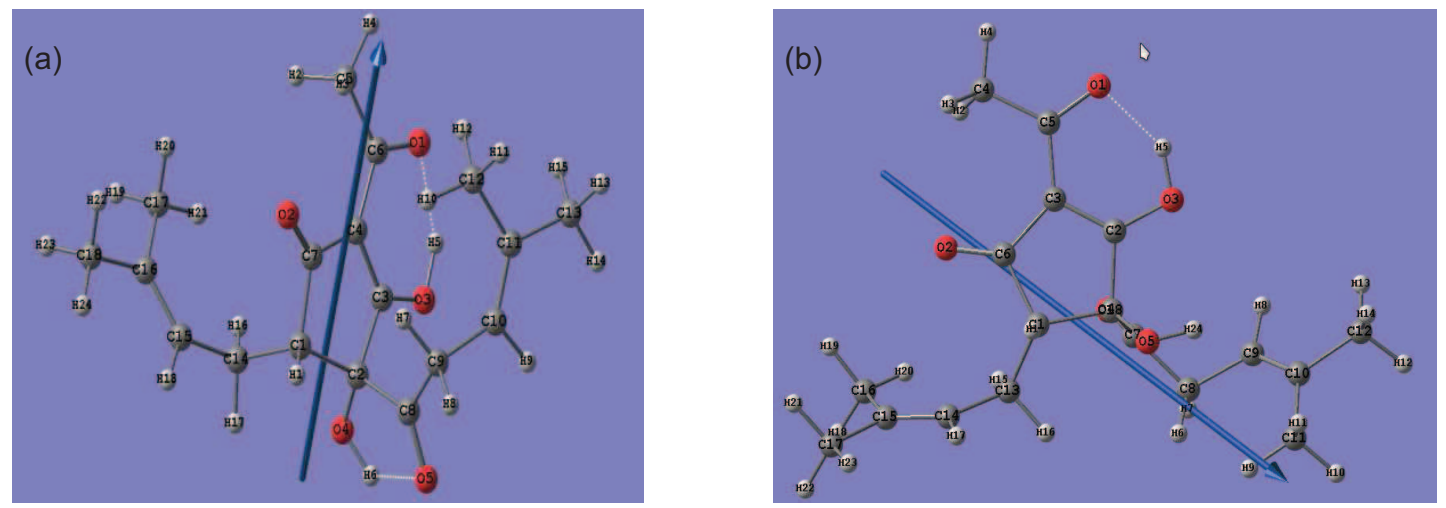

Figura 37. Configuração espacial das cis-isohumulonas (a) e trans-isohumulonas (b), com os respectivos momentos de dipolo elétrico.

Ainda, constatou-se que a conformação cis- é mais estável termodinamicamente que a forma trans-, pois a diferença entre as energias totais verificadas para as moléculas de cis- e trans-iso- $\alpha$-ácidos foi 3,8 $\mathrm{kcal} \mathrm{mol}^{-1}$.

Todavia, pela análise dos orbitais de fronteira, verificou-se que as energias dos orbitais moleculares HOMO (orbital molecular ocupado de maior energia) das espécies cis- e trans- apresentam valores próximos, não justificando, desta forma, a diferença na reatividade destes compostos frente ao radical. O gráfico do contorno dos orbitais moleculares HOMO para as estruturas otimizadas dos diastereoisômeros estão ilustrados na Figura 38. Aqui, verifica-se uma contribuição dos mesmos átomos para o orbital HOMO das cis- e trans-isohumulonas, estando estes localizados no cromóforo $\beta$-tricarbonílico e principalmente sobre a cadeia lateral conectada ao carbono $\mathrm{C} 5$, referente ao grupo prenila. 


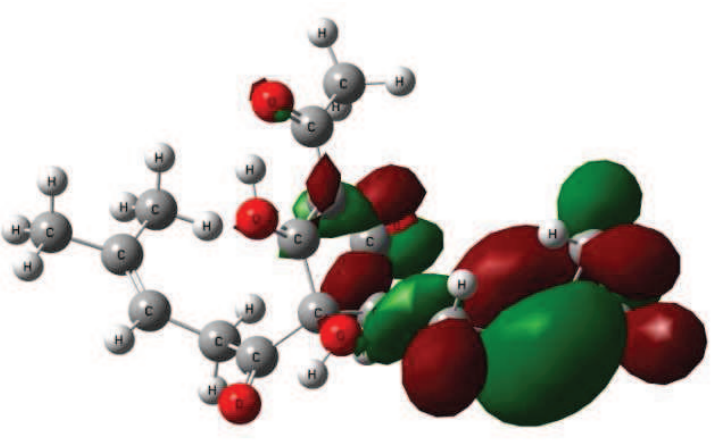

(a)

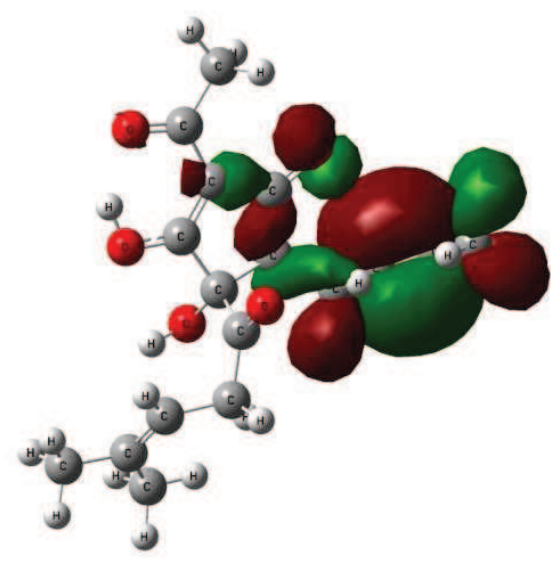

(b)

Figura 38. llustração dos orbitais moleculares ocupados de maior energia (HOMO) calculados para os diastereoisômeros cis- (a) e trans-isohumulonas (b).

Em estudo recente ${ }^{42}$, constatou-se que reações de oxidação de alguns metil ésteres derivados de ácidos graxos insaturados, tais como metil oleato, metil linoleato e metil linolenato $\left(E_{o x} \sim 2,0 \vee v s\right.$. $\left.N H E\right)$, ocorrem preferencialmente via transferência de átomo de hidrogênio (BDE $=328,9,291,5,290,5$, respectivamente) em detrimento ao processo de transferência de elétron. Este fato pode ser estendido à reação entre os iso- $\alpha$-ácidos e o radical 1-hidroxietila ao eliminar a possibilidade de oxidação do grupo prenila por transferência de elétron.

Ainda, sabe-se que a oxidação do cromóforo $\beta$-tricarbonílico dos iso- $\alpha$-ácidos pelo radical por transferência de elétron é termodinamicamente inviabilizada. De fato, analisando os potenciais dos compostos envolvidos, verifica-se que o potencial

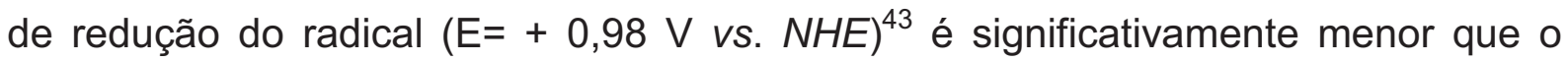
potencial de oxidação dos compostos envolvidos, considerando tanto a forma molecular $(1,8 \mathrm{~V} v s$. $N H E)$ quanto a forma aniônica $(1,4 \vee v s$. NHE). Logo, a partir destes dados, verifica-se a não dependência estereoquímica do potencial de oxidação na reação em questão, sendo esta governada pelo processo de oxidação via transferência de átomo de hidrogênio alílico. 
No entanto, pela leitura das entalpias de dissociação das ligações C-H referentes aos grupos prenila e isohexenoila, $C_{a}$ e $C_{b}$, Figura 39, constata-se que este parâmetro não justifica a diferença na reatividade apresentada pelas isohumulonas. Conforme nota-se na Tabela 5, estes dados não diferem significativamente, sendo um forte indício de que a abstração do átomo de hidrogênio ocorra tanto na cadeia lateral do carbono C4 referente ao grupo isohexenoila, quanto na cadeia lateral do carbono C5, grupo prenila.

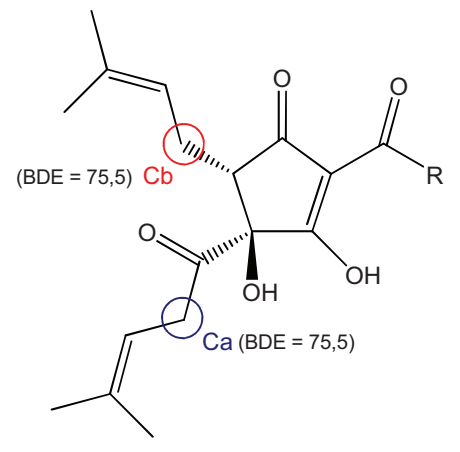

(a)

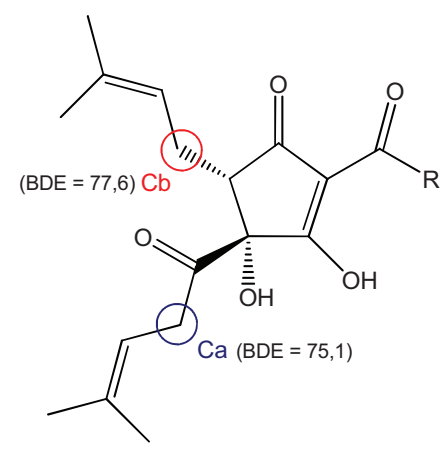

(b)

Figura 39. Representação das ligações $\mathrm{C}-\mathrm{H}$ envolvidas na abstração do átomo de hidrogênio na reação. (a) trans-isohumulonas; (b) cis-isohumulonas.

Portanto, é possível inferir que a reação dos iso-a-ácidos com o radical 1-hidroxietila ocorre preferencialmente via abstração de átomo de hidrogênio alílico tanto nas moléculas das cis-isohumulonas, quanto nas moléculas das espécies trans-. Ainda, diante deste conjunto de dados, constata-se que o aumento da reatividade é decorrente de um fator entrópico, já que a reação com a espécie transisohumulonas ocorre no mesmo plano espacial enquanto que para os distereoisômeros cis- os grupos encontram-se em diferentes planos. 
4.4.3.2. Reatividade de alguns fenóis frente ao radical 1-hidroxietila.

Determinou-se também a constante de velocidade aparente da reação entre o radical 1-hidroxietila e a quercetina por ESI-(+)-MS/MS para fins de validação do método ao comparar a constante obtida com a constante reportada na literatura ${ }^{31}$. Neste caso, as mesmas condições experimentais foram mantidas, exceto pelo fato de que as medidas foram realizadas em solução alcoólica $(90 \%)$ devido à baixa solubilidade da quercetina em meio aquoso. Assim, a constante de velocidade aparente obtida foi $3,110^{4} \mathrm{~L} \mathrm{~mol}^{-1} \mathrm{~s}^{-1}$, sendo a constante de velocidade específica da reação em questão igual a $4,010^{4} \mathrm{~L} \mathrm{~mol}^{-1} \mathrm{~s}^{-1}$, segundo determinado por radiólise de pulso por Marfak e Trouillas ${ }^{30}$. De fato, apesar da constante de velocidade obtida pela cinética de competição aparentar ser diferente da constante de velocidade específica, esta diferença não é significativa, uma vez que a constante aqui determinada apresenta um erro relativamente grande. Assim, a constante de velocidade especifica está contida na faixa abordada pela constante de velocidade aparente. Portanto, a nova metodologia desenvolvida (ESI-(+)-MS/MS) está validada para este fim.

Logo, uma vez validada a determinação das constantes de velocidade aparentes da reação do radical 1-hidroxietila com os compostos em estudo utilizando o detector espectrômetro de massas (ESI-(+)-MS/MS), a reatividade do radical perante os ácidos p-cumárico, cafeico e clorogênico foi determinada com o intuito de avaliar o grau de competição destes compostos fenólicos comparada aos iso- $\alpha$-ácidos na captação do radical 1-hidroxietila. Para tanto, seguiu-se a mesma metodologia utilizada nas reações em que as isohumulonas foram empregadas. 
Assim, da cinética de competição, obteve-se uma constante de velocidade aparente da reação do ácido p-cumário frente o radical igual a $1,010^{7} \mathrm{~L} \mathrm{~mol}^{-1} \mathrm{~s}^{-1}$. Entretanto, para o ácido cafeico e clorogênico um comportamento distinto foi verificado. Neste caso, pela análise das áreas do ín $240 \mathrm{~m} / \mathrm{z}$ isolado (aduto radical), Figura 40, inerente às reações, verifica-se que as áreas dos picos 2 e 3, referentes as reações processadas na presença dos ácidos clorogênico e cafeico, respectivamente, mostraram-se maior que a área do pico 1, o qual remete à reação do 4-POBN com o radical 1-hidroxietila.

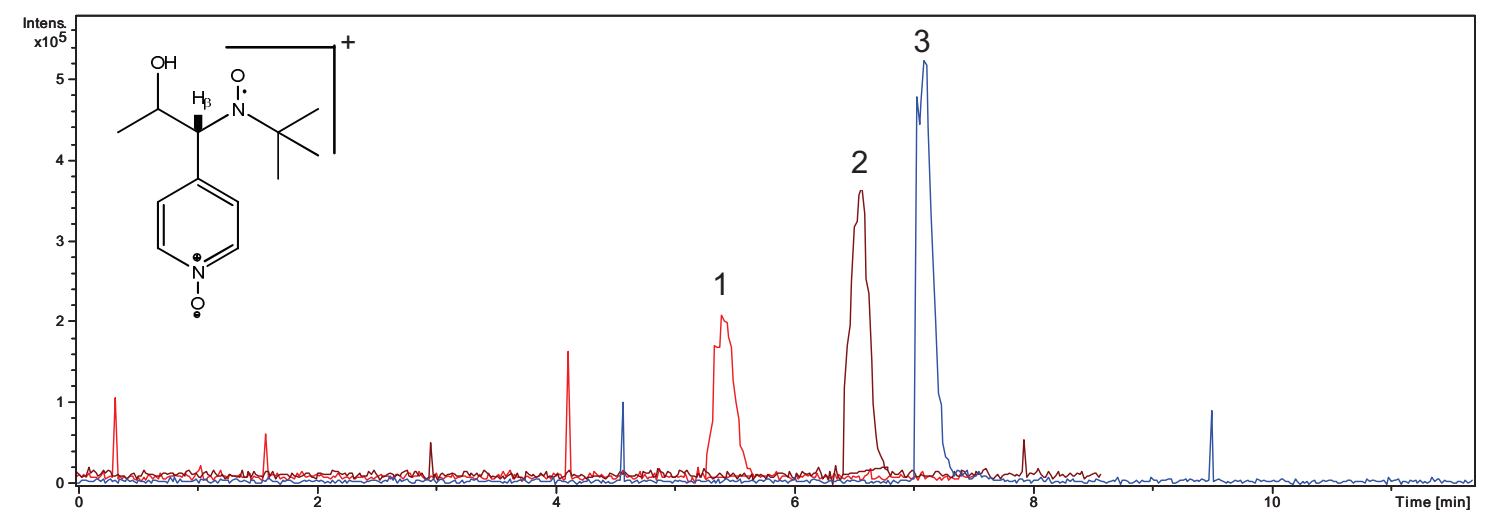

Figura 40. Espectro de íon isolado $240,1 \mathrm{~m} / \mathrm{z}$ decorrente da reação do radical 1-hidroxietila e 4-POBN (pico 1), na presença de ácido clorogênico (pico 2) ou ácido cafeico (pico 3). As injeções foram realizadas em batelada.

Estas últimas reações foram analisadas também por RPE. Analogamente, é notório o acréscimo das áreas referentes à detecção do aduto radical [4-POBN/CH( $\left.\left(\mathrm{CH}_{3}\right) \mathrm{OH}\right]^{\bullet}$ nas reações conferidas na presença dos ácidos clorogênico e cafeico, Figura 41. Consequentemente, estes dados corroboraram com os resultados observados por ESI-(+)-MS/MS. 


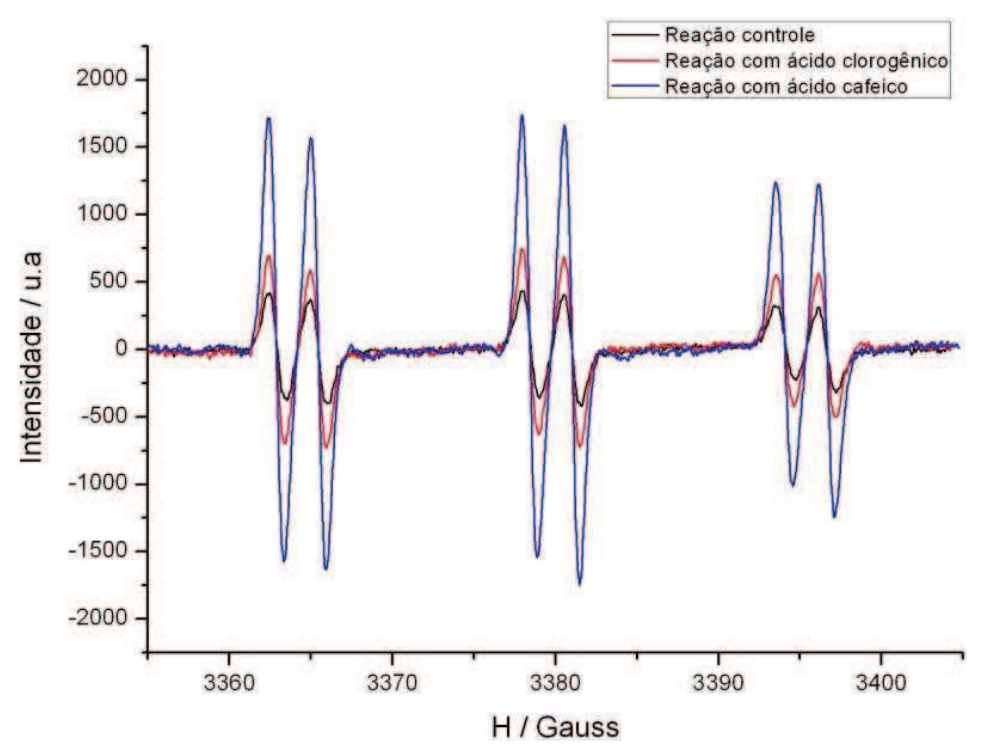

Figura 41. Espectros de ressonância paramagnética de elétrons (RPE) registrados em banda-X $(9,521 \mathrm{GHz})$ do aduto radical [4-POBN/CH$\left(\mathrm{CH}_{3}\right) \mathrm{OH}$ ] decorrente da reação controle (em preto), reação processada na presença ácido clorogênico (em vermelho) e reação processada na presença do ácido cafeico (em azul). Os espectros foram obtidos a temperatura de $25^{\circ} \mathrm{C}$.

De fato, aqui não se verifica uma cinética de competição propriamente dita, uma vez que os ácidos envolvidos não reagem exclusivamente com o radical. Todavia, segundo Sakihama et. all. ${ }^{44}$ os ácidos cafeico e clorogênico reagem facilmente com íons de $\mathrm{Fe}(\mathrm{III})(\mathrm{E}=+0,77 \mathrm{Vvs} \text {. NHE })^{45}$ reduzindo-o a espécie $\mathrm{Fe}(\mathrm{II})$. Este feito é suportado pelos baixos potencias de redução dos ácidos clorogênico e cafeico, 0,59 e $0,55 \vee$ vs. $N H E^{46,47}$, respectivamente.

Em estudo recente foi demonstrado que polifenóis contendo o grupo catecol atuam no processo de oxidação do vinho ${ }^{48}$. Neste contexto, os fenóis reduzem o $\mathrm{Fe}(\mathrm{III})$ a espécie $\mathrm{Fe}(\mathrm{II})$, o qual reagem como o oxigênio molecular para formar o radical hidroperoxila $\left(\cdot \mathrm{OOH} ; \mathrm{pK}_{\mathrm{a}} \sim 4,7\right)^{49}$. No entanto, este radical é rapidamente extinto pelos fenóis ao gerar peróxido de hidrogênio na bebida que, pela Reação de Fenton, culmina na formação do radical hidroxila $(\cdot \mathrm{OH})$. Portanto, estes compostos fenólicos atuam como pró-oxidantes no sistema, acentuando a formação do radical 
1-hidroxietila, conforme demonstrado no Esquema 8, e, consequentemente, induzem a deterioração da bebida.

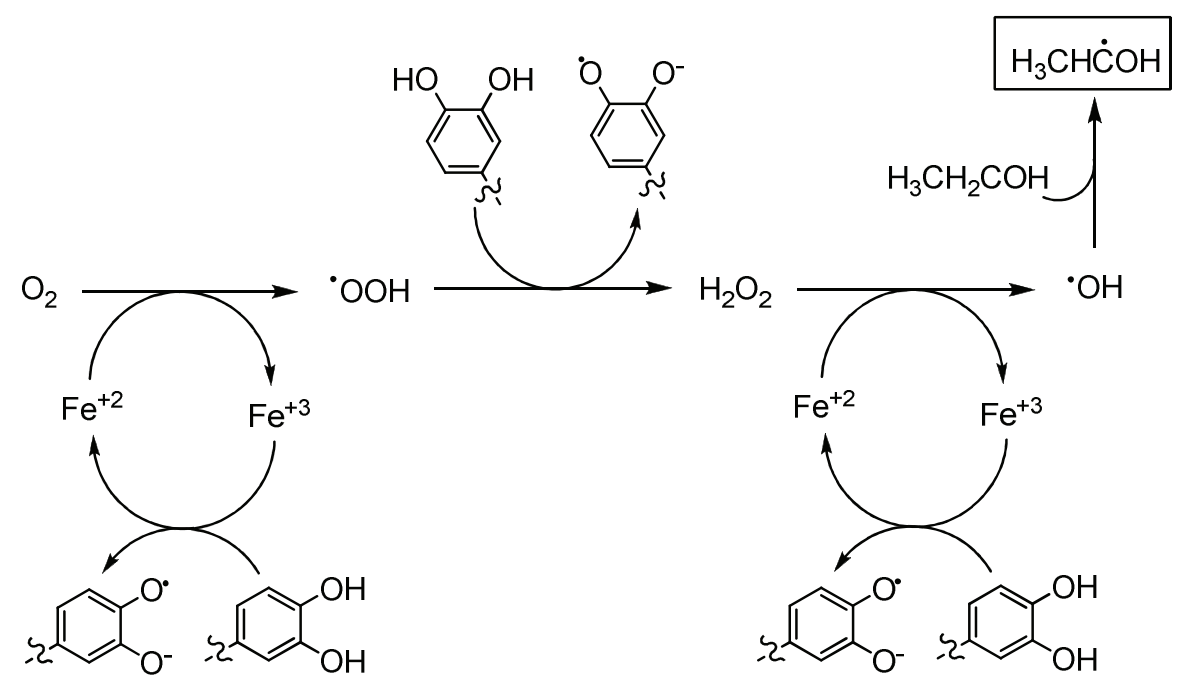

Esquema 8. Esquema de reação propondo o efeito de polifenóis contendo o grupo catecol na oxidação do etanol no vinho e na cerveja. Adaptado de Elias e Andersen ${ }^{48}$.

Ainda, de acordo com os dados, um maior efeito pró-oxidante foi conferido ao ácido cafeico, uma vez que as áreas referentes à detecção do aduto radical, por ambas as técnicas, foram significativamente maior para a reação contendo este ácido. Este conjunto de dados corrobora com o relatado na literatura ${ }^{44}$.

4.5. Identificação dos produtos de reação.

Os produtos da reação entre os iso- $\alpha$-ácidos e o radical 1-hidroxietila foram identificados por LC-ESI-MS ${ }^{n}$ utilizando as trans-isohumulonas como substrato. Desta forma, a Figura 42a apresenta o cromatograma resultante da mistura reacional obtido após 1 minuto de reação (em azul), bem como o perfil cromatográfico de íons total de uma solução alcoólica (etanol) contendo os diastereoisômeros trans- (em vermelho). Aqui, pode-se notar que, na mistura 
reacional, as espécies trans- não foram completamente consumidas na reação, sendo os picos 3, 4, 5 e 6 referentes as eluições dos análogos das trans-humulonas, em ( $\left.t_{r}\right) 26,1,27,7,29,6$ e 31,9 minutos, respectivamente. Ainda, do cromatograma de íons total respectivo à mistura reacional, verificou-se a formação de dois novos picos em $\left(t_{r}\right) 17,7$ minutos, pico 1, e 21,5 minutos, pico 2. O primeiro pico apresentam o íon $[\mathrm{M}-\mathrm{H}]^{-} 363 \mathrm{~m} / \mathrm{z}$ referente às moléculas desprotonadas, Figura $\mathbf{4 2 b}$, ao passo que o íon das moléculas desprotonadas [M-H] $]^{-}$do segundo pico foi 377 m/z, Figura 42c. 


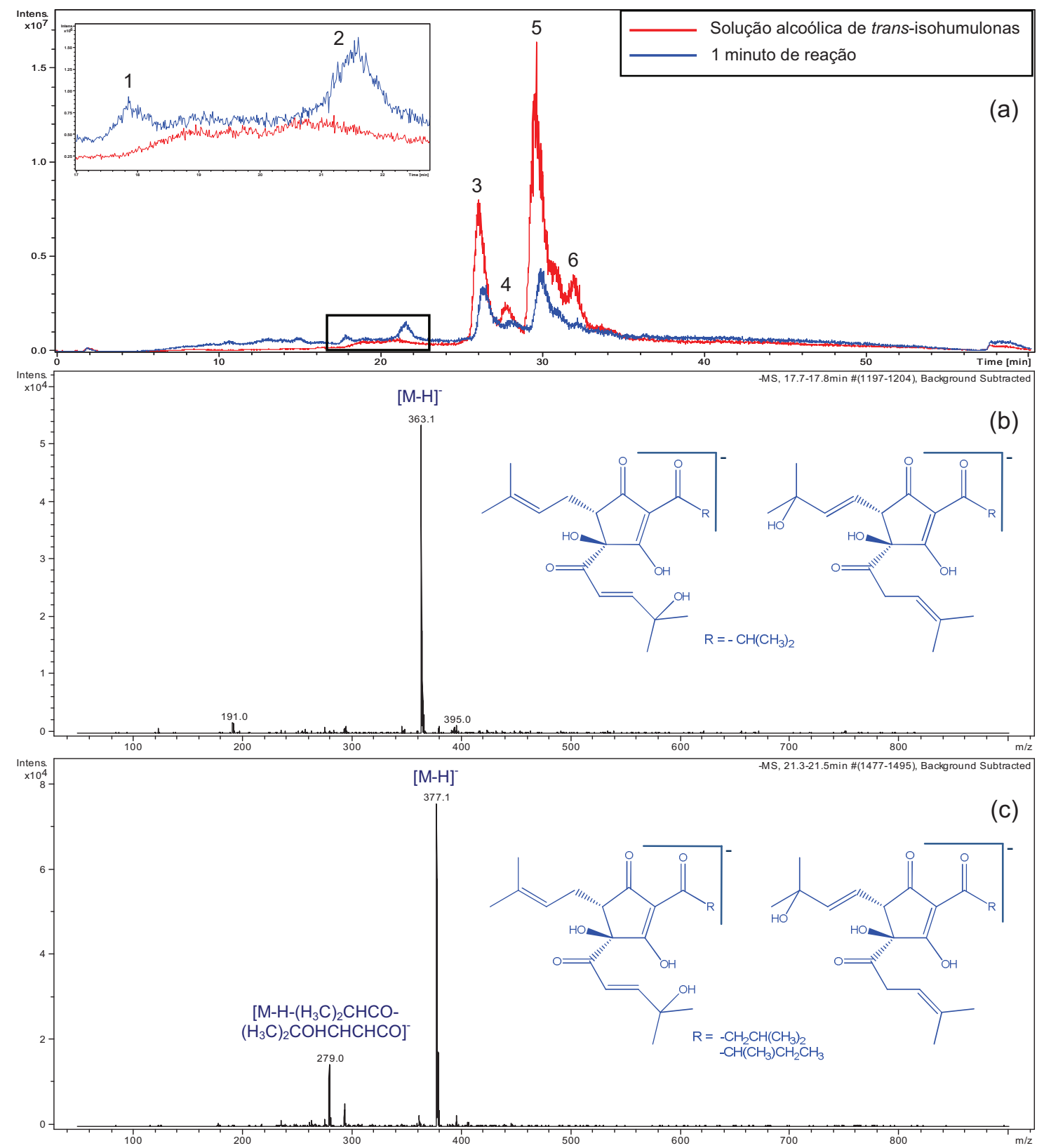

Figura 42. (a) Cromatograma de íons total da solução alcoólica contendo as trans-isohumulonas (em vermelho) e dos produtos decorrentes da reação das trans-isohumulonas e o radical 1-hidroxietila (em azul),sob atmosfera de $\mathrm{Ar}, \mathrm{T}=25^{\circ} \mathrm{C}, \mathrm{t}=1$ minuto de reação. (b) Espectro de massas (ESI(-)MS) com atribuição do íon do eluato em $\mathrm{t}_{\mathrm{r}}=17,7 \mathrm{~min}$. (c) Espectro de massas (ESI(-)MS) com atribuição do íon do eluato em $\mathrm{t}_{\mathrm{r}}=21,5 \mathrm{~min}$.

De fato, Intelmann et. all. ${ }^{17}$ e Haseleu et. all. ${ }^{18}$ apontaram recentemente compostos presentes na cerveja decorrentes da degradação dos iso-a-ácidos, cujas massas moleculares são 364 e $378 \mathrm{~g} \mathrm{~mol}^{-1}$. Estes compostos são gerados a partir da oxidação de ambos os diastereoisôemeros cis- e trans- na ausência de luz e presença de traços de oxigênio molecular e metais de transição, tais como $\mathrm{Fe}(\mathrm{II})$. 
Ainda, conforme consta na literatura, os produtos de degradação em questão apresentam a estrutura química dos iso- $\alpha$-ácidos contendo um grupo hidroxila na cadeia lateral conectada ao carbono C4, grupo isohexenoila, recebendo a denominação hidroxi-allo-isohumulonas.

Todavia, pelos espectros de massas referentes às fragmentações secundárias dos íons das moléculas desprotonadas apresentados, 363 e $377 \mathrm{~m} / \mathrm{z}$, contidos no Apêndice $\mathbf{C}$, não foi possível inferir a estrutura química exata dos compostos. Neste contexto, é admissível tanto a cadeia lateral conectada ao carbono C4 quanto a cadeia lateral em C5 apresentar o grupo hidroxila adicionado. Conforme já exposto no texto, constatou-se pelos cálculos das entalpias de dissociação das ligações $\mathrm{C}-\mathrm{H}_{\mathrm{Ca}}$ e $\mathrm{C}-\mathrm{H}_{\mathrm{Cb}}$ que ambos os átomos de hidrogênios pertencentes aos grupos isohexenoila e prenila são suscetíveis a serem abstraídos. Logo, pode-se inferir que o íon $363 \mathrm{~m} / \mathrm{z}$ é referente a dois compostos derivados das isocohumulonas, os quais um contém um grupo hidroxila adicionado à cadeia lateral em C4 - isohexenoila, sendo o outro composto resultante da adição de um grupo hidroxila à cadeia lateral conectada ao carbono C5 - prenila. O mesmo feito foi verificado para os compostos decorrentes da degradação dos homólogos iso-nhumulonas $\mathrm{e}$ isoadhumulonas, os quais apresentam o íon das moléculas desprotonadas $[\mathrm{M}-\mathrm{H}]^{-} 377 \mathrm{~m} / \mathrm{z}$.

4.6. Mecanismo da reação.

O mecanismo da reação proposto, no presente trabalho, envolvendo os iso- $\alpha$-ácidos e o radical 1-hidroxietila está contemplado no Esquema 9. Neste 
contexto, a reação é iniciada pela abstração de um átomo de hidrogênio contido no grupo prenila ou e isohexenoila pertencentes às cadeias laterais das isohumulonas. Esta abstração se dá pelo radical 1-hidroxietila, resultando em um radical terciário estabilizado por ressonância.

Sabe-se que o nível de oxigênio residual dissolvido na cerveja (garrafa) gira em torno de $0,1 \mathrm{mg} \mathrm{L}^{-1}{ }^{14}$, o qual é responsável por causar várias reações de degradação da bebida durante a sua estocagem. Desta forma, o oxigênio tripleto reage com $\circ$ radical terciário supracitado gerando o radical peroxil, o qual posteriormente abstrai um átomo de hidrogênio de substratos passíveis de sofrer oxidação, tais como etanol ou iso- $\alpha$-ácidos, culminando na formação dos hidroperóxidos, chamados de hidroperoxi-alloisohumulonas. Ainda, a presença de traços de íons metálicos tais como ferro $(\mathrm{Fe}(\mathrm{II}))$ conduz a clivagem dos grupos hidroperóxidos e, após a abstração de mais um átomo de hidrogênio de substratos, os hidróxidos são formados, sendo estes denominados hidroxi-alloisohumulonas.

Outro caminho reacional consiste na reação entre o radical hidroxila, gerado constantemente na solução, e o radical terciário derivado das isohumulonas. Como resultado, temos a formação direta dos hidróxidos identificados. Este mecanismo é suportado pelo fato da constante de velocidade da reação entre os radicais supracitados ser próxima ao limite difusional. 
$\mathrm{R}=\mathrm{CH}\left(\mathrm{CH}_{3}\right)_{2}$

$\mathrm{R}=\mathrm{CH}_{2} \mathrm{CH}\left(\mathrm{CH}_{3}\right)_{2} \quad$ (b)

$\mathrm{R}=\mathrm{CH}\left(\mathrm{CH}_{3}\right) \mathrm{CH}_{2} \mathrm{CH}_{3} \quad$ (c)

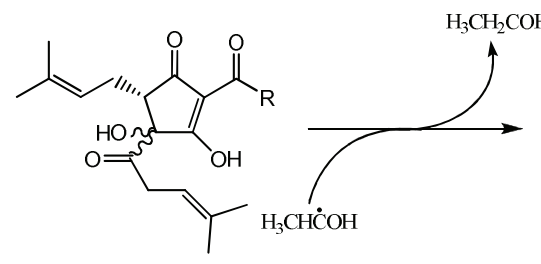

isohumulonas

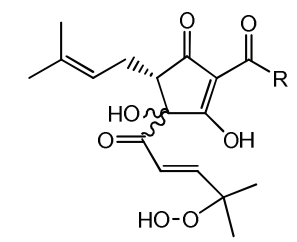

hidroperoxi-alloisohumulonas
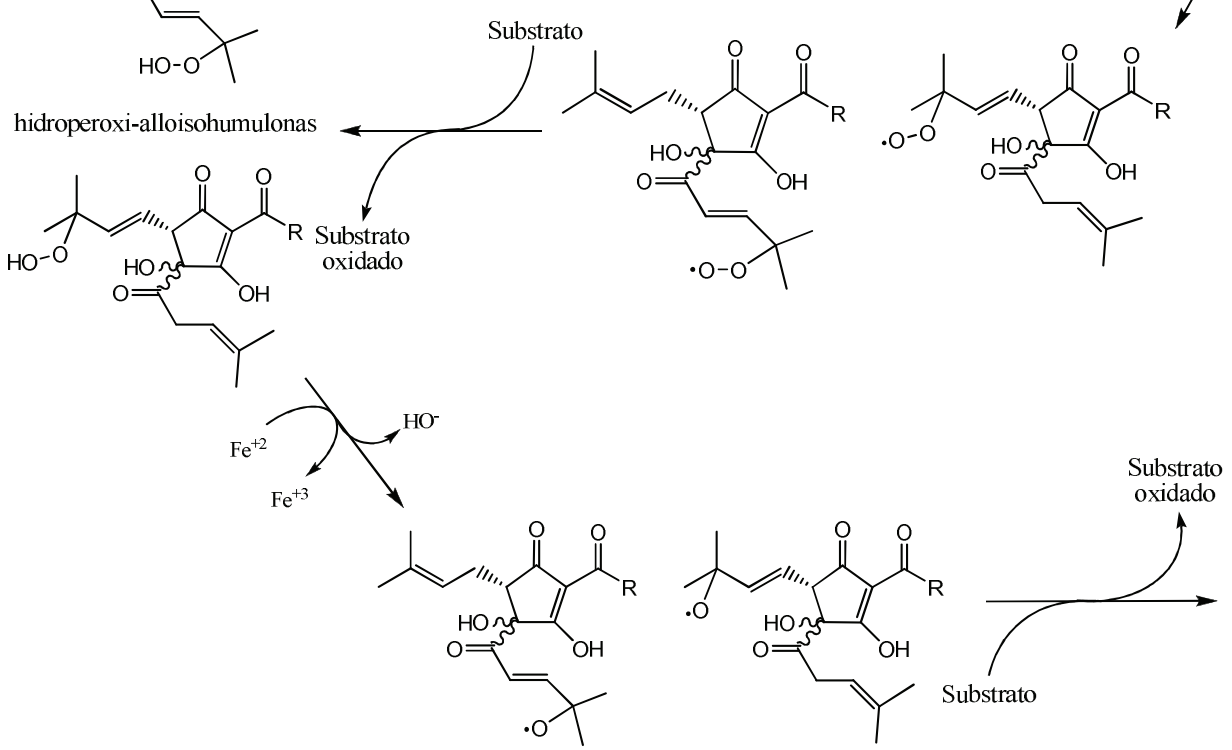
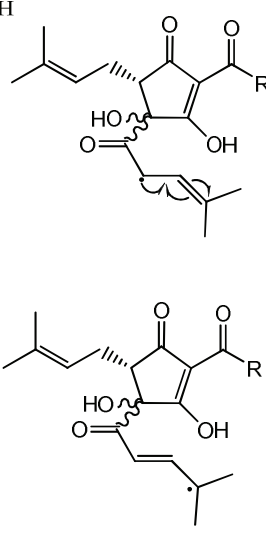

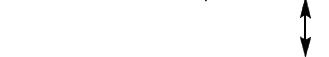
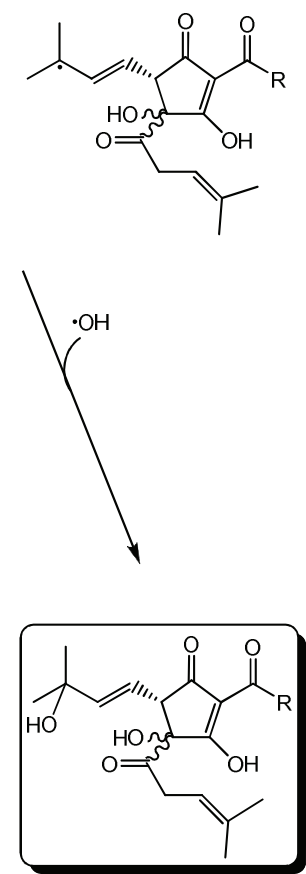

hidroxi-alloisohumulonas

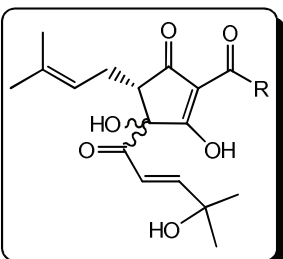

Esquema 9. Mecanismo proposto para a reação entre as isohumulonas e o radical 1-hidroxietila.

Logo, verificou-se que os iso-a-ácidos sofrem degradação via reação radical, formando hidróxidos. Entretanto, estudos sobre estes compostos de degradação ainda estão na fase inicial; consequentemente, não se sabe o efeito sensorial que estes conferem a bebida. 


\section{CONCLUSÕES}

Como um todo, os diastereoisômeros trans- e cis-isohumulonas, bem como as tetrahidro-isohumulonas e dihidro-isohumulonas foram obtidas de forma eficaz constatada pela posterior caracterização. A reatividade destes compostos frente o radical 1-hidroxietila foi estudada através de uma abordagem cinética de competição envolvendo a armadilha química 4-POBN, além dos compostos supracitados. Assim, analisando a reação entre o 4-POBN e o radical de interesse, verificou-se a formação de quatro produtos decorrentes da reação: aduto radical [4-POBN/CH$\left.\left(\mathrm{CH}_{3}\right) \mathrm{OH}\right]^{0},[\mathrm{M}+\mathrm{H}]^{+} 240 \mathrm{~m} / \mathrm{z}$; aduto oxidado, $[\mathrm{M}+\mathrm{H}]^{+} 239 \mathrm{~m} / \mathrm{z}$; e duas espécies cujas estruturas são referente à molécula do 4-POBN ligada a duas moléculas do radical 1-hidroetila, $[\mathrm{M}+\mathrm{H}]^{+} 285 \mathrm{~m} / \mathrm{z}$. Ainda, constatou-se que as espécies referentes aos íons 285 e $239 \mathrm{~m} / \mathrm{z}$ estão provavelmente relacionadas às reações subsequentes envolvendo o aduto radical, a partir do consumo deste.

A partir das constantes de velocidade aparentes determinadas, referentes à reação entre o radical de 1-hidroxietila e os iso-a-ácidos, naturais e sintéticos, verificou-se que as técnicas espectroscopia de ressonância paramagnética de elétrons (RPE) e espectrometria de massas (ESI-(+)-MS/MS) foram equivalentes $(p=0,05)$ para esta finalidade. Neste contexto, constatou-se uma maior reatividade por parte dos diastereoisômeros trans- $\left(\sim 9,210^{9} \mathrm{~L} \mathrm{~mol}^{-1} \mathrm{~s}^{-1}\right)$, sendo as espécies cismenos reativas frente ao radical 1-hidroxietila $\left(\sim 1,810^{8} \mathrm{~L} \mathrm{~mol}^{-1} \mathrm{~s}^{-1}\right)$. Em suma, verificou-se que a reação entre os iso- $\alpha$-ácidos e o radical 1-hidroxietila ocorre preferencialmente via abstração de átomo de hidrogênio alílico pertencentes aos grupos laterais prenila e isohexenoila, em ambos os diastereoisômeros cis- e trans- 
iso- $\alpha$-ácidos. Ainda, diante deste conjunto de dados, constatou-se que o aumento de reatividade da espécie trans- está provavelmente relacionada ao fator entrópico.

Análogo a reatividade apresentada pelos iso-a-ácidos, as dihidroisohumulonas, formas cis- e trans-, apresentaram constantes de velocidade aparentes $\left(\sim 1,510^{9} \mathrm{~L} \mathrm{~mol}^{-1} \mathrm{~s}^{-1}\right)$ estatisticamente $(p=0,05)$ iguais as verificadas para a mistura diastereoisomérica de iso- $\alpha$-ácidos $\left(\sim 1,310^{9} \mathrm{~L} \mathrm{~mol}^{-1} \mathrm{~s}^{-1}\right)$, contendo a mesma proporção cis-/trans-. Todavia, os derivados hidrogenados das isohumulonas, as tetrahidro-isohumulonas, não foram reativos frente o radical estudado.

A constante de velocidade aparente da reação entre o ácido p-cumárico e o radical foi determinada por ESI-(+)-MS/MS $\left(1,010^{7} \mathrm{~L} \mathrm{~mol}^{-1} \mathrm{~s}^{-1}\right)$. Assim, ao comparar a reatividade do ácido p-cumárico e outros compostos fenólicos presentes na cerveja, já relatada da literatura ${ }^{30}$, frente o radical 1 -hidroxietila com a reatividade do mesmo radical com os iso- $\alpha$-ácidos, conclui-se que, apesar das substâncias fenólicas estarem presentes em concentração mais elevadas, os ácidos amargos derivados do lúpulo foram mais reativos perante o radical 1-hidroxietila, o que deixa patente a degradação destes e a importância destas reações no processo de envelhecimento da cerveja.

Ainda, os ácidos cafeico e clorogênico mostraram-se pró-oxidantes no sistema, uma vez que estes induzem a formação do radical 1-hidroxietila e acentuam a deterioração da bebida.

Como produto da reação entre os iso- $\alpha$-ácidos e o radical 1-hidroxietila, foram identificados compostos contendo um grupo hidroxila ligado à cadeia lateral isohexenoila ou à cadeia lateral prenila (hidroxi-allo-isohumulonas). Estes compostos foram recentemente reportados na literatura ${ }^{17,18}$ e são decorrentes de reações de 
oxidação das isohumulonas seguindo um mecanismo governado por radicais, na presença de traços de oxigênio e íons de metais de transição tais como Fe(II). 


\section{REFERÊNCIAS BIBLIOGRÁFICAS}

1. GRIGG, D. Wine, spirits and beer: world patterns of consumption. Geography, v. 89, p. 99-110, 2004.

2. SERVIÇO do Sindicato Nacional da Indústria da cerveja SINDICERV. Disponível em: <http://www.sindicerv.com.br/mercado.php>. Acesso em: 15 out. 2010.

3. SILVA, J. B. A. Cerveja. In: VENTURINI FILHO, W. G. (Coord.). Tecnologia de bebidas. São Paulo: Edgard Blucher, 2005. p. 347-356.

4. INTELMANN, D.; DEMMER, O.; DESMER, N.; HOFMANN, T. ${ }^{18} \mathrm{O}$ stable isopote labeling, quantitative model experiments, and molecular dynamics simulation studies on the trans-specific degradation of the bitter tasting iso- $\alpha$-acids of beer. Journal of Agricultural and Food Chemistry, v. 57, p. 11014-11023, 2009.

5. DE KEUKELEIRE, D. Fundamentals of beer and hop chemistry. Química Nova, v. 23, p. 108-112, 2000.

6. BAMFORTH, C. W. Brewing and brewing research: past, present and future. Journal of the Science of Food and Agriculture, v. 80, p. 1371-1378, 2000.

7. DE KEUKELEIRE, D.; HUVAERE, K. Shining light on the photodecomposition of beer. The Spectrum, v. 18, p. 18-25, 2005.

8. DE COOMAN, L.; EVERAERT, E.; DE KEUKELEIRE, D. Quantitative analysis of hop acids, essential oils and flavonoids as a clue to the identification of hop varieties. Phytochemical Analysis, v. 9, p. 145-150, 1998.

9. VERZELE, M.; DE DEKEUKELEIRE, D. Chemistry and analysis of hop and beer bitter acids. Amsterdam: Elsevier, 1991. 417 p..

10. VAN CLEEMPUT, M.; CATTOOR, K.; DE BOSSCHER, K.; HAEGEMAN, G.; DE KEUKELEIRE, D.; HEYERICK, A. Hop (Humulus lupulus)-derived bitter acids as multipotent bioactive compounds. Journal of Natural Products, v. 72, p. 1220-1230, 2009. 
11. HUVAERE, K.; ANDERSEN, M. L.; SKIBSTED, L. H.; HEYERICK, A.; DE KEUKELEIRE, D. Photooxidative degradation of beer bittering principles: a key step on the route to lightstruck flavor formation in beer. Journal of Agricultural and Food Chemistry, v. 53, p. 1489-1494, 2005.

12. HUVAERE, K.; ANDERSEN, M. L.; OLSEN, K.; SKIBSTED, L. H.; HEYERICK, A.; De Keukeleire, D. Radicaloid-type oxidative decomposition of beer bittering agents revealed. Chemistry - A European Journal, v. 9, p. 4693-4699, 2003.

13. KHATIB, A.; WILSON, E. G.; KIM, H. K.; SUPARDI, M.; CHOI, Y. H.; VERPOORTE, R. NMR assignment of iso- $\alpha$-acids from isomerised extracts of Humukus lupulus L. cones. Phytochemical Analysis, v. 18, p. 371-377, 2007.

14. VANDERHAEGEN, B.; NEVEN, H.; VERACHTERT, H.; DERDELINCKX, G. The Chemistry of Beer Aging - a critical review. Food Chemistry, v. 95, p. 357-381, 2006.

15. VANDERHAEGEN, B.; DELVAUX, F.; DAENEN, L.; VERACHTERT, H.; DELVAUX, F. R. Aging characteristics of different beer types. Food Chemistry, v. 103, p. 404-412, 2007.

16. DE COOMAN, L.; AERTS, G.; OVERMEIRE, H.; DE KEUKELEIRE, D. Alterations of the profiles of iso- $\alpha$-acids during beer ageing, marked instability of trans-iso- $\alpha$-acids and implications for beer bitterness consistency in relation to tetrahydroiso- $\alpha$-acids. Journal of the Institute of Brewing, v. 106, p. 169-178, 2000.

17. INTELMANN, D.; HOFMANN, T. On the autoxidation of bitter-tasting iso-a-acids in beer. Journal of Agricultural and Food Chemistry, v. 58, p. 5059-5067, 2010.

18. HASELEU, G.; LAGEMANN, A.; STEPHAN, A.; INTELMANN, D.; DUNKEL, A.; HOFMANN, T. Quantitative sensomics profiling of hop-derivated bitter compounds throughout a full-scale beer manufacturing process. Journal of Agricultural and Food Chemistry, v. 58, p. 7930-7939, 2010.

19. HEYERICK, A.; ZHAO, Y.; SANDRA, P.; HUVAERE, K.; ROELENS, F.; DE KEUKELEIRE, D. Photolysis of hop-derived trans-iso- $\alpha$-acids and transtetrahydroiso- $\alpha$-acids: product identification in relation to the lighstruck flavour of beer. Photochemical \& Photobiological Sciences, v. 2, p. 306-314, 2003. 
20. HUVAERE, K.; OLSEN, K.; ANDERSEN, M. L.; SKIBSTED, L. H.; HEYERICK, A.; DE KEUKELEIRE, D. Riboflavin-sensitized photooxidation of isohumulones and derivatives. Photochemical \& Photobiological Sciences, v. 3, p. 337-340, 2004.

21. HEYERICK, A.; HUVAERE, K.; DE KEUKELEIRE, D.; FORBES, M. D. E. Fate of flavins in sensitized photodegradation of isohumulones and reduced derivatives: studies on formation of radicals via EPR combined with detailed product analyses. Photochemical \& Photobiological Sciences, v. 4, p. 412-419, 2005.

22. HUVAERE, K.; SINNAEVE, B.; BOCXLAER, J. V.; DE KEUKELEIRE, D. Photooxidative degradation of beer bitterng principles: product analysis with respect to lightstruck flavour formation. Photochemical \& Photobiological Sciences, v. 3, p. 854-858, 2004.

23. LUSK, L. T.; MURAKAMI, A.; NIEKSEN, L.; KAY, S.; RYDER, D. Beer Photooxidation creates two compounds with aromas indistinguishable from 3-methyl2-butene-1-thiol. Jorunal of the American Society of Brewing Chemists, v. 67, p. 189-192, 2009.

24. KUNIMUNE, T.; SHELLHAMMER, T. H. Foam-stabilizing affects and cling formation patterns of iso- $\alpha$-acids and reduced iso- $\alpha$-acids in lager beer. Journal of Agricultural and Food Chemistry, v. 56, p. 8629-8634,.2008.

25. ANDERSEN, M. L.; SKIBSTED, L. H. Electron spin resonance spin trapping identification of radicals formed during aerobic forced aging of beer. Journal of Agricultural and Food Chemistry, v. 46, p. 1272-1275, 1998.

26. FREDERIKSEN, A. M.; FESTERSEN, R. M.; ANDERSEN, M. L. Oxidative reactions during early stages of beer brewing studied by electron spin resonance and spin trapping. Journal of Agricultural and Food Chemistry, v. 56, p. 8514-8520, 2008.

27. ELIAS, R. J.; ANDERSEN, M. L.; SKIBSTED, L. H.; WATERHOUSE, A. L. Identification of free radical intermediates in oxidized wine using electron paramagnetic resonance spin-trapping. Journal of Agricultyre and Food Chemistry, v. 57, p. 4359-4365, 2009.

28. BARREIRO, J. C.; CAPELATO, M. D.; MARTIN-NETO, L.; HANSEN, H. C. B. Oxidative decomposition of atrazine by a fenton-like reaction in a $\mathrm{H}_{2} \mathrm{O}_{2}$ /ferrihydrite system. Water Research, v. 41, p. 55-62, 2007. 
29. HRYNTSEVICH, I. B.; SHADYRO, O. I. Reactions of a-hydrixyethyl radicals with flavonoids of various structures. Bioorganic \& Medicinal Chemistry Letters, v. 15, p. 4252-4255, 2005.

30. MARFAK, A.; TROUILLAS, P.; ALLAIS, D. P.; CALLISTE, C. A.; COOKMOREAU, J.; DUROUX, J. Reactivity of flavonoids with 1-hydroxyethyl radical: a Yradiolysis study. Biochimica et Biophysica Acta, v. 1670, p. 28-39, 2004.

31. CARDOSO, D. R.; OLSEN, K.; MØLLER, J. K. S.; SKIBSTED, L. H. Phenol and terpene quenching of singlet and triplet excited statis of riboflavin in relation to lightstruck flavor formation in beer. Journal of Agriculture and Food Chemistry, v. 54, p. 5630-5636, 2006.

32. FLORIDI, S.; MONTANARI, L.; MARCONI, O.; FANTOZZI, P. Determination of free phenolic acids in wort and beer by coulometric array detection. Journal of Agriculture and Food Chemistry, v. 51, p. 1548-1554, 2003.

33. PERRIN, D. D.; ALMARGE, W. L.; PERRIN, D. P. Purification of laboratory chemicals. New York: Pergamon, 1983. 529 p.

34. KHATIB, A.; WILSON, E. G.; SUPARDI, M.; VERPOORTE, R. Isolation of individual hop iso- $\alpha$-acids stereoisomers by $\beta$-cyclodextrin. Food Chemistry, v. 119, p. 354-357, 2010.

35. VANHOENACKER, G.; DE KEUKELEIRE, D.; SANDRA, P. Analysis of iso- $\alpha-$ acids in beer by direct injection and liquid chromatography with ultraviolet absorbance detection or with mass spectrometry. Journal of Chromatography A, v. 1035, p.53-61, 2004.

36. PAVLISHCHUK, V. V.; ADDISON, A. W. Conversion constants for redox potentiols measured versus different reference electrodes in acetonitrile solutions at $25{ }^{\circ} \mathrm{C}$. Inorganica Chimica Acta, v. 298, p. 97-102, 2000.

37. POU, S.; RAMOS, C. L.; GLADWELL, T.; RENKS, E.; CENTRA, M.; YOUNG, D.; CAHEN, M. S.; ROSEN, G. M. A kinetic approach to the selection of a sensitive spin trapping system for the detection of hydroxyl radical. Analytical Biochemistry, v. 217, p. 76-83, 1994. 
38. CARLSEN, C. U.; SKOVGAARD, M.; SKIBSTED, L. H. Pseudoperoxidase activity of myoglobin: kinetics and mechanism of the peroxidase cycle of myoglobin with $\mathrm{H}_{2} \mathrm{O}_{2}$ and 2,2-azino-bis(3-ethylbenzthiazoline-6-sulfonate) as substrates. Journal of Agricultural and Food Chemistry, v. 51, p. 5815-5823, 2003.

39. OGUSUCU, R.; RETTORI, D.; MUNHOZ, D. C.; SOARES NETTO, L. E.; OHARA, A. Reactions of yeast thioredoxin peroxidases I and II with hydrogen peroxide and peroxunitrine: rate constants by competitive kinetics. Free radical Biology \& Medicine, v. 42, p. 326-334, 2007.

40. Winterbourn, C. C. The ability of scavengers to distinguish $\mathrm{OH}^{\circ}$ production in the iron-catalyzed Haber-Weiss reaction: comparison of four assays for $\mathrm{OH}^{\circ}$. Free Radical Biology \& Medicine, v. 3, p. 33-39, 1987.

41. DA SILVA, G.; BOZZELLI, J. W.; LIANG, L.; FARRELL, J. T. Ethanol oxidation: kinetics of the $\alpha$-hydroxyethyl radical $+\mathrm{O}_{2}$ reaction. Journal of Physycochemistry A, v. 113, p. 8923-8933, 2009.

42. HUVAERE, K.; CARDOSO, D. R.; HOMEM-DE-MELLO, P.; WESTERMANN, S.; SKIBSTED, L. H. Light-induced oxidation of unsaturated lipids as sensitized by flavins. The Journal of Physical Chemistry B, v. 114, p. 5583-5593, 2010.

43. KOPPENOL, W. H.; BUTLER, J. Energetics of interconversion reactions of oxyradicals. Advances in Free Radical Biology \& Medicine, v. 1, p. 91-131, 1985.

44. SAKIHAMA, Y.; COHEN, M. F.; GRACE, S. C.; YAMASAKI, H. Plant phenolic antioxidant and prooxidan activities: phenolics-induced oxidative damage mediated by metals in plants. Toxicology, v. 177, p. 67-80, 2002.

45. ATKINS, P.; JONES, L. In. Princípios de química: questionando a vida moderna e o meio ambiente. Porto Alegre: Bookman, 2001. 914 p.

46. JOVANOVIC, S. V.; STEEDEN, S.; TOSIC, M.; MORJANOVIC, B.; SIMICG, M. G. Flavonoids as antioxidants. Journal of American Chemical Society, v. 116, p. 4846-4851, 1994.

47. BOYER, R. F.; CLARK, H. M.; LAROCHE, A. P. Reduction and release of ferritin iron by plant phenolics. Journal of Inorganic Biochemistry, v. 32, p. 171-181, 1998. 
48. ELIAS, R. J.; ANDERSEN, M. L.; SKIBSTED, L. H.; WATERHOUSE, A. L. Key factors affecting radical formation wine studied by spin trapping and EPR spectroscopy. American Journal of Enology and Viticulture, v. 60, p. 471-476, 2009.

49. HEELIS, P. F.; PARSONS, B. J.; PHILLIPS, G. O.; SWALLOW, A. J. Oneelectron oxidation of flavins. A flash photolysis and pulse radlolysis study. Journal of Physical Chemistry, v. 90, p. 6833-6836, 1986. 


\section{APÊNDICE A}

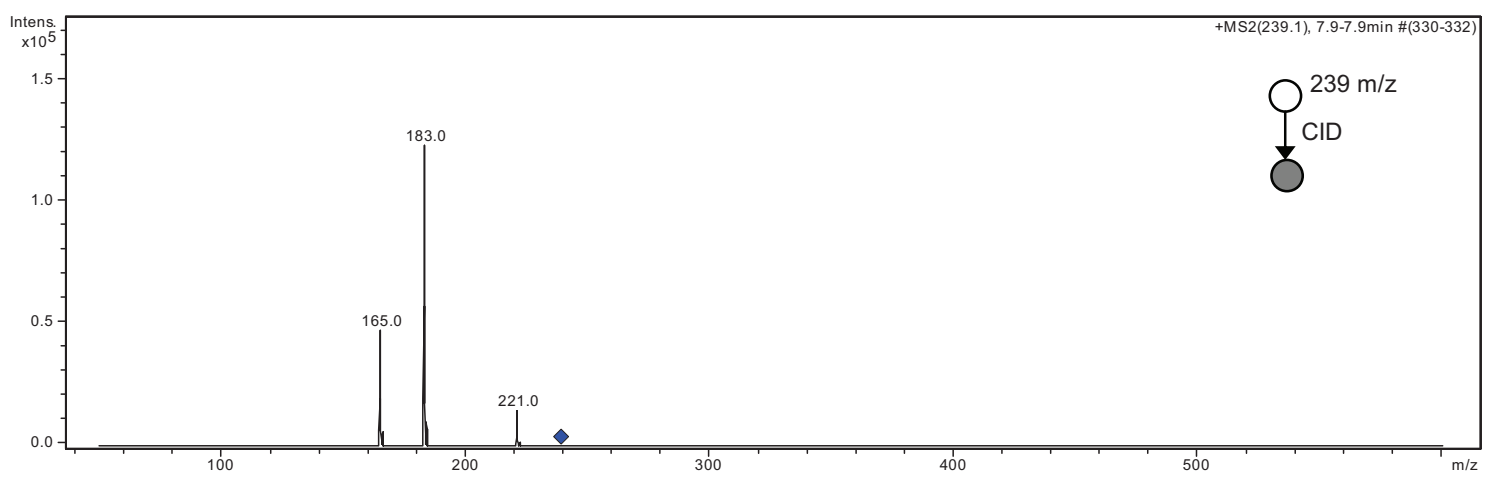

Figura A1. Espectro de massas por CID do eluato em $t_{r}=7,9$ min do cromatograma ilustrado na Figura 31a.

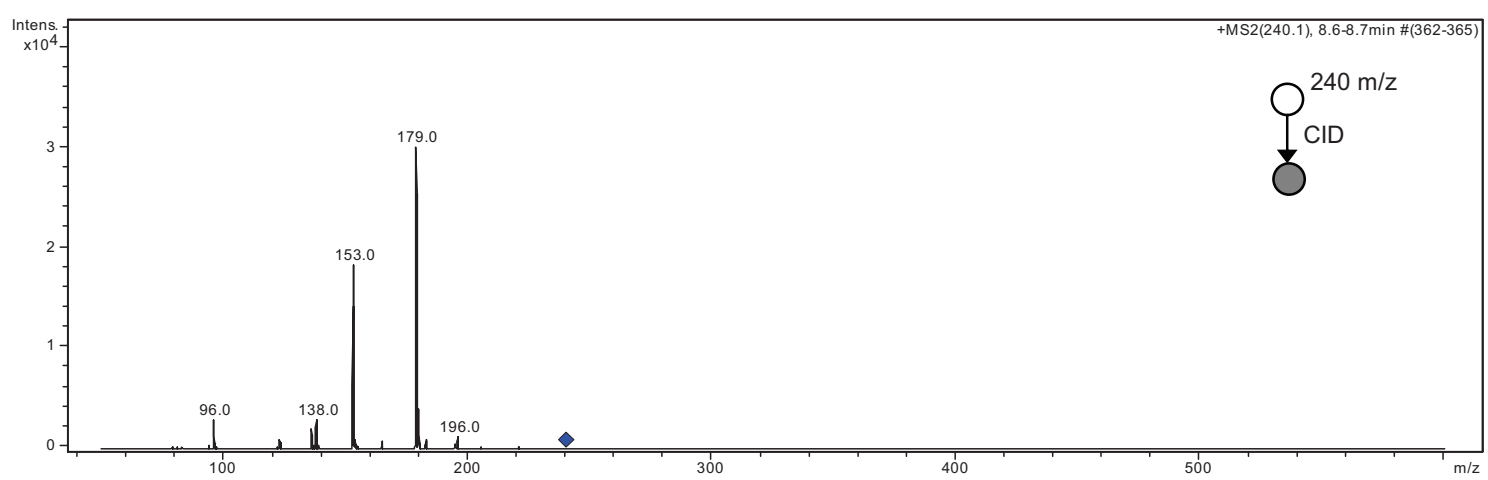

Figura A2. Espectro de massas por $C I D$ do eluato em $t_{r}=8,6$ min do cromatograma ilustrado na Figura $31 \mathrm{~b}$.

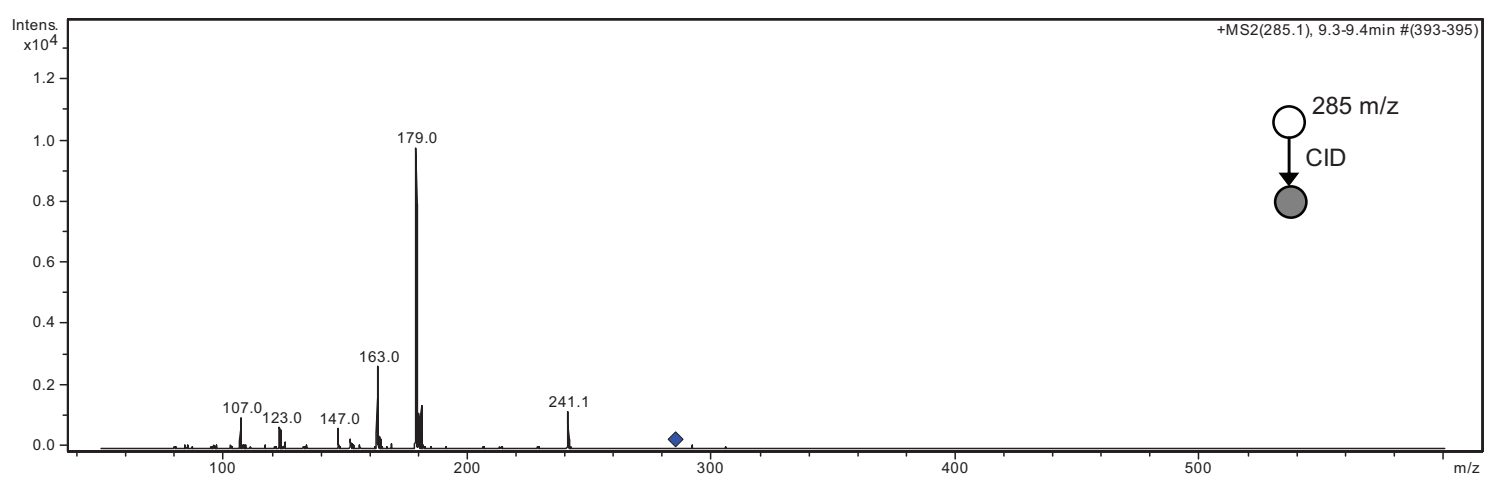

Figura A3. Espectro de massas por CID do eluato em $t_{r}=9,3$ min do cromatograma ilustrado na Figura 31c. 


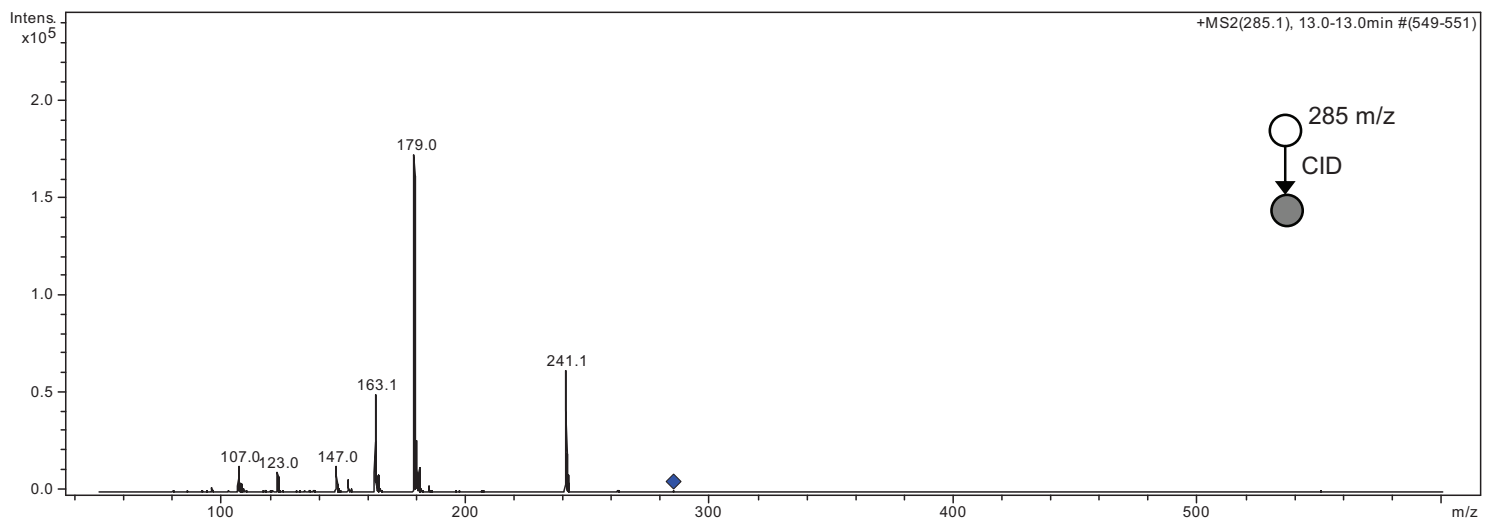

Figura A4. Espectro de massas por $C I D$ dos íons do eluato em $t_{r}=13,0$ min do cromatograma ilustrado na Figura 31d. 


\section{APÊNDICE B}

Primeiramente, assume-se que os processos cinéticos das reações abaixo (1 e 2) são majoritários durante a captação do radical 1-hidroxietila.

$$
\begin{aligned}
& 4-\mathrm{POBN}+\mathrm{H}_{3} \mathrm{CHC} \mathrm{CH} \stackrel{\mathrm{k}_{2}}{\longrightarrow}\left[4-\mathrm{POBN} / \mathrm{CH}\left(\mathrm{CH}_{3}\right) \mathrm{OH}\right]^{\circ} \\
& \mathrm{IAA}+\mathrm{H}_{3} \mathrm{CHC} \mathrm{CH} \stackrel{\mathrm{k}_{2}^{\prime}}{\longrightarrow} \text { Produtos }
\end{aligned}
$$

Pode-se assumir as seguintes equações para o consumo do radical 1-hidroxietila:

$$
\begin{aligned}
& -\frac{\mathrm{d}\left[\mathrm{H}_{3} \dot{\mathrm{C}} \mathrm{HCOH}\right]}{\mathrm{dt}}=\mathrm{k}_{2}{ }^{*}[4-\mathrm{POBN}]{ }^{*}\left[\mathrm{H}_{3} \mathrm{CHC} \mathrm{CH}\right] \\
& -\frac{\mathrm{d}\left[\mathrm{H}_{3} \dot{\mathrm{C}} \mathrm{HCOH}\right]}{\mathrm{dt}}=\mathrm{k}_{2}{ }^{*}[\mathrm{IAA}]{ }^{*}\left[\mathrm{H}_{3} \mathrm{CHCO} \dot{\mathrm{H}}\right]
\end{aligned}
$$

Quando a captação do radical pelos iso- $\alpha$-ácidos (IAA) é igual a $50 \%$ tem-se que as taxas de consumo do radical 1-hidroxietila (3) e (4) se igualam. Logo, a equação abaixo pode ser escrita, a qual expressão a relação entre as constantes de velocidade das duas reações envolvidas $\left(k_{2}\right.$ e $\left.k_{2}{ }^{\prime}\right)$.

$$
\mathrm{k}_{2}{ }^{*}[4-\mathrm{POBN}]=\mathrm{k}_{2}{ }^{\prime}{ }^{*}[\mathrm{IAA}]
$$


Esta equação pode ser generalizada para qualquer percentual de captação do radical:

$$
\left.\left(\frac{F}{1-F}\right) * k_{2} *[4-P O B N]=k_{2} * \text { * [IAA }\right]
$$

Assim, a porcentagem de captação do radical $(F)$ é obtida através do experimento de controle, o qual apresenta um sinal analítico referente do aduto radical [4- $\left.\mathrm{POBN} / \mathrm{CH}\left(\mathrm{CH}_{3}\right) \mathrm{OH}\right]^{\circ}$, e de experimentos variando a concentração de iso- $\alpha$-ácidos, no qual verifica-se uma redução do sinal analítico referente ao aduto radical. 


\section{APÊNDICE C}

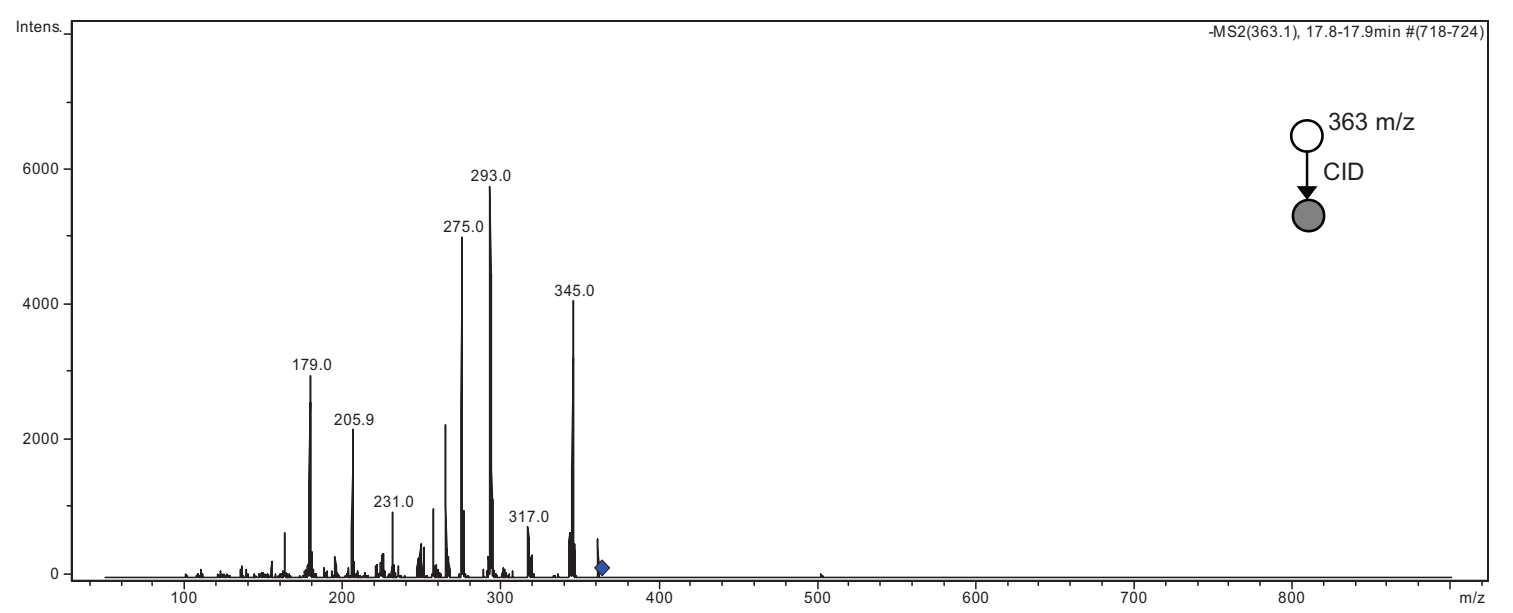

Figura C1. Espectro de massas por CID do íon $363 \mathrm{~m} / \mathrm{z}$ referente ao eluato em $t_{r}=17,8 \mathrm{~min}$ do cromatograma ilustrado na Figura 42a.

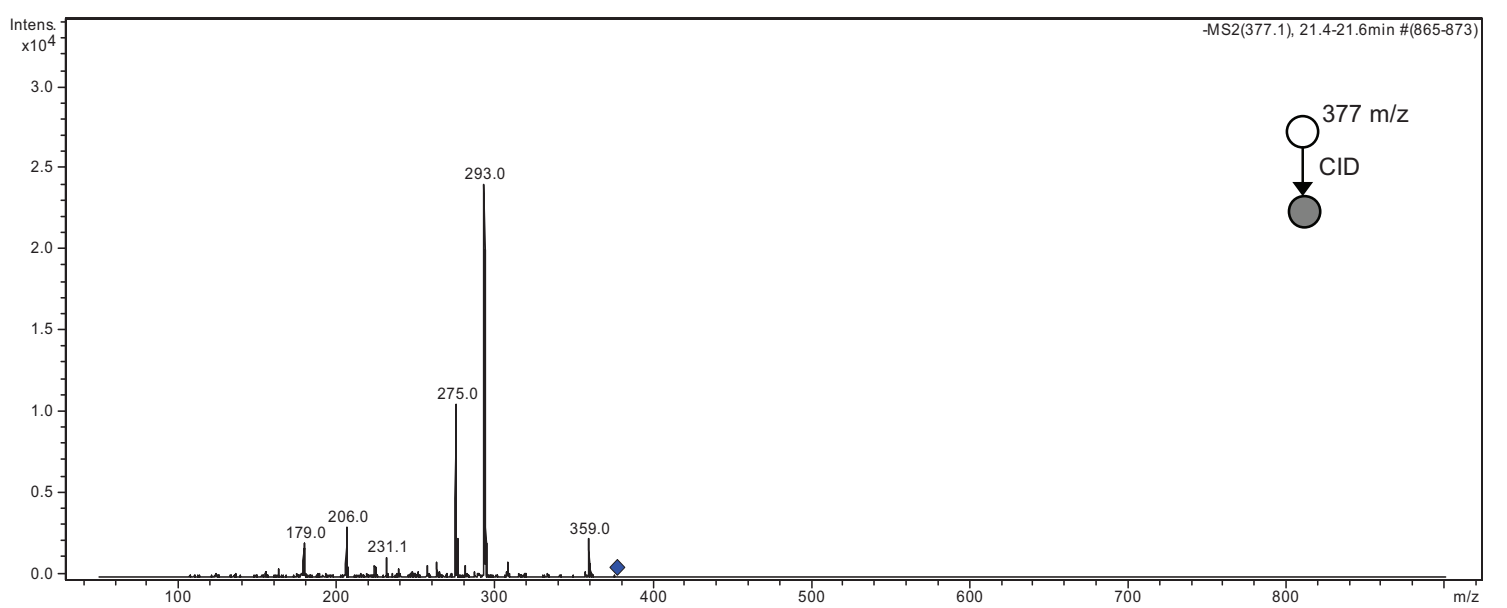

Figura C1. Espectro de massas por CID do íon $377 \mathrm{~m} / \mathrm{z}$ referente ao eluato em $t_{r}=21,5 \mathrm{~min}$ do cromatograma ilustrado na Figura 42b. 